\title{
WestVirginiaUniversity
}

THE RESEARCH REPOSITORY @ WVU

Graduate Theses, Dissertations, and Problem Reports

2010

\section{The stability of the WALA Ridge as a landmark for determining dental arch form}

\author{
Kolin E. Weaver \\ West Virginia University
}

Follow this and additional works at: https://researchrepository.wvu.edu/etd

\section{Recommended Citation}

Weaver, Kolin E., "The stability of the WALA Ridge as a landmark for determining dental arch form" (2010). Graduate Theses, Dissertations, and Problem Reports. 2983.

https://researchrepository.wvu.edu/etd/2983

This Thesis is protected by copyright and/or related rights. It has been brought to you by the The Research Repository @ WVU with permission from the rights-holder(s). You are free to use this Thesis in any way that is permitted by the copyright and related rights legislation that applies to your use. For other uses you must obtain permission from the rights-holder(s) directly, unless additional rights are indicated by a Creative Commons license in the record and/ or on the work itself. This Thesis has been accepted for inclusion in WVU Graduate Theses, Dissertations, and Problem Reports collection by an authorized administrator of The Research Repository @ WVU. For more information, please contact researchrepository@mail.wvu.edu. 


\title{
THE STABILITY OF THE WALA RIDGE AS A LANDMARK FOR DETERMINING DENTAL ARCH FORM
}

Kolin E. Weaver, D.D.S.

\section{A THESIS}

\author{
Submitted to: \\ The School of Dentistry \\ at West Virginia University \\ in partial fulfillment of the requirements \\ for the degree of \\ Master of Science \\ In \\ Orthodontics
}

Peter Ngan, D.M.D., Chair

Chris Martin, D.D.S., M.S.

Mark Richards, D.D.S., M.S.

West Virginia University

Department of Orthodontics

Morgantown, West Virginia

2010 


\title{
ABSTRACT
}

\section{The Stability of the WALA Ridge As a Landmark for Determining Dental Arch Form}

\author{
Kolin E. Weaver, D.D.S.
}

\begin{abstract}
Objectives: To evaluate changes to the WALA Ridge when subjected to orthodontic treatment using customized WALA Ridge archwires and preformed archwires, and ascertain trends within the United States amongst practicing orthodontists regarding arch form selection. Methods: 10 control subjects, 20 customized archwire subjects, and 20 preformed archwire subjects were compared using pre and post treatment mandibular casts for the experimental groups and two timepoint mandibular casts with two years between collection for the control group. Dental and Dentoalveolar changes were then measured from T1 to T2 for each of the groups. Furthermore, an electronic survey was distributed to all active practicing orthodontists in the United States. Results: Statistically significant changes in dental and dentoalveolar arch width measured at the WALA Ridge were found in the preformed archwire group at all points of measurement except the cuspid dental measurement when compared with the control. The WALA Ridge customized archwire group had statistically non-significant changes in dental and dentoalveolar arch width at all points of measurement compared with the control. Net treatment changes when compared between the two experimental groups showed statistically non-significant differences in dental arch width changes at all points of measurement. However, statistically significant differences in changes to the dentoalveolar arch width when measured at the WALA Ridge existed at all points of evaluation. In addition, 66\% orthodontists use preformed archwires in their clinical practice. Conclusions: The WALA Ridge is a stable landmark when subjected to orthodontic treatment when customized archwires shaped to the WALA Ridge are used. Changes to the WALA Ridge result with the use of preformed archwires where greater changes in pretreatment archform result. The orthodontic profession within the United States is divided between the use of preformed and customized archwires, and what to shape customized archwires to.
\end{abstract}




\section{DEDICATION}

To my amazing wife, Ashlyn. You are my best friend and biggest supporter. I will always be grateful for the sacrifices you made and patience you have shown during the pursuit of my dreams. Thanks for always being there.

To my parents, Wayne and Susan, for always believing in me and my potential. Thanks for all the sacrifices and support it took to get me to this point. Thank you for instilling in me the work ethic and discipline necessary to pursue my dreams and to succeed in life.

To my children, Morghan, Lleyton, and Maddox. Thanks for all the joy you bring to my life. Thanks for always cheering me up and reminding me every day how lucky I am. You challenge and inspire me daily to be a better person, and remind me of what is truly important in life.

To my brothers, Kevin and Kenton, my companions since the beginning. Thanks for all your love and support. Your belief in me has given me confidence to reach for goals I would never have thought possible.

To my grandmother, Betty, thanks for all your love and support. I have been able to experience so many incredible things that have greatly enhanced my life as a result of your incredible generosity and incredible friendship. I have been blessed to have such a wonderful relationship with you.

To my in-laws, Laye and Kathy, thanks for all the encouragement and support through the years.

To GOD, who has blessed, and continues to bless me with more than I could ask for or deserve. 


\section{ACKNOWLEDGEMENTS}

A special thanks to the following people,

Dr. Peter Ngan, for your commitment to education and this program. Thanks for your incredible patience and insight on this project. Your unique leadership and willingness to try new things has made this program one of a kind, and a true pleasure to be a part of.

Dr. Chris Martin, for being a great teacher, friend, and advisor. You were always there to bounce ideas off of, and provided a great atmosphere for growth as a professional.

Dr. Bryan Weaver, for being a great uncle, friend, and teacher. Your skills and knowledge in all aspects of life inspire me to never stop learning. Thanks for your support and insight, and always being there when I needed you..

Dr. Mark Richards, thanks for your willingness to participate in my research, and your insight and ideas for my project.

Dr. Erdogan Gunel, for your patience and input into this project. Thanks for your willingness to re-run the numbers many times.

Dr. Timothy Tremont, for your dedication to orthodontic education and this program. Thanks for your willingness to participate and contribute to this study. I feel incredibly blessed to have learned under such an incredible teacher.

Dr. Terry Dischinger, for you willingness to participate in this project, and your commitment to research, so that we all may provide a better level of care for our patients.

Dr. Henry Fields, for your efforts and willingness to participate in this study.

Drs. McFarland, Tremont, Gilmore, Hazey, Foley, Boyles, Kirsch, Bonello, Dempsey, Hamilton, and Jarrett, for all the invaluable lessons and clinical knowledge that you have given me. Thank you for sacrificing time spent from your families and practices to teach.

Pam, Vivian, Karen, Leona, Joyce, Carrie, and Hillary, for your assistance every day. You all made everything so much easier.

Dean Heinrichs and Mike Munn, great friends and people. Thanks for challenging me every day to try and keep up with you. Being around you guys truly made me better personally and professionally. You two are the "GREEN" of our group. I will miss you guys. STAY CLASSY!

Tim Wigal and Mike Becht, two wonderful mentors. You taught me as much as anyone else. Thanks for your patience and willingness to help. I will miss our business lunches. 
Thuy, for your encouragement and generosity. I miss our morning commutes.

Nikia, Lindsay, Rajia, Rob, Maggie, Erica, Ronnie, Holly, and Jung Mee, for being good friends, and great classmates. You all truly enhanced my education, and made this residency all the more enjoyable and an unforgettable part of my life. 


\section{TABLE OF CONTENTS}

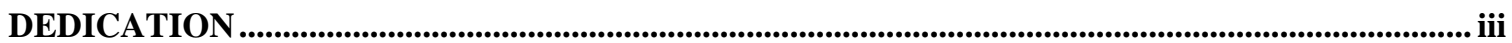

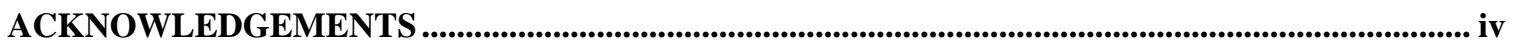

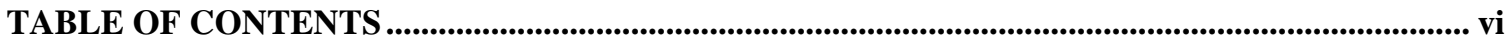

LIST OF TABLES......................................................................................................................... ix

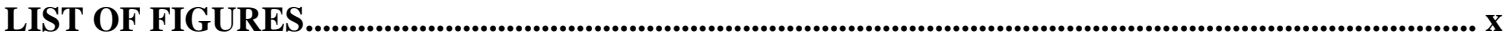

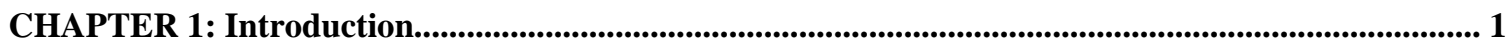

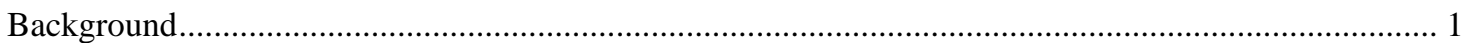

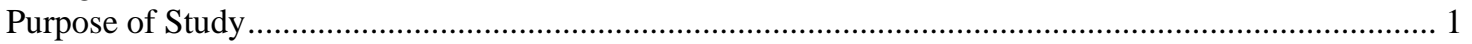

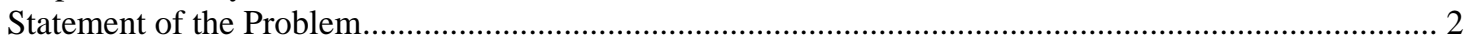

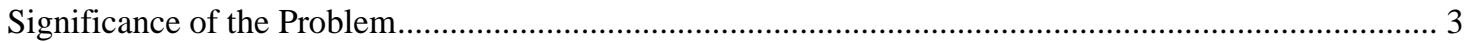

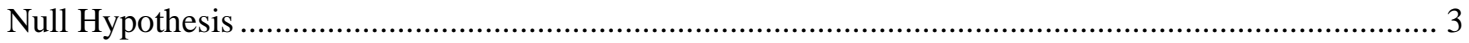

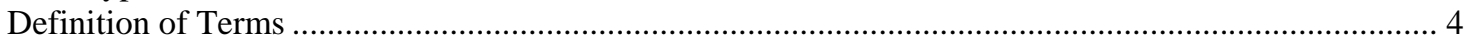

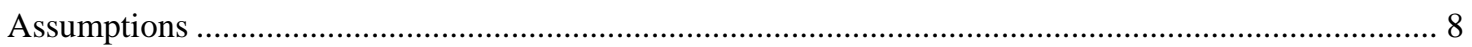

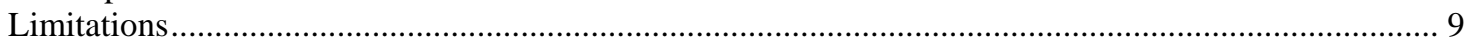

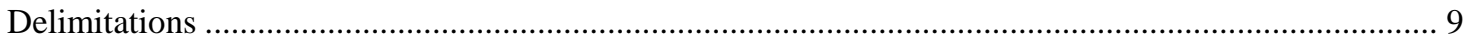

CHAPTER 2: Review of Literature......................................................................................................... 10

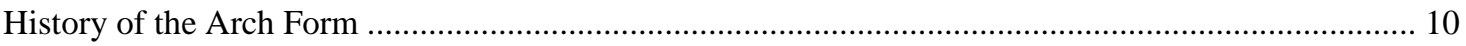

Clinical Implications Associated with Changes to the Arch Form ........................................................... 12

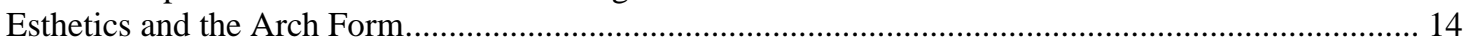

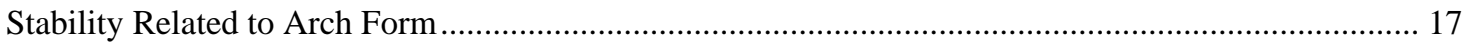

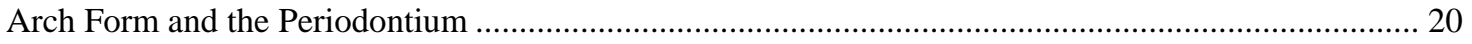

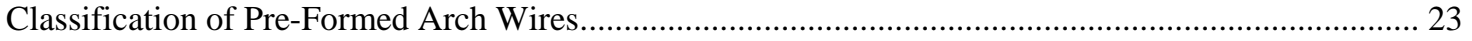

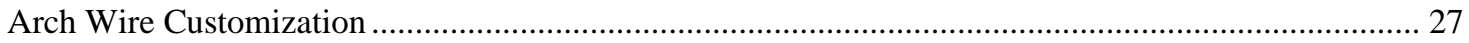

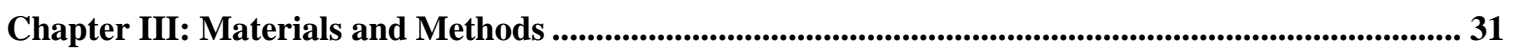

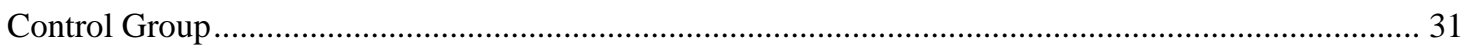

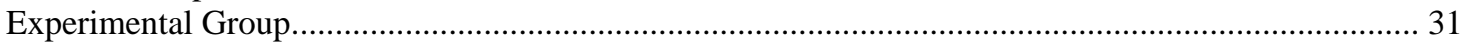

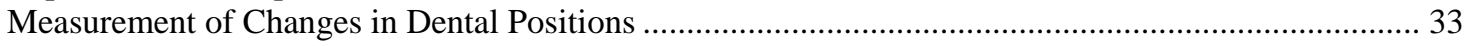

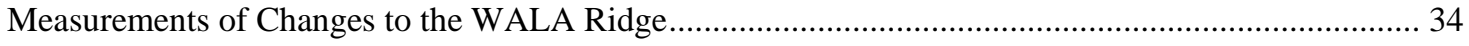

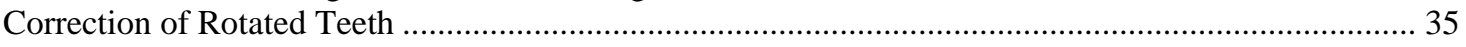

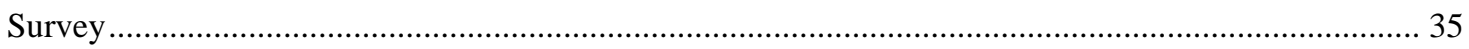

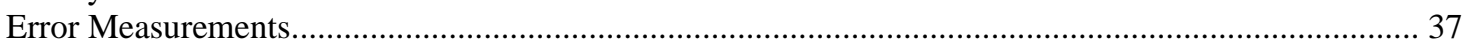

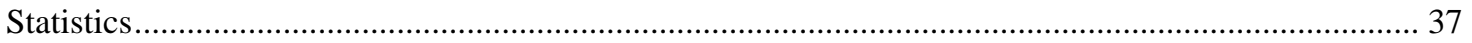

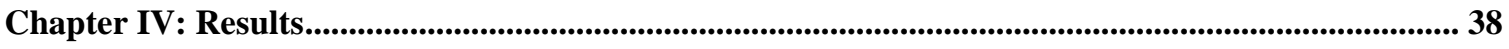

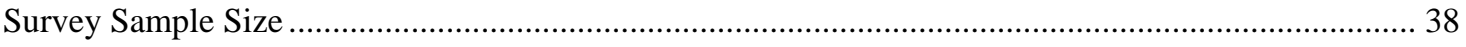

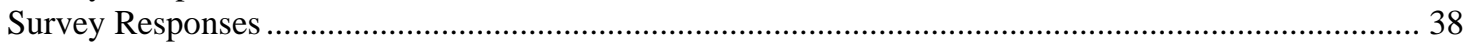

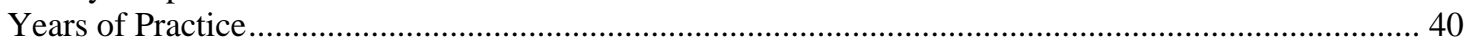

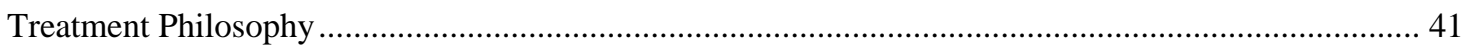

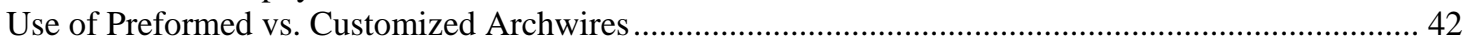

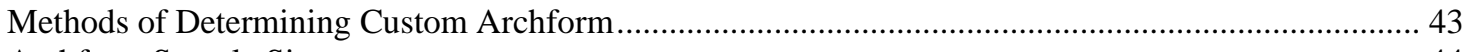

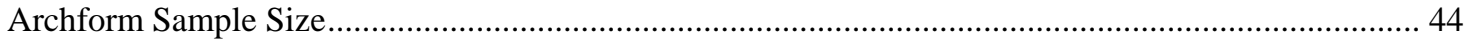

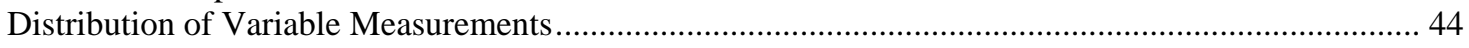

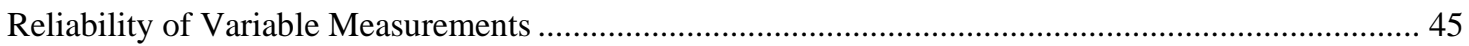

Comparison of Dental and Dentoalveolar Arch Width Changes From T1 to T2 at the Second Molars for

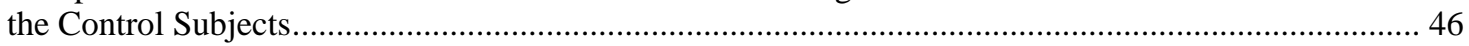

Comparison of Dental and Dentoalveolar Arch Width Changes From T1 to T2 at the Second Molars for the Preformed Archwire Subjects 
Comparison of Dental and Dentoalveolar Arch Width Changes From T1 to T2 at the Second Molars for the Customized Archwire Subjects...................................................................................................... 47 Comparison of Dental and Dentoalveolar Arch Width Changes From T1 to T2 at the First Molars for the Control Subjects 49 Comparison of Dental and Dentoalveolar Arch Width Changes From T1 to T2 at the First Molars for the Preformed Archwire Subjects..... 50 Comparison of Dental and Dentoalveolar Arch Width Changes From T1 to T2 at the First Molars for the

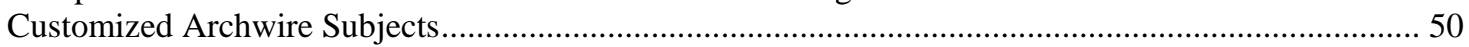
Comparison of Dental and Dentoalveolar Arch Width Changes From T1 to T2 at the Second Bicuspids

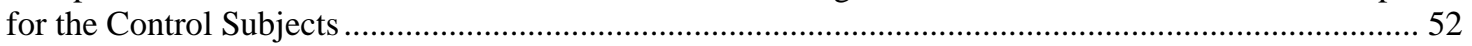
Comparison of Dental and Dentoalveolar Arch Width Changes From T1 to T2 at the Second Bicuspids

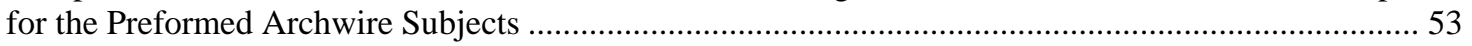
Comparison of Dental and Dentoalveolar Arch Width from T1 to T2 at the Second Bicuspids for the Customized Archwire Subjects.......................................................................................................... 53 Comparison of Dental and Dentoalveolar Arch Width Changes From T1 to T2 at the First Bicuspids for

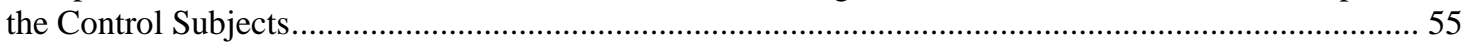
Comparison of Dental and Dentoalveolar Arch Width Changes From T1 to T2 at the First Bicuspids for the Preformed Archwire Subjects ....................................................................................................... 56 Comparison of Dental and Dentoalveolar Arch Width Changes From T1 to T2 at the First Bicuspids for the Customized Archwire Subjects ........................................................................................................ 56 Comparison of Dental and Dentoalveolar Arch Width Changes From T1 to T2 at the Cuspids for the

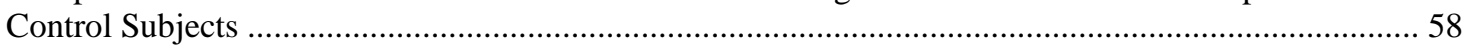
Comparison of Dental and Dentoalveolar Arch Width Changes From T1 to T2 at the Cuspids for the Preformed Archwire Subjects ................................................................................................................... 59 Comparison of Dental and Dentoalveolar Arch Width Changes From T1 to T2 at the Cuspids for the

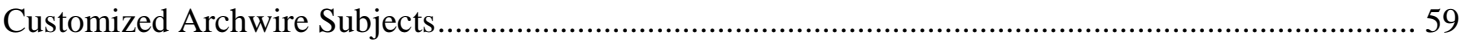
Comparison of Dental and Dentoalveolar Arch Width Changes of the Preformed and Customized Archwire Groups Against the Control at the Second Molars.................................................................... 61 Comparison of Dental and Dentoalveolar Arch Width Changes of the Preformed and Customized Archwire Groups Against the Control at the First Molars .......................................................................... 62 Comparison of Dental and Dentoalveolar Arch Width Changes of the Preformed and Customized Archwire Groups Against the Control at the Second Bicuspids .............................................................. 62 Comparison of Dental and Dentoalveolar Arch Width Changes of the Preformed and Customized Archwire Groups Against the Control at the First Bicuspids ................................................................. 63 Comparison of Dental and Dentoalveolar Arch Width Changes of the Preformed and Customized Archwire Groups Against the Control at the Cuspids............................................................................. 63 Comparison of Net Treatment Changes to Dental and Dentoalveolar Arch Width Between the Preformed and Customized Archwire Groups at the Second Molars ........................................................................... 65 Comparison of Net Treatment Changes to Dental and Dentoalveolar Arch Width Between the Preformed

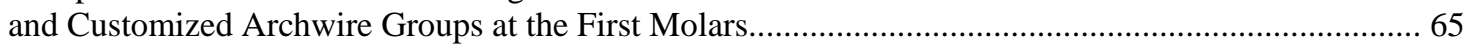
Comparison of Net Treatment Changes to Dental and Dentoalveolar Arch Width Between the Preformed and Customized Archwire Groups at the Second Bicuspids 65 Comparison of Net Treatment Changes to Dental and Dentoalveolar Arch Width Between the Preformed and Customized Archwire Groups at the First Bicuspids ........................................................................ 66 Comparison of Net Treatment Changes to Dental and Dentoalveolar Arch Width Between the Preformed

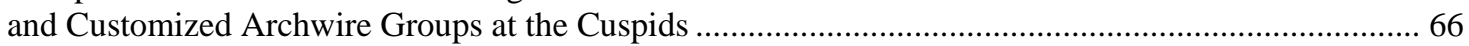
Correlation Between the Net Treatment Change in Dental and Dentoalveolar Arch Width in the

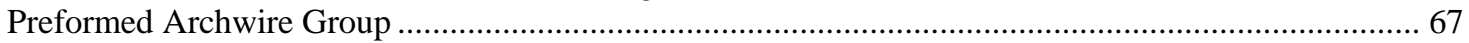
Correlation Between Net Treatment Change in Dental and Dentoalveolar Arch Width in the Customized

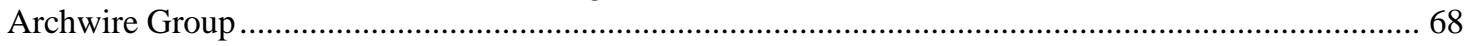

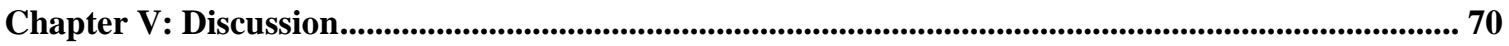

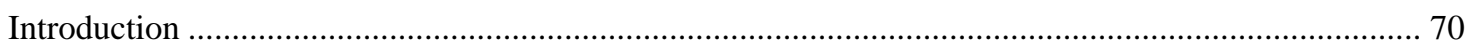

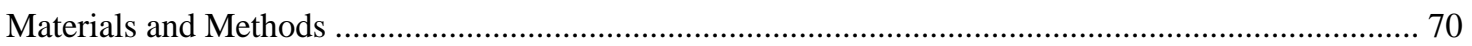

Practice Trends Related to Archform within the United States ................................................................ 71 
Comparison of Transverse Dental Changes (7-7D) and Transverse Dentoalveolar Changes (7-7W) at the

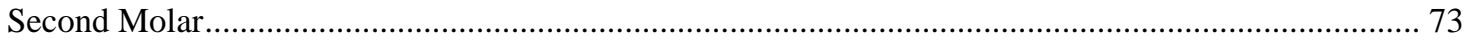
Comparison of Transverse Dental Changes (6-6D) and Transverse Dentoalveolar Changes (6-6W) at the

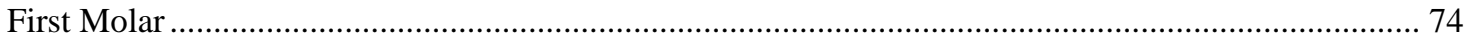
Comparison of Transverse Dental Changes (5-5D) and Transverse Dentoalveolar Changes (5-5W) at the

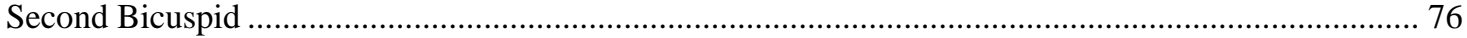
Comparison of Transverse Dental Changes (4-4D) and Transverse Dentoalveolar Changes (4-4W) at the

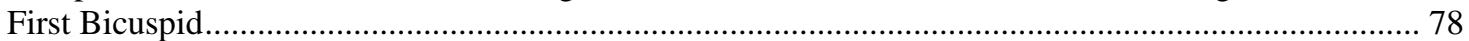
Comparison of Transverse Dental Changes (3-3D) and Transverse Dentoalveolar Changes (3-3W) at the

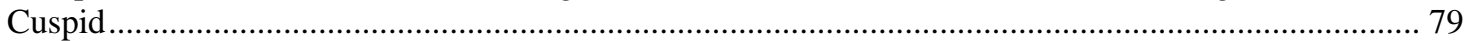

The Correlation Between Dental and Dentoalveolar Arch Width Changes in the Preformed and

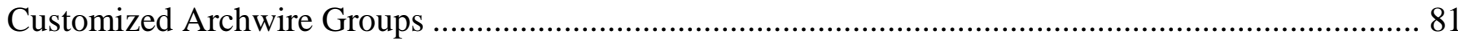

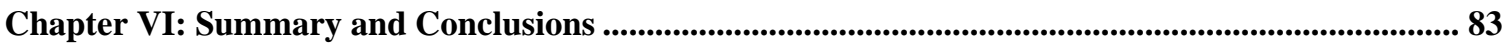

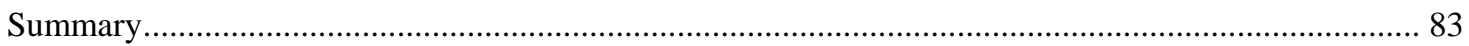

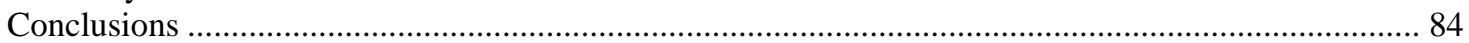

Chapter VII: Recommendations for Future Research................................................................86

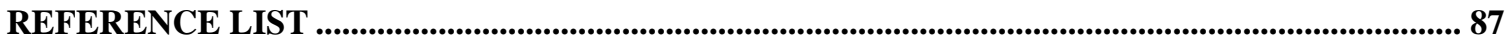

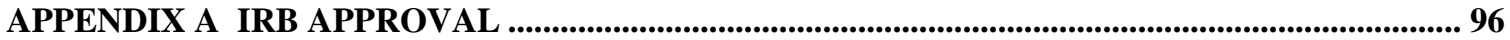

APPENDIX B CONTROL DATA

APPENDIX C PREFORMED ARCHWIRE DATA ...........................................................................100

APPENDIX D CUSTOMIZED ARCWIRE DATA .......................................................................103

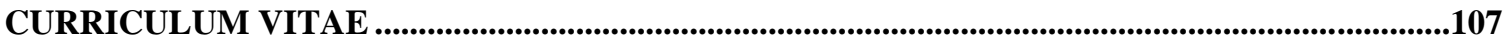




\section{LIST OF TABLES}

Table 1. Geographic Distribution of Responses to Survey......................................... 39

Table 2. Number of Responses by Residency Graduation ......................................... 41

Table 3. Summary of Reliability of Variable Measurements ...................................... 46

Table 4. Summary of Changes in Dental Arch Width at the Second Molars From T1 to

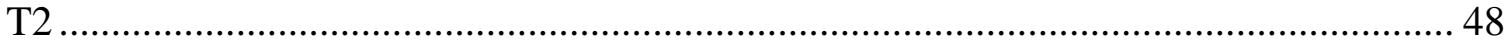

Table 5. Summary of Changes in Dentoalveolar Arch Width at the Second Molars from

$\mathrm{T} 1$ to $\mathrm{T} 2$ 48

Table 6. Summary of Change in Dental Arch Width at the First Molars From T1 to T2 51 Table 7. Summary of Changes in Dentoalveolar Arch Width at the First Molars from T1 to $\mathrm{T} 2$ 51

Table 8. Summary of Change in Dental Arch Width at the Second Bicuspids From T1 to

$\mathrm{T} 2$..... 54

Table 9. Summary of Changes in Dentoalveolar Arch Width at the Second Bicuspids

From $\mathrm{T} 1$ to $\mathrm{T} 2$ 54

Table 10. Summary of Changes in Dental Arch Width at the First Bicuspids From T1 to

T2 57

Table 11. Summary of Change in Dentoalveolar Arch Width at the First Bicuspids from

T1 to T2

Table 12. S Summary of Change in Dental Arch Width at the Cuspids From T1 to T2 .. 60

Table 13. Summary of Change in Dentoalveolar Arch Width at the Cuspids from T1 to

T2.

Table 14. Summary Of Dental and Dentoalveolar Changes and Comparisons ............... 64

Table 15. Summary of Net Treatment Changes....

Table 16. Correlation Of Net Treatment Change in Dental Arch Width and

Dentoalveolar Arch Width in the Preformed and Customized Archwire Groups 69 


\section{LIST OF FIGURES}

Figure 1. Occlusal View of Optimal Arch Core Lines .................................................. 5

Figure 2. Occlusal View of Optimal Midsaggital Lines ............................................... 7

Figure 3. Occlusal View of Optimal Perimeter Lines.................................................. 7

Figure 4. Lateral and Occlusal View of the WALA Ridge............................................. 8

Figure 5. Andrews' Findings on the Effects of Leveling the Curve of Spee .................... 14

Figure 6. (A) Original Photograph of Patient Exhibiting No Buccal Corridors (B) Same

Image Digitally Altered to Increase Buccal Corridors ................................................. 16

Figure 7. Marginal Bone Recession in Non-Orthdontically Treated Patients ................. 21

Figure 8. Fenestrations and Tissue Recession Associated Teeth Resting Beyond the

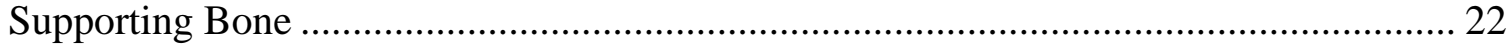

Figure 9. Bonwill-Hawley Arch Form......................................................................... 25

Figure 10. (L) Demonstration of Catenary Curve Arch Form w/ Suspended Chain, (R)

Brader/Trifocal Ellipse Arch Form .............................................................................. 26

Figure 11. Identification of WALA Ridge and Shaping of Stainless Steel Wire to WALA

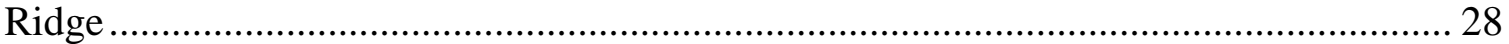

Figure 12. Clinical Technique Used to Customize Arch Wires by Wax Bite ................. 29

Figure 13. SureSmile Intraoral Scanner and Wire Bending Robotic Arm ..................... 30

Figure 14. Preformed Archform Used in Preformed Experimental Group w/ WALA

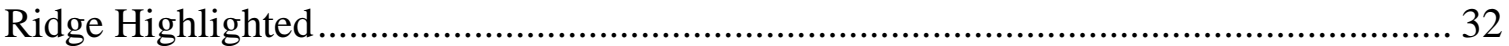

Figure 15. Customized WALA Ridge Archwire to the WALA Ridge used in the

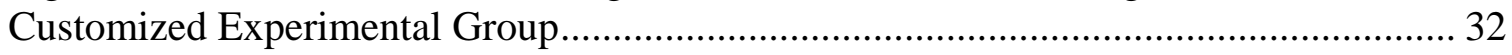

Figure 16. Marking of FA Points and Measuring Transverse Dimension....................... 33

Figure 17. Identification of WALA Ridge and FACC and Measuring the Intersection.. 34

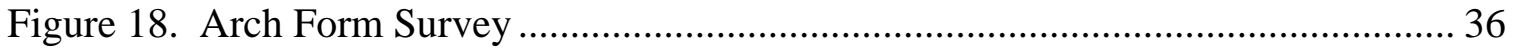

Figure 19. Distribution of Treatment Philosophies....................................................... 42

Figure 20. Percentage Preformed and Cusotmized Archwire Use ................................ 43

Figure 21. Distribution of Landmark Selection for Customizing Archforms.................. 44

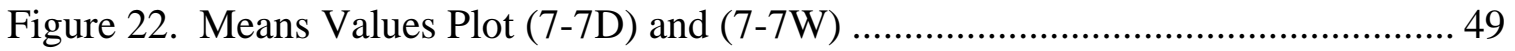

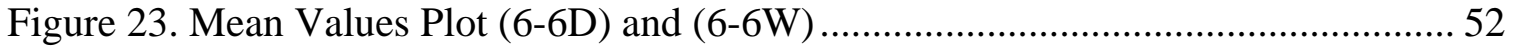

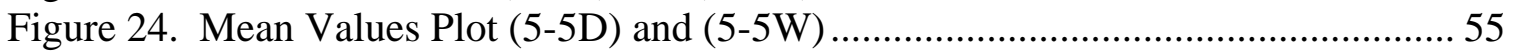

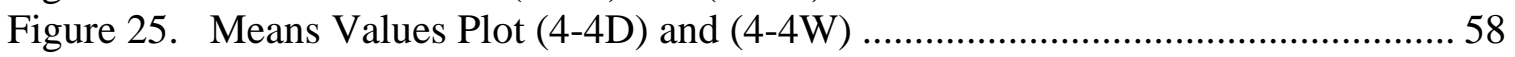

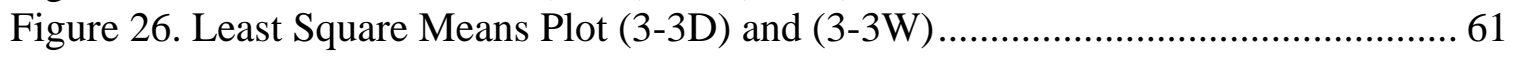




\section{CHAPTER 1: INTRODUCTION}

\section{Background}

Arch form is a topic that has been heavily discussed in the dental and orthodontic publications for well over 100 years. In the past when treatment with standard edgewise appliances was the standard of care, most orthodontists customized arch wires to each patient's arch form. With the invention of the preadjusted appliance by Larry Andrews, there became a sense of assumption among clinicians that there was one ideal arch form for every patient. ${ }^{1}$ Therefore, there have been many attempts to design and commercialize the ideal arch form. ${ }^{2-8}$ Attempts to classify them have involved various geometric terms and complex mathematical formulas. ${ }^{3,9-15}$ Manipulation of the dental arch form has significant impacts on the patient in areas of stability, ${ }^{16-39}$ esthetics, ${ }^{40-46}$ space available, ${ }^{47-51}$ and the periodontium. ${ }^{52-59}$ However, if there is no one ideal arch form for every patient, and customizing arch forms should be the orthodontic standard of care, then there is no consensus amongst the profession as to what should serve as a landmark to shape finishing arch wires, and at the same time correctly represents each patient's basal bone anatomy. As with preformed arch wires, there are several methods developed for uniquely shaping arch forms, however, little data is available to assess these techniques.

\section{Purpose of Study}

In a recent publication by Ronay et $\mathrm{al}^{60}$, they concluded that arch form could not be defined by a generalized shape, and that the WALA Ridge described by Andrews and Andrews ${ }^{61}$ was a useful representation of the apical base and helpful in the 
predetermination of an individualized dental arch form. The WALA Ridge is a band of soft tissue immediately superior to the mandible's mucogingival junction and is at the same superior or inferior level as the horizontal center of rotation of the teeth in the arch. Andrews hypothesized that shaping archwires to this landmark would result in widening of the dental arches by tipping of the teeth about their center of resistance to an upright dental position centered within basal bone. This study plans to investigate the stability of the WALA Ridge by investigating changes to the WALA Ridge width following orthodontic treatment when the WALA Ridge was used as a template for shaping arch forms, and comparing that with treatment mechanics that employs preformed arch wires in which the shape bears no resemblance to the basal bone anatomy. Class I pre and post treatment mandibular models will be measured to determine the changes to the transverse dimensions of the dentition and the WALA Ridge when the WALA Ridge is used to shape stainless steel arch wires. Measurements will be compared to a sample of patients treated with preformed arch wires, and a control sample of untreated subjects whose mandibular casts were taken a minimum of two years apart. The results of this study will provide information to the clinician involving the use and stability of the WALA Ridge as landmark in determining the shape the dental arch form.

\section{Statement of the Problem}

There is no consensus as to the determination of an ideal arch form. The WALA Ridge described by Larry Andrews is a proposed landmark for customization of arch wires, however, there is no documentation of the stability of this landmark, and what impact orthodontic treatment may have on it. 


\section{Significance of the Problem}

It is commonly believed that no ideal arch form exists, and that arch form is different for every patient, thus requiring custom shaping of arch wires to accommodate variations between individual patients. The question then arises as to what represents the landmark to which customized arch forms should be shaped. There are various protocols for shaping customized arch forms, but most involve shaping wires to the existing dentition as a landmark once the teeth are aligned. Larry Andrews proposed the WALA Ridge as a landmark for shaping mandibular finishing arch wires, and states that this ridge reflects the shape of each patient's basal bone anatomy. He claims that this ridge is likely to be a stable landmark unaffected by environmental forces. Knowing the significance of this landmark and its stability will allow clinicians to better determine a patient's unique arch shape, and make better clinical decisions related to patient treatment.

\section{Null Hypothesis}

1. There is no significant difference between the change in dental and dentoalveolar arch width in untreated subjects, or when treated with preformed or WALA Ridge customized arch wires.

2. There is no significant difference in dental and dentoalveolar arch width changes between the experimental groups and the control .

3. There is no significant difference in the net treatment changes of the two experimental groups.

4. There is no significant correlation in dental and dentoalveolar arch width changes. 


\section{Definition of Terms}

\section{- Apical Base/Basal Bone}

- 1. Orthodontic term defining a horizontal plane coincident with the region of bone in which the apices of the roots are located. 2 . The apical third of the alveolus and the bone that supports the alveolar processes below the mandibular teeth.

\section{- Buccal}

- Term referring to the tooth surface of posterior teeth that lies adjacent to the cheeks.

\section{- Class I Occlusion}

- The mesiobuccal cusp of the maxillary permanent first molar occludes in the groove between the mesial and middle buccal cusps of the permanent mandibular first molar.

\section{- Core Line}

- An imaginary line that best represents the length of the dental arch at its core, passing mesiodistally through the center of each crown whose alignment conforms to the arch form. 

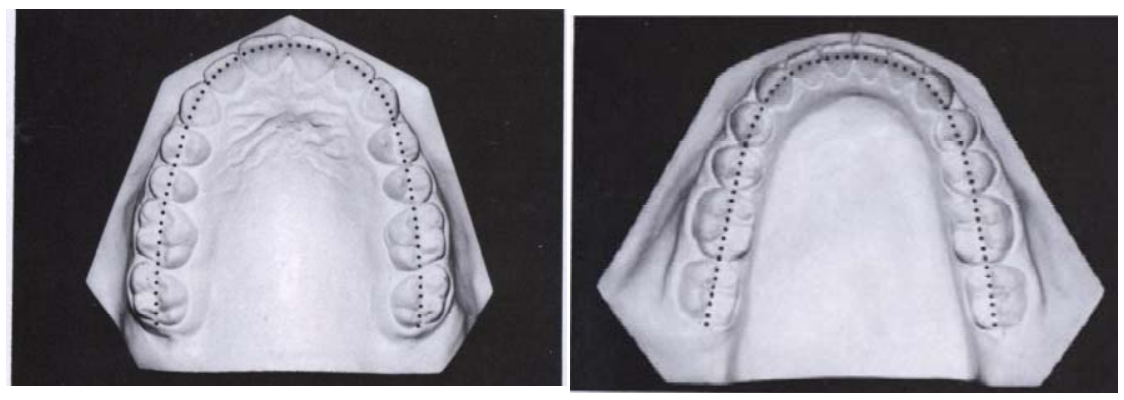

Figure 1. Occlusal View of Optimal Arch Core Lines

- Curve of Spee

- The curvature of the mandibular occlusal plane beginning at the tip of the lower cuspid and following the buccal cusps of the posterior teeth, continuing to the terminal molar.

- Customized Arch Wire

- A commercially produced arch wire that is modified in shape by the doctor to uniquely fit each individual patient.

\section{- Dentoalveolar}

- A term referring alveolar bone surrounding the teeth

\section{- Facial}

- Term referring to the tooth surface that lies adjacent to the cheeks or lips. 


\section{- Facial Axis of the Clinical Crown (FACC)}

- For all teeth except molars, the most prominent portion of the central lobe on each crown's facial surface; for molars, the buccal groove that separates the two large facial cusps.

\section{- FA Point}

- The point on the facial axis of the clinical crown that separates the gingival half of the clinical crown from the occlusal half.

\section{- Gingival}

- Term relating movement of an object or location of that object relative to the gingival tissues.

\section{- Lingual}

- Term referring to the tooth surface that lies adjacent to the tongue.

\section{- Midsaggital Line}

- An imaginary line that best represents the anteroposterior length of an arch measured in the midsaggital plane of an arch from the anterior limit of the core line to a line connecting the most distal aspect of the core line. 

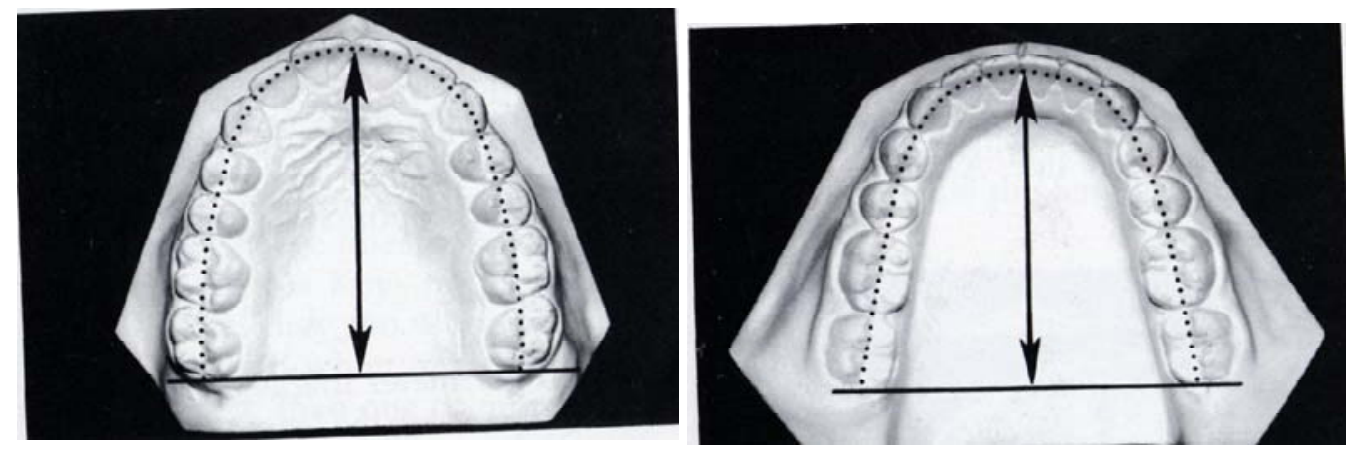

Figure 2. Occlusal View of Optimal Midsaggital Lines

\section{- Occlusal}

o Dental term relating to movement of an object of location of that object relative to the chewing surfaces of the teeth.

\section{- Perimeter Line}

o An imaginary line that best represents the length of the occlusofacial portion of the dental arch measured along a line that connects the most facial points of the occlusal surfaces of the crown that are on the core line.
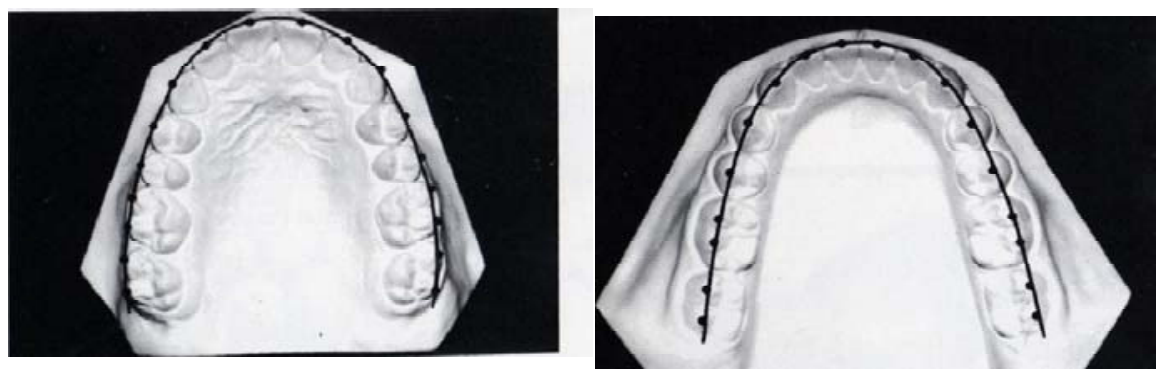

Figure 3. Occlusal View of Optimal Perimeter Lines 


\section{- Preformed Archwire}

o A commercially shaped archwire that is produced on mass scales to yield identical wire shape from one lot to the next.

\section{- WALA Ridge}

- A band of soft tissue immediately superior to the mandible's mucogingival junction, that is at, or nearly at, the same superior or inferior level as the horizontal center of rotation of the teeth in an arch.
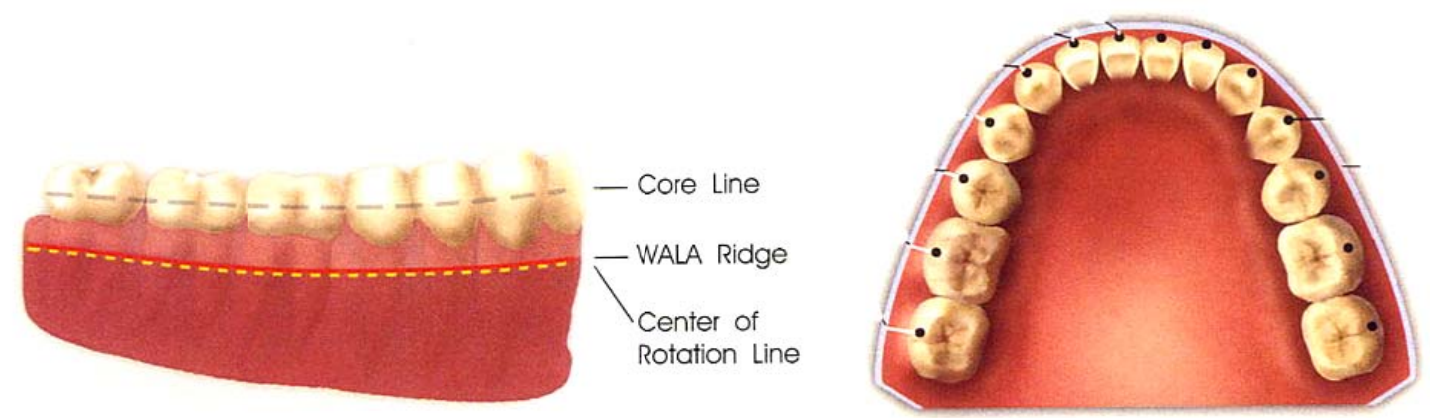

Figure 4. Lateral and Occlusal View of the WALA Ridge

\section{Assumptions}

1. The WALA Ridge can be accurately identified on mandibular casts.

2. The WALA Rridge experimental group had finishing arch wires correctly formed to the WALA Ridge.

3. The preformed archwire experimental group was treated employing the use of only preformed archwires.

4. The control group never received orthodontic treatment prior to collection of models. 


\section{Limitations}

1. Due to variability of incisor inclination of treated subjects' incisor FA point measurements to the WALA Ridge will be excluded from the study.

2. Measurements are limited to the researchers ability accurately define the WALA Ridge and FA points on the casts

\section{Delimitations}

1. All experimental and control groups were measured by one investigator.

2. All treatment subjects require a class I pre and post treatment dental relationship.

3. All treatment subjects require a non-extraction treatment plan. 


\section{CHAPTER 2: REVIEW OF LITERATURE}

\section{History of the Arch Form}

The shape of the arch wire and the bracket system employed for orthodontic treatment determine the final arch form at the completion of fixed orthodontic therapy. Since the beginning of orthodontics researchers and clinicians have been attempting to determine and classify the human dental arch form. The size and shape of the arch significantly impacts decisions made in during orthodontic diagnosis and treatment. Arch form effects the space available, post treatment stability, and dental esthetics. It is believed that the dental arch form is initially shaped by the configuration of the supporting bone $\mathrm{e}^{62}$, and following the eruption of teeth, forces by the circumoral musculature, and intraoral function begin to shape the $\operatorname{arch}^{63}$.

Two basic opposing theories exist as to what occurs when modifications to the arch form take place during orthodontic treatment. Angle ${ }^{64}$ first advocated the bone growing theory in his reports of stable orthodontic treatment results of crowded cases that he had expanded in order to fit all the teeth in. The bone-growing theory believes that the supporting alveolar bone grows in response to normal stimulation, for example mastication, if the teeth are placed in an ideal position. This theory was further supported by the arrival of Wolff's law which is a theory developed by the German Anatomist/Surgeon Julius Wolff in the 19th century that states that bone in a healthy person or animal will adapt to the loads it is placed under. If loading on a particular bone increases, the bone will remodel itself over time to become stronger to resist that sort of loading. The external cortical portion of the bone becomes thicker as a result. The converse is true as well: if the loading on a bone decreases, the bone will become weaker 
due to turnover, it is less metabolically costly to maintain and there is no stimulus for continued remodeling that is required to maintain bone mass. In other words, the size and shape of the supporting bones depends largely on environmental forces like the tongue, cheeks, and mastication. This approach to arch form has been labeled the nonextraction theory due to the fact that it resulted in fewer extractions.

The opposing theory, the apical base theory, proposed by Lundstrom ${ }^{65}$ in 1925 , states that the size and shape of the supporting bone is largely under genetic control, and that there is a limit to the expansion that can take place in the dental arch. He stated three fundamental principles with this theory. First, the apical base is not changed after loss of teeth, second, it is not influenced by orthodontic tooth movement or mastication, and third, it limits the size of the dental arch. The implications of this theory on orthodontic treatment are that if teeth are moved beyond the apical base, labial or buccal tipping of teeth would occur ${ }^{65}$, periodontal problems can be created ${ }^{66}$, and an unstable treatment result could be expected ${ }^{36,67}$. Instability of treatment was observed by some of Edward Angle's students when treating patients using the bone growing theory and nonextraction treatment employed under Angle’s mechanics. In the 1930’s Tweed ${ }^{67}$ developed a $^{\prime}$ diagnostic analysis and employed mechanics that favored extraction of teeth in treatment of his patients. At about the same time, Begg ${ }^{68}$ also changed to an extraction technique, based on anthropologic evidence and the fact that less mastication was required in the modern diet.

The apical base theory dominated orthodontic philosophy for many years, until the recent re-emergence of the bone growing theory involving a new orthodontic appliance, the Damon appliance. ${ }^{69}$ Its developer claims that buccal tooth movement can 
occur without tipping if extremely light forces are employed during treatment. The favor of nonextraction treatment is associated with esthetic preferences along with other issues, but the greatest contributing factor associated again with the swing is the fact that extraction therapy is not associated with greater stability ${ }^{70}$. This lack of greater stability that was the perceived advantage associated with extraction therapy resulted in its decline in favor.

Despite the swing towards nonextraction treatment, most clinicians believe that there is a limit to the amount of expansion that can take place with orthodontic appliances, but there is no consensus as to the limit of expansion and simultaneous broadening of the arch form, as well as a consensus as to its ideal shape and whether one exists. In 2000, Andrews and Andrews ${ }^{71}$ proposed a new term, the WALA Ridge, to indicate a surface structure that was a the level of the basal bone, and could serve as a template for shaping arch wires. A recent study by Ronay et $\mathrm{al}^{72}$ shed evidenced based light on this structure, and concluded that the WALA Ridge was a useful representation of the apical base and helpful in the predetermination of an individualized dental arch form. They also found that FA and WALA point derived arch forms were individual and therefore could not be defined by a generalized shape, thus suggesting that customization of arch wires is necessary in order to properly place teeth in basal bone.

\section{Clinical Implications Associated with Changes to the Arch Form}

The clinical implications that size and shape of the dental arches have on orthodontic diagnosis and treatment planning is very significant. The orthodontic manipulation of the dental arch form is what determines how much space is available. Changes to the arch form in all three planes of space result in changes to the core line, 
perimeter line, and midsaggital lines. There have been several lines developed for the use of measuring the length of the dental $\operatorname{arch}^{73-76}$. Use of core, perimeter, and midsagittal lines will be discussed due to their close correlation with Larry Andrews' Six Keys to Optimal Occlusion ${ }^{77}$.

Faciolingual positioning of the buccal segments affects the core and perimeter lines. Facial tipping of the buccal segments in either arch increases these lines, and lingual tipping decreases them. According to Andrews ${ }^{47}$, for every millimeter of buccal movement of either side of the core line, there is one millimeter of space created. Conversely, for every millimeter of lingual movement you lose one millimeter of space. Kirshcen et $\mathrm{al}^{78}$ account for $0.5 \mathrm{~mm}$ of space for each millimeter of intermolar arch width change, and a greater amount associated with rapid palatal expansion like that reported of Adkins et $\mathrm{al}^{79}$ and Akkaya et al ${ }^{80}$. They stated that $0.7 \mathrm{~mm}$ of space and $0.65 \mathrm{~mm}$ of core length is created for each millimeter of expansion respectively.

Anteroposterior positioning, or tipping, of all four incisors affects all three arch lines: core, perimeter, and midsagittal. Andrews ${ }^{47}$ states that for every millimeter of advancement or retraction of the incisors, there is a gain of loss respectively of two millimeters to the core line. These conclusions are also supported by Kirschen et $\mathrm{al}^{81}$ who also state that from each millimeter in incisor anteroposterior change account for $2 \mathrm{~mm}$ of space. Proffit ${ }^{82}$ describes this by stating that when incisors move forward or posteriorly, they can create or reduce space available by arranging teeth on an arc of a larger or smaller circle respectively.

The vertical shape, core line depth, or curve of Spee of the arch form also has implications in the amount of space available for treatment. Changing the vertical 
position of one tooth has no effect on the arch lines, however, leveling the entire curve results in decrease in the core line and a decrease in space available. A popular theory is that $1 \mathrm{~mm}$ of arch circumference is needed to level each millimeter of the curve of Spee ${ }^{83,84}$. However, more recent investigations into the effect of leveling the curve of Spee, has shown that this overestimates the amount of core length necessary to flatten the curve of Spee ${ }^{49,85}$. Research by Kirschen et $\mathrm{al}^{86}$ allows for $1 \mathrm{~mm}$ of space for a $3 \mathrm{~mm}$ curve depth, $1.5 \mathrm{~mm}$ for $4 \mathrm{~mm}$ curve, and $2 \mathrm{~mm}$ for $5 \mathrm{~mm}$ of depth. Larry Andrews ${ }^{47}$ did a study evaluating curve of Spee and its impact on the core length and lists his findings in the table below.

\begin{tabular}{|c|c|}
\hline $\begin{array}{l}\text { Depth } \\
\text { of core line }\end{array}$ & $\begin{array}{l}\text { Effect on length } \\
\text { of core line }\end{array}$ \\
\hline $2 \mathrm{~mm}$ & $1 \mathrm{~mm}$ \\
\hline $3 \mathrm{~mm}$ & $2 \mathrm{~mm}$ \\
\hline $4 \mathrm{~mm}$ & $3 \mathrm{~mm}$ \\
\hline $5 \mathrm{~mm}$ & $5 \mathrm{~mm}$ \\
\hline $6 \mathrm{~mm}$ & $7 \mathrm{~mm}$ \\
\hline
\end{tabular}

Figure 5. Andrews' Findings on the Effects of Leveling the Curve of Spee

\section{Esthetics and the Arch Form}

The impact of the smile on attractiveness is a well documented phenomenon. In fact, a research study by Miller ${ }^{87}$ concluded that individuals mainly 
focus on other people's eyes and mouth during interpersonal interaction, with little time spent on other facial features. In the eyes of the general public, the smile ranks second only to the eyes as the most important feature in facial attractiveness ${ }^{88}$.

There are many components involved in the determination of an attractive smile. First, the smile arc should follow the path defined by the edges of the maxillary central incisors, lateral incisors, and tips of the canines ${ }^{40}$, and should be consonant with the curvature of the lower lip ${ }^{41,45}$. The gingival margins of the central incisors should be positioned apical to those of the lateral incisors and at the same level as the canines ${ }^{89}$. There should be approximately 1.0 and $-1.0 \mathrm{~mm}$ of gingival display for females and males respectively ${ }^{90,91}$. Studies have also determined that whiter teeth are also more esthetically pleasing to patients ${ }^{92,93}$, and that the golden proportion is a useful guide in the determination for tooth size relationships ${ }^{94,95}$.

An important feature of smile attractiveness, and a subject that has received a lot of attention in the area of cosmetic dentistry ${ }^{40}$ is the presence or absence of the buccal corridors. The buccal corridors were first defined by Frush and Fisher in 1958 as the spaces between the facial surfaces of the posterior teeth and the corners of the lips when the patient is smiling. Research by Dunn et al ${ }^{96}$, concluded that lay persons found having a greater number of teeth displayed during smiling is significantly more attractive that having fewer teeth displayed. Assuming that small buccal corridors make a smile more attractive, orthodontic expansion has been proposed to broaden the arch form and improve smile attractiveness ${ }^{45,46}$. These findings, that wider smiles are more attractive was supported by Moore's et $\mathrm{al}^{43}$ research, in which having minimal buccal corridors is a preferred esthetic feature in both men and women. There was a consistent relationship 
between smile fullness and smile attractiveness in their study. In fact, lay persons were able to discriminate, to a statistically significant extent, between the varying degrees of smile fullness in altered images used in their study. In order to provide clinical guidelines, determination as to whether orthodontists and laypeople perceive buccal corridors differently was studied by Martin et al ${ }^{97}$. They concluded that both orthodontists and lay people significantly rated smiles with small to no buccal corridors as more attractive than those with large buccal corridors. Furthermore, it was determined that orthodontists preferred wider smiles that displayed teeth through the first molars (12 teeth), and lay people preferred smiles showing teeth through the second premolars (10 teeth).
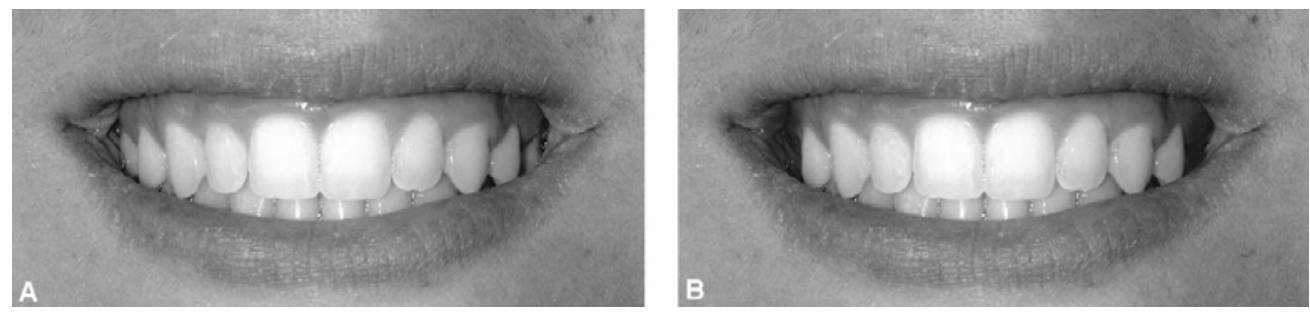

Figure 6. (A) Original Photograph of Patient Exhibiting No Buccal Corridors (B) Same Image Digitally Altered to Increase Buccal Corridors

There is one study by Hulsey ${ }^{41}$, in which the influence of buccal corridors on smile attractiveness was examined and it was determined that variations in buccal corridors seemed to have no significance. However, Hulsey measured the ratio of the distance between the maxillary canines to the distance between the corners of the smile, which is not an actual measure of the buccal corridors as Frush and Fisher had originally defined it. This further points to the fact that attractiveness of the smile is not only the six anterior teeth, but involves the first, and sometimes second bicuspids and molars. 
Research by Roden-Johnson et al ${ }^{44}$ also compared orthodontists and laypersons and found no differences between smile attractiveness associated with buccal corridors, but their definition of buccal corridors was also based on inter-canine width.

\section{Stability Related to Arch Form}

When treating cases, one of the objectives high on the orthodontist's list is to produce results that are stable, and will last the patient for a lifetime. This unfortunately has not been the case, and one area that has been intensely studied for its impact on stability of treatment results is arch form. Angle believed that placing the teeth in an ideal occlusion with a full complement of teeth, and the arch form that resulted ensured post treatment stability ${ }^{98}$. This, however, was not experienced by other orthodontists, and they came to realize that there are limitations associated with orthodontic therapy.

Rogers ${ }^{34}$ put forth the importance and limitation of establishing proper functional muscle balance between the dentition and circumoral musculature as an aid in treating and retaining orthodontic cases. He believed that moving teeth beyond that balance would result in relapse to the original position following the removal of the appliances. The relationship of the circumoral musculature, dentition, and stability was further expanded upon by Strang ${ }^{36,37}$ and others ${ }^{26,30}$, who believed that the intercanine and intermolar arch width are accurate indices of the inherent muscular balance for each patient and further dictate the limits of arch expansion in those areas during treatment. Research by Weinstein ${ }^{38}$ further demonstrated the minimal change that is necessary to take place in order to disrupt this harmony, when he showed that small localized surface additions where encroachment upon adjacent tissues altered the balance, and upon removal the teeth promptly returned in the direction of their origins. This further 
supported the theory that teeth assume unique positions between the opposing forces of the tongue and cheek musculature. In a study by De La Cruz et al ${ }^{99}$, arch form tended to return toward the pretreatment shape after retention. The greater the treatment change, the greater the tendency for post retention change, however, individual variation was considerable. The patient's pretreatment arch form appeared to be the best guide to future arch form stability, but minimizing treatment change was no guarantee of post-retention stability. Burke et al ${ }^{100}$ reported findings in their study indicating that regardless of patient diagnostic and treatment modalities, mandibular intercanine width tends to expand during treatment on the order of one to two millimeters, and to contract postretention to approximately the original dimension. Evaluating tendencies for relapse following changes in the arch form have been documented in several studies $^{16,17,24,27,33,39,101}$. They have shown that the intercanine and intermolar widths tend to decrease during the post retention period, especially if expanded during treatment from their original positions. Other studies ${ }^{19,21,29}$ have shown that teeth also return toward their original inclinations and positions after all retentive appliances are removed.

Based on the above information, it is suggested that violation of the lower intercanine width should not be increased during treatment, due to increased risk of relapse. Felton et al ${ }^{25}$ pointed out that buccal uprighting will result in lower relapse in approximate $70 \%$ of cases, however, there were $30 \%$ of cases studied where mandibular transverse increases in arch form were stable. These stable cases were likely deep bite cases in which the lower canines were inclined lingually in response to the palatal contour of the upper canines according to research by Shapiro ${ }^{102}$, in which stability was believed to be associated with the fact that when the bite is opened, the incisal edges of 
the mandibular canines may move labially, but the apices of the roots of these teeth move lingually, and the bodies of the teeth remain in the same position. Other cases reported to have stable results are patients that rapid maxillary expansion is indicated in the upper arch and this expansion is maintained post-treatment. Ladner and Muhl $^{28}$ reported that the lower arch follows maxillary expansion with buccal uprighting, which is stable.

Understanding that increasing arch length and changing the dimensions of the arch form resulted in post treatment relapse, extraction therapy became very popular to try and combat significant changes in arch form. A landmark study by Little et $\mathrm{al}^{103}$, demonstrated results showing that extraction therapy did not result in greater post treatment stability. Their study was a follow up 65 cases in which the mandibular first premolars had been extracted. These cases underwent assessment at least 10 years post retention, and the results revealed considerable variation among patients. The long-term response to mandibular anterior alignment was unpredictable, and no variables such as degree of initial crowding, age, sex, Angle classification, etc., were useful in establishing a prognosis. Typically, arch width and length decreased after retention, regardless of treatment expansion or constriction. Two thirds of the patients had unsatisfactory lower anterior alignment after retention. Cases that were minimally crowded before treatment usually became more crowded, while initially severe crowding cases usually moderated. McReynolds et $\mathrm{al}^{31}$ obtained similar results is a study evaluating extraction of second premolars as well.

Changes to the arch form by increasing incisor anteroposterior position, also has implications on stability, and is often the first visible sign of relapse with incisor crowding. Proffit ${ }^{82}$ suggests a $2 \mathrm{~mm}$ limitation of forward movement of the incisors from 
their original position. He states that lip pressure increases significantly beyond this point, by disrupting the balance of forces represented by the incisors original pretreatment position.

It is also important to note the changes that take place in individuals that did not go through orthodontic treatment. A moderate increase in width of the dental arches can be expected, particularly in the anterior region, until the permanent canines erupt into place. ${ }^{32}$ However, after this point it has been shown that arch length decreases in the transition from the deciduous to permanent dentition, and continues throughout life $\mathrm{e}^{18,19,23}$. Therefore, similar effects are seen in the arch form whether or not orthodontic treatment was rendered.

\section{Arch Form and the Periodontium}

Treatment of orthodontic patients hopefully leads to an improvement in the patients’ overall oral health, and long term stability of the supporting periodontium. Consideration of the patients' pre treatment periodontal condition should be evaluated prior to initiation of treatment. Planned changes to the dental arch form should be considered, due to the impact this has on the supporting hard and soft tissues.

Orthodontic tooth movement can result in serious negative effects to the periodontium. A commonly seen phenomenon in non-orthodontically treated patients is marginal bone recession. This is displacement of the soft tissue margin apical to the cementoenamel junction with exposure of the root surface. Tissue trauma and tooth 


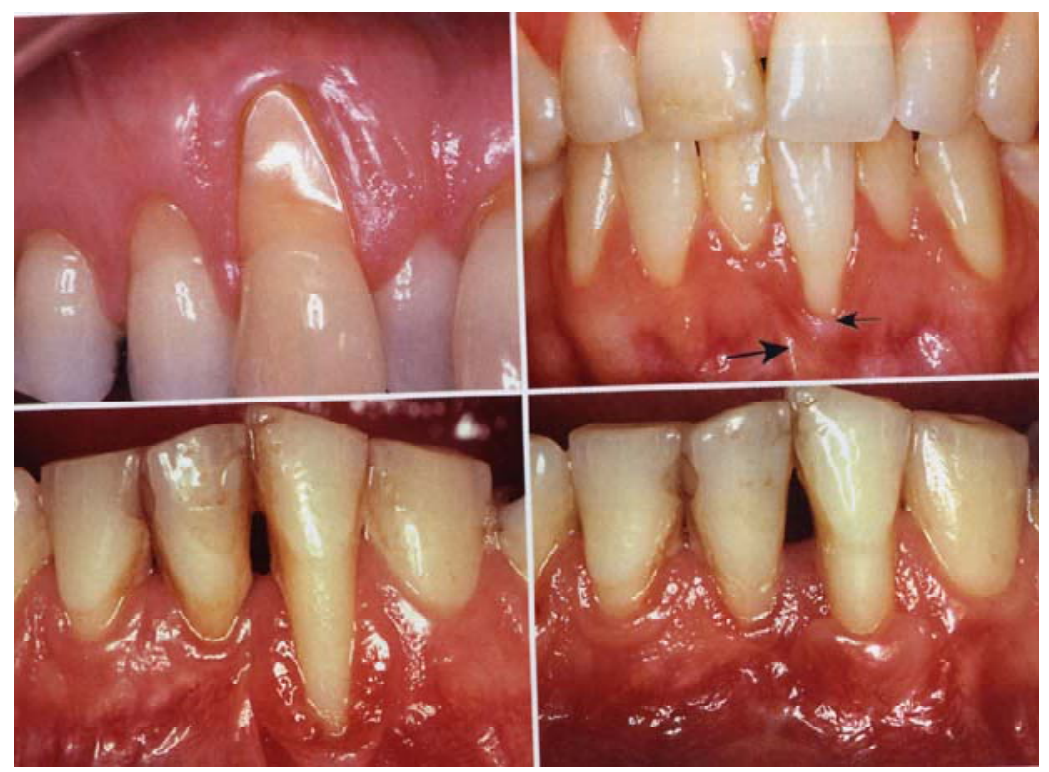

Figure 7. Marginal Bone Recession in Non-Orthdontically Treated Patients

malposition are considered to be a dominating causative factor for the development of gingival recession, particularly in younger individuals ${ }^{104}$. Similar presentations are seen in patients treated with orthodontic therapy, and are related to the direction, and amount of tooth movement. Research has shown that facial tooth movement results in reduced facial gingival dimensions, whereas an increase in facial gingival dimension is seen after lingual movement ${ }^{54,105}$ The present belief is that gingival recession occurs secondarily to an alveolar bone dehiscence, if the overlying tissues are stressed ${ }^{82}$. Therefore, root dehiscence establishes an environment that is conductive to loss of gingival tissue. This implies that orthodontic tooth movement that is done within the alveolar bone does not result in soft tissue recession. 


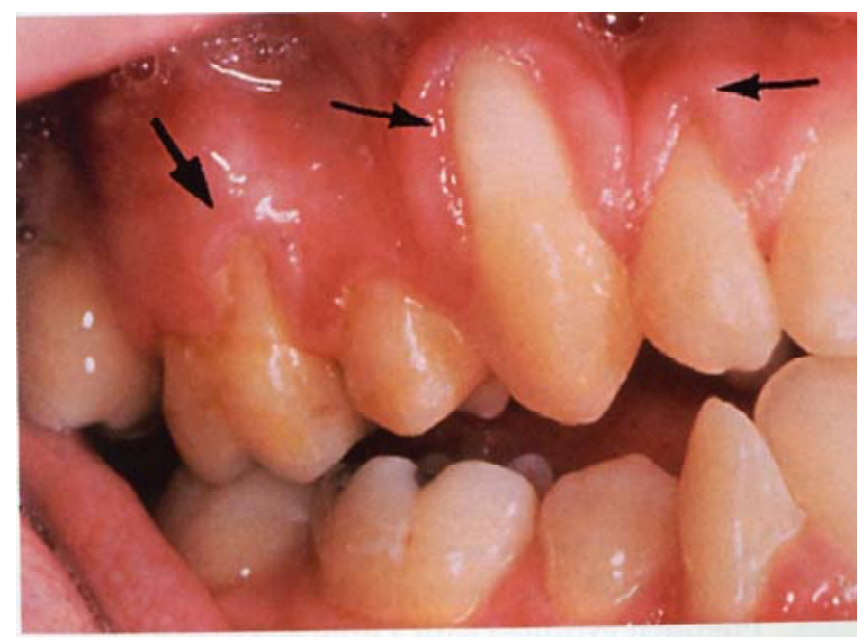

Figure 8. Fenestrations and Tissue Recession Associated Teeth Resting Beyond the Supporting Bone

Animal experimentation has shown that predisposing bone dehiscences may be induced by uncontrolled labial expansion of teeth through the cortical plate, thus making those teeth susceptible to the development of gingival recession ${ }^{53,55-58}$. However, experimental studies have shown that labial bone reforms in the area of dehiscence with an intact junctional epithelium when the tooth is returned to its proper position with the root centered within the alveolar process ${ }^{58,106}$. Furthermore, an experiment done by Wennstrom ${ }^{107}$ showed that teeth that were moved orthodontically in a labial direction into areas with varying thickness and quality of marginal soft tissue, showed an apical displacement of the soft tissue margin and a reduced alveolar height. Thus, suggesting that regardless of the thickness of marginal gingiva present, facial movement beyond the alveolar bone results in loss of attachment. As long as tooth movement is confined 
within the envelope of the alveolar process, the risk of side effects to the marginal tissue is minimal, regardless of the quality of the soft tissue.

Expansion of the arch form has been shown to produce gingival recession when expressed beyond the alveolar bone. However, similar findings were seen when maxillary transverse discrepancies that were not corrected. Research by Anzilotti ${ }^{108}$ determined that a transverse skeletal discrepancy is a risk marker for identifying patients susceptible to gingival recession and periodontal disease, when discrepancies of $5 \mathrm{~mm}$ of greater go uncorrected. Therefore, expansion or lack of expansion of the arch form can be damaging to the periodontal condition of the patient. The key to maintaining attachment is to produce movement that results in tooth movement within the alveolar bone, and thus the prevention of any dehiscences.

\section{Classification of Pre-Formed Arch Wires}

The multitude of available preformed arch wires on the market is broken down into two basic categories. Arch forms are either classified based on descriptions related to their shape, or have their shape described on the basis of mathematical or geometrical formulas. Both descriptions have received their share of criticism and praise. Some feel that the preformed arch wire in general is an entirely too simplistic approach to orthodontic treatment in search of a "one size fits all” or "cookie cutter" attempt to treat patients. The concept of individualized arch forms is a focal point of every dentist's education in complete denture prosthodontics. Therefore, it seems sensible that the same principle of variability of arch forms among orthodontic patients exists in the natural

dentition. Research conducted by Felton et $\mathrm{al}^{25}$, stated that customizing arch forms appeared to be necessary in most cases to obtain optimum long-term stability, because of 
the great variability in arch form observed in their study. However, despite the wide acceptance of variability of arch form, there is a long tradition in orthodontics for the search of a single ideal arch form. This more likely than not, is driven by the desire to increase efficiency and profitability in the private practice setting.

Various geometric terms have been applied to the description of available preformed arch wires. This list includes ovoid, trapezoid, squared, U-shaped, and tapered to name a few. Among available arch forms today most are classified under three basic geometric descriptions: tapered, square, and ovoid. These terms are based on the description of the mandibular anterior curve of the arch form cuspid to cuspid with a more gradual curve extending posteriorly. According to McLaughlin et $\mathrm{al}^{1}$, the tapered arch form has the narrowest arch form from cuspid to cuspid. This arch form is recommended in patients with narrow arches, especially cases with gingival recession in the canine and premolar areas (common in adult cases), and cases undergoing single arch treatment in order to prevent expansion of the treated arch relative to the untreated arch. The square arch form is the broadest of the three arch forms. Cases that present with broad pretreatment arches, and cases requiring buccal uprighting of the lower posterior segments and expansion of the upper arch. It is also beneficial for maintenance of expansion in the maxillary arch following rapid maxillary expansion. The ovoid arch form is the arch form that most commonly resembles the arch form of most cases. Comparison of the three arch forms when superimposed show that the variation between the three types occurs mainly in inter-canine and inter-first-premolar width.

The Bonwill-Hawey arch form was one of the earliest to be used by orthodontists, and dominated orthodontic thinking for many years. This arch form is based on an 
equilateral triangle with a base representing the inter intercondylar width. The lower anterior teeth are arranged on the arc of a circle with a radius determined by the combined width of the lower incisors and canines, with the premolars and molars aligned with the second and third molars turned toward the center. The posterior segments of the arch form are fabricated by extending straight lines back from each cuspid ${ }^{109}$. This created arch form is directly related to the sizes of the anterior teeth, and does not take into consideration the shape of the patient's original arch. This arch form is rarely used today.

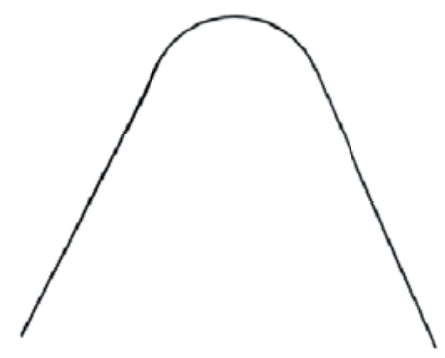

Figure 9. Bonwill-Hawley Arch Form

One of the first mathematical formulas used to describe the dental arch form was the catenary curve. Pepe ${ }^{110}$ and Germane et al $^{111}$ related the dental arch form to a catenary curve which is most easily described by visualizing a length of chain suspended by two hooks and noticing the shape that is assumes. This form has been shown to be fairly accurate for the anterior to premolars regions of many arches, but it doesn't allow for the commonly seen lingual curvature that occurs in the molar regions of many individuals $^{112}$. Neilans ${ }^{113}$ found the catenary curve a better representation of the mandibular dental arch than either the ellipse or parabola, while the reverse was true for 
the maxillary dental arch. White ${ }^{114}$ through subjective evaluation of curve fit found that the catenary curve was a "good fit" in only $27 \%$ of the sample studied. Despite the noted inadequacies, most of the preformed arch wires offered by contemporary manufacturers are based on a catenary curve, with average intermolar dimensions ${ }^{82}$.

The Brader arch form is another arch form described by a mathematical formula. This arch form is based on a trifocal ellipse that differs from the catenary curve shape by being slightly wider in the bicuspids followed by a gradual constriction in the molar areas, giving the arch form a more rounded appearance. The anterior segment of the trifocal ellipse closely approximates the anterior segment of a catenary curve, but the trifocal ellipse gradually constricts posteriorly in a way the catenary curve does not, thus making the Brader arch form more closely represent the position of the second and third molars $^{82}$.
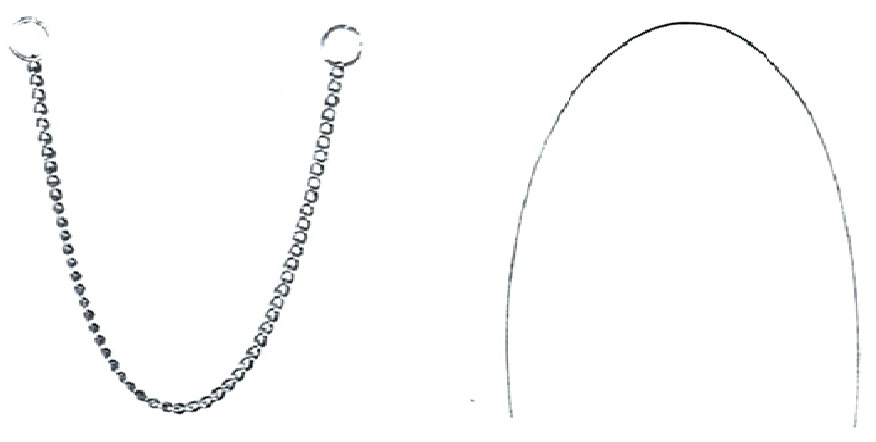

Figure 10. (L) Demonstration of Catenary Curve Arch Form w/ Suspended Chain, (R) Brader/Trifocal Ellipse Arch Form 
There has been recent developments in the description of arch forms by complex mathematical formulas such as the cubic spline ${ }^{115,116}$, polynomial functions ${ }^{117,118}$ and beta function ${ }^{119}$. As with other preformed arch wires, the response has been mixed, however, several have been used to produce commercial arch forms ${ }^{120-122}$.

\section{Arch Wire Customization}

Various methods of arch wire customization are practiced in contemporary orthodontics. The difference between them is what serves as the basis for shaping the arch form. One such method of shaping finishing arch wires is the WALA Ridge concept proposed by Andrews and Andrews ${ }^{71}$. This concept is based upon the goal of centering the roots of mandibular teeth over basal bone between its buccal and lingual borders, and to have the crowns inclined correctly in order for them to occlude properly with the opposing dentition. The WALA Ridge is believed by the Andrews' to reflect the shape of each individual's basal bone and be resistant to environmental forces. This concept of individualized arch form and the relationship to the WALA Ridge was supported by Ronay et $\mathrm{al}^{123}$ who concluded that the WALA Rridge proved to be a useful representation of the apical base and helpful in the predetermination of an individualized dental arch form. Furthermore, this anatomical structure is very easily distinguished clinically, thus making it a practical landmark upon which to base arch wire shape. Identification of the WALA Ridge on pretreatment models allows for identification and shaping of stainless steel arch wires. 


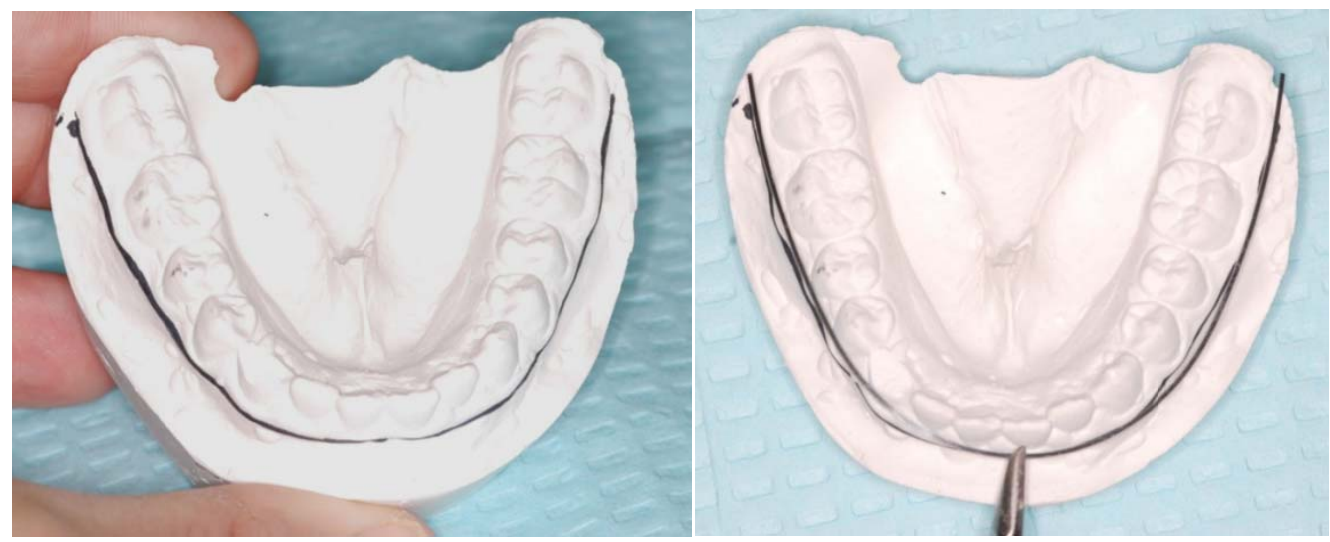

Figure 11. Identification of WALA Ridge and Shaping of Stainless Steel Wire to WALA Ridge

Another method of customizing arch forms is the wax bite method. Various treatment philosophies employ this technique. The MBT treatment philosophy ${ }^{124}$ employs the use of clear templates at the start of treatment to determine which of three arch forms the mandibular arch falls into; tapered, square, ovoid. These forms are used through rectangular heat activated nickel titanium wires during leveling and aligning. Once rectangular stainless steel wires are used they are customized to each patient's individual arch form based on the form of the lower dentition. A wax template is molded over the lower arch to gain indentations of the brackets and the wire is then formed to the indentations in the wax bite. A maxillary arch form is then coordinated with the lower to be $3 \mathrm{~mm}$ wider in all areas.

This same customized arch form technique is employed using the Damon System treatment philosophy ${ }^{125}$. However, the only difference is all patients receive the same nickel titanium arch forms in the early phases of treatment in which leveling and aligning are taking place, and once treatment moves into the "major mechanics phase”, stainless steel arch forms are used using the same wax bite technique described above. 

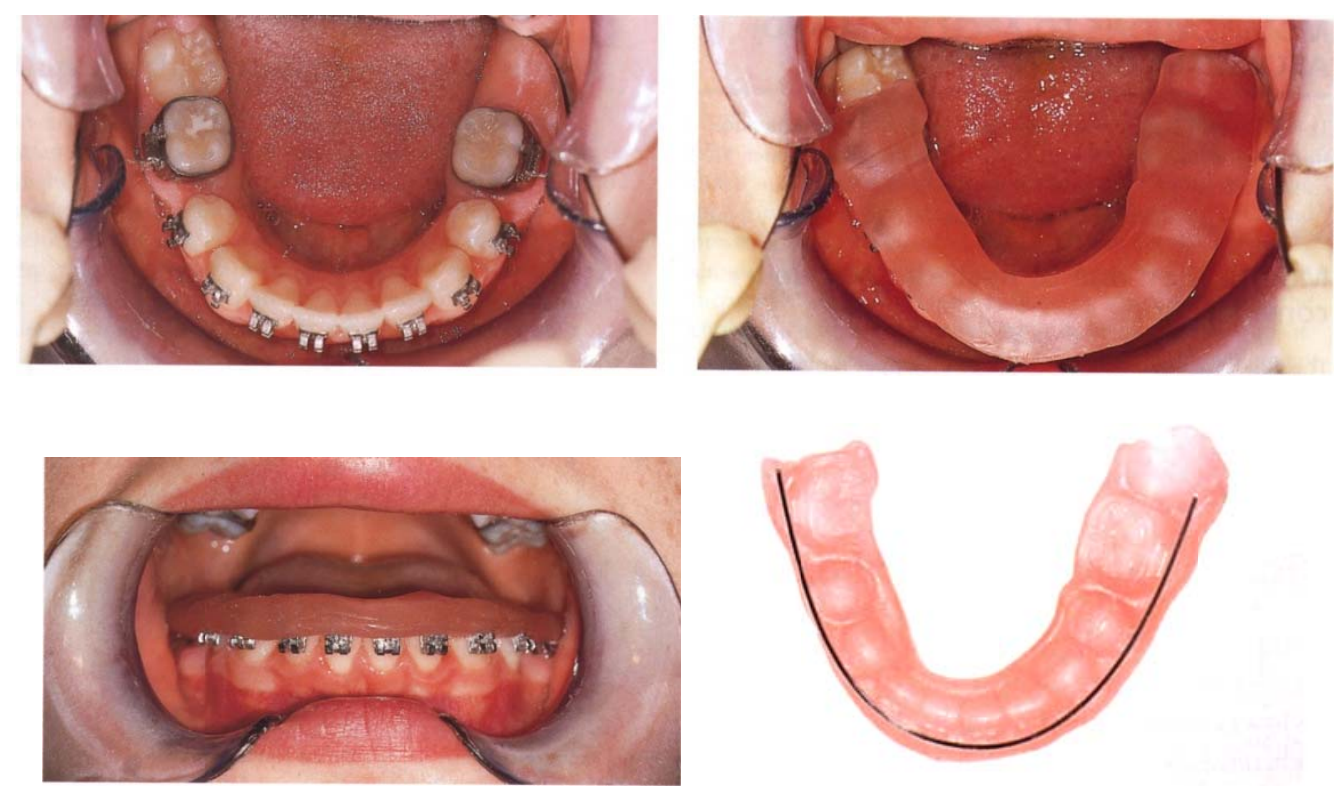

Figure 12. Clinical Technique Used to Customize Arch Wires by Wax Bite

Advances in technology along the lines of computer management, 3-dimensional imaging, and incorporation of robotics have lead to a new approach to arch wire customization during orthodontic treatment. SureSmile (OraMetrix, Dallas, TX) incorporates intraoral scanning, cone-beam computed tomography, special alloy arch wires, and precision robotic wire bending to customize arch wires. The process requires an intraoral hand scan of the dentition in a rocking motion to visualize all areas of the teeth. Through sophisticated data registration and management techniques, the captured images are processed, and a digital computer model of the dentition is produced in real time. Upon completion of this process, the teeth are able to be manipulated independently in 3 dimensions on a computer monitor. Once the 3 dimensional models are created with the desired tooth positions, this data is transferred via the internet to OraMetrix, and a robot then bends arch wires to coordinate with the doctor determined positions of the 
teeth while taking into consideration bracket prescription and placement. Investigation by Mah and Sachdeva ${ }^{126}$ into the accuracy of SureSmile found that error was within 1 degree in stainless steel arch wires.

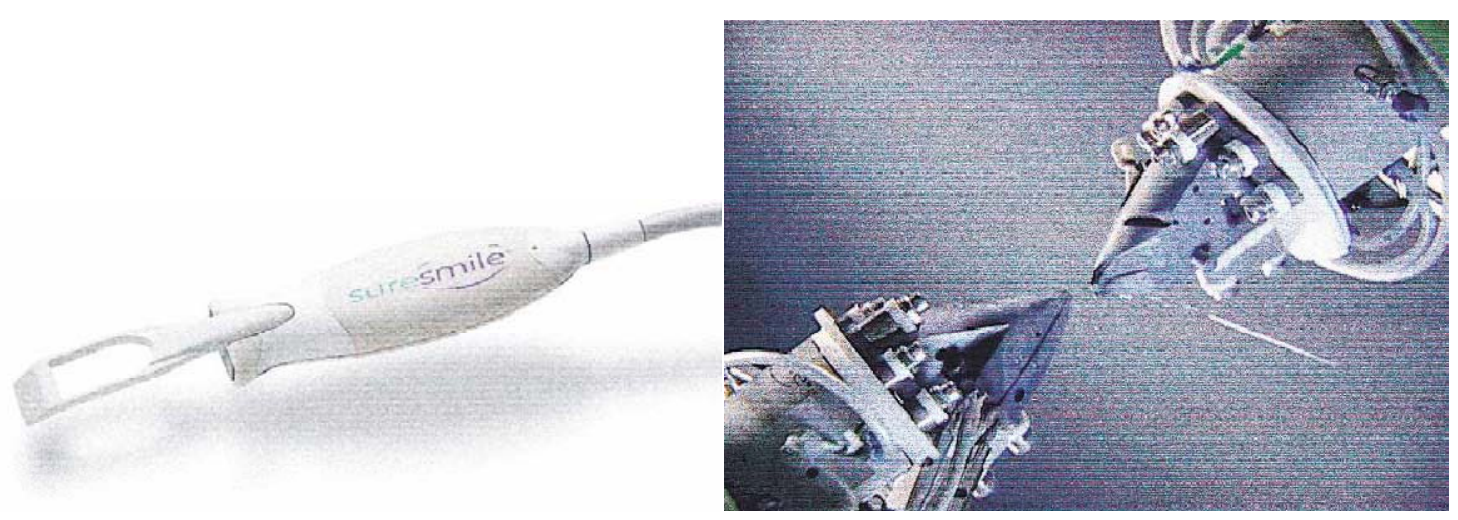

Figure 13. SureSmile Intraoral Scanner and Wire Bending Robotic Arm 


\section{Chapter III: Materials and Methods}

\section{Control Group}

Mandibular casts of 10 non-orthodontically treated samples were obtained from The Ohio State University Department of Orthodontics, Columbus, OH. Records were taken from the Wade study group. Inclusion criteria for these subjects required no previous orthodontic treatment, a minimum of two years between the acquisition of the casts (T1 and T2) used in this study for analysis, and eruption of the permanent teeth second molar to second molar.

\section{Experimental Group}

Mandibular casts, pre and post treatment (T1 and T2), of twenty patients using preformed archwires (Figure 14) was selected from the private practice of one of the investigators, Dr. Terry Dischinger, Lake Oswego, OR. Mandibular casts, pre and post treatment (T1 and T2), of twenty patients using the WALA Ridge (Figure 15) as a reference for shaping finishing arch wires was selected from the private practice of one of the investigators, Dr. Timothy Tremont, White Oak, PA. Each cast was duplicated for marking and measurement in the manner described below. Inclusion criteria for these patients required the presence of all permanent teeth second molar to second molar, a class I occlusion with no anteroposterior discrepancy present prior to treatment, and a non-extraction treatment plan. 


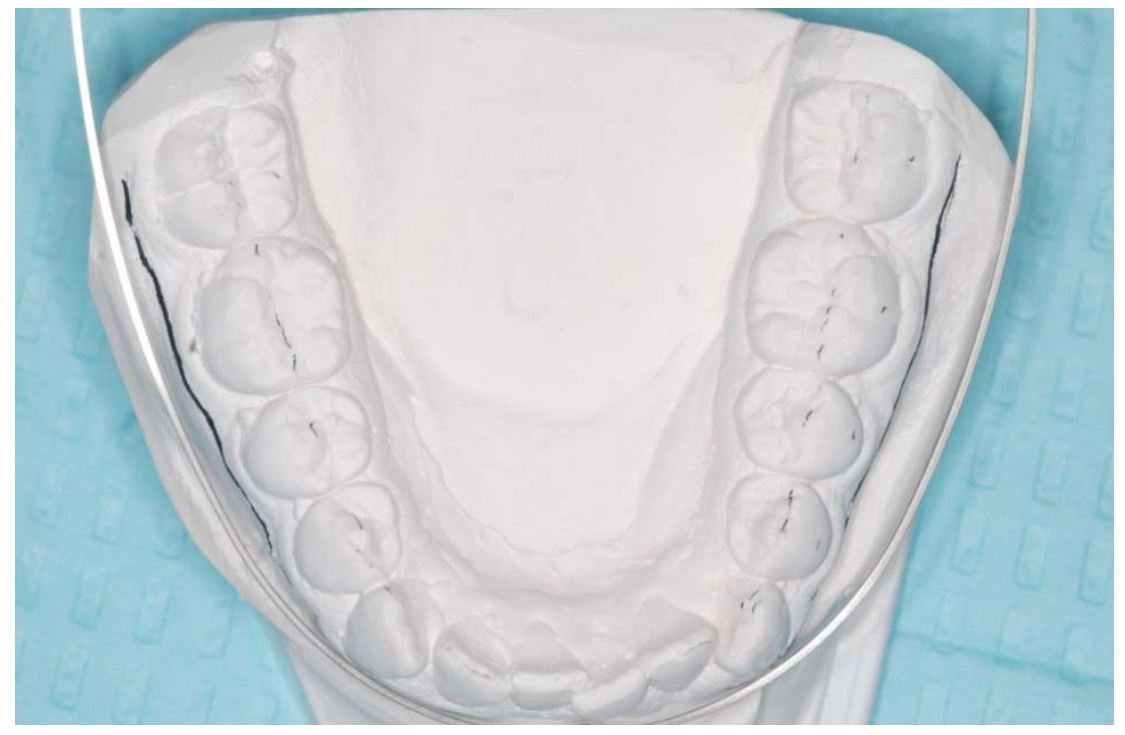

Figure 14. Preformed Archform Used in Preformed Experimental Group w/ WALA Ridge Highlighted

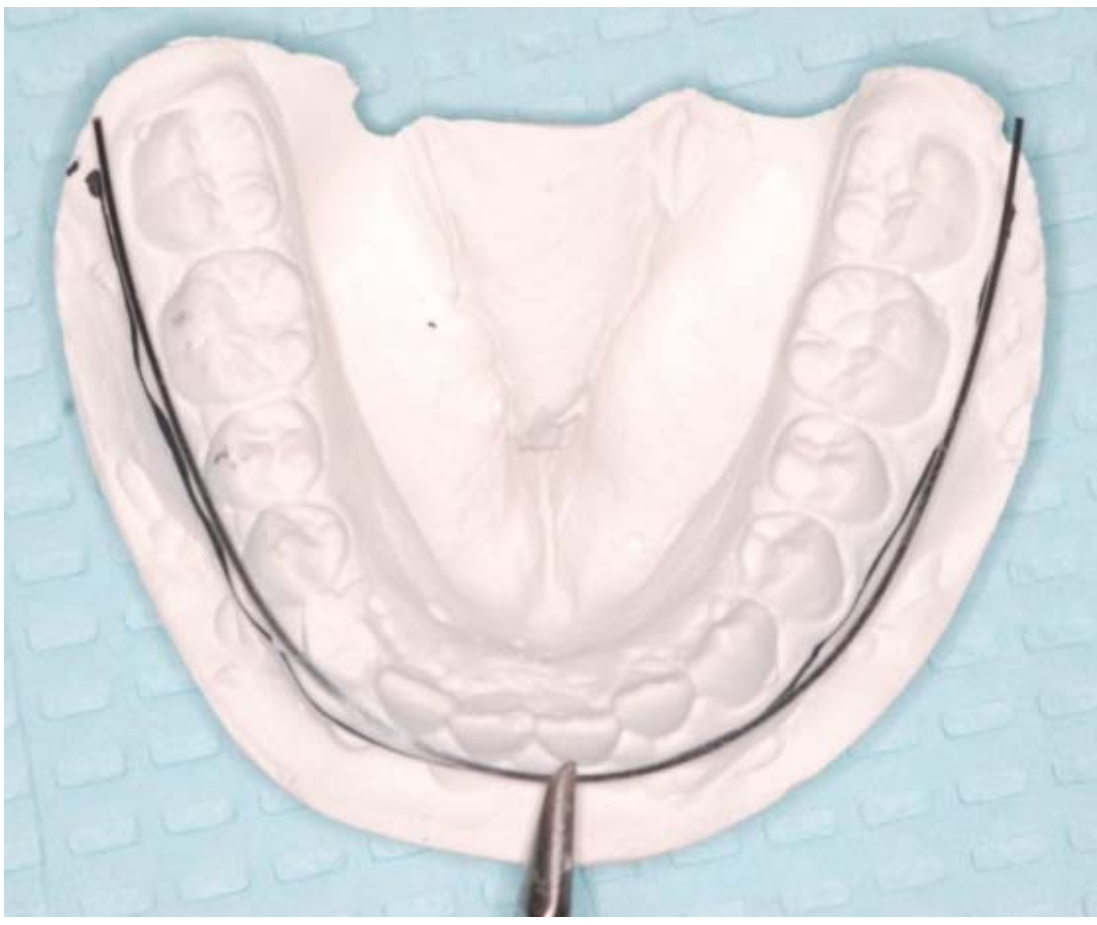

Figure 15. Customized WALA Ridge Archwire to the WALA Ridge used in the Customized Experimental Group 


\section{Measurement of Changes in Dental Positions}

All the control and experimental group’s pre, and post treatment mandibular casts were marked on the FA points of the canines, premolars, first molars, and second molars. The transverse distance between the corresponding contralateral tooth's FA point was measured using a digital caliper (General Tools and Instruments, New York, New York) and recorded to the one thousandth of a millimeter in order to establish a baseline dental position prior to treatment (Figure 16).

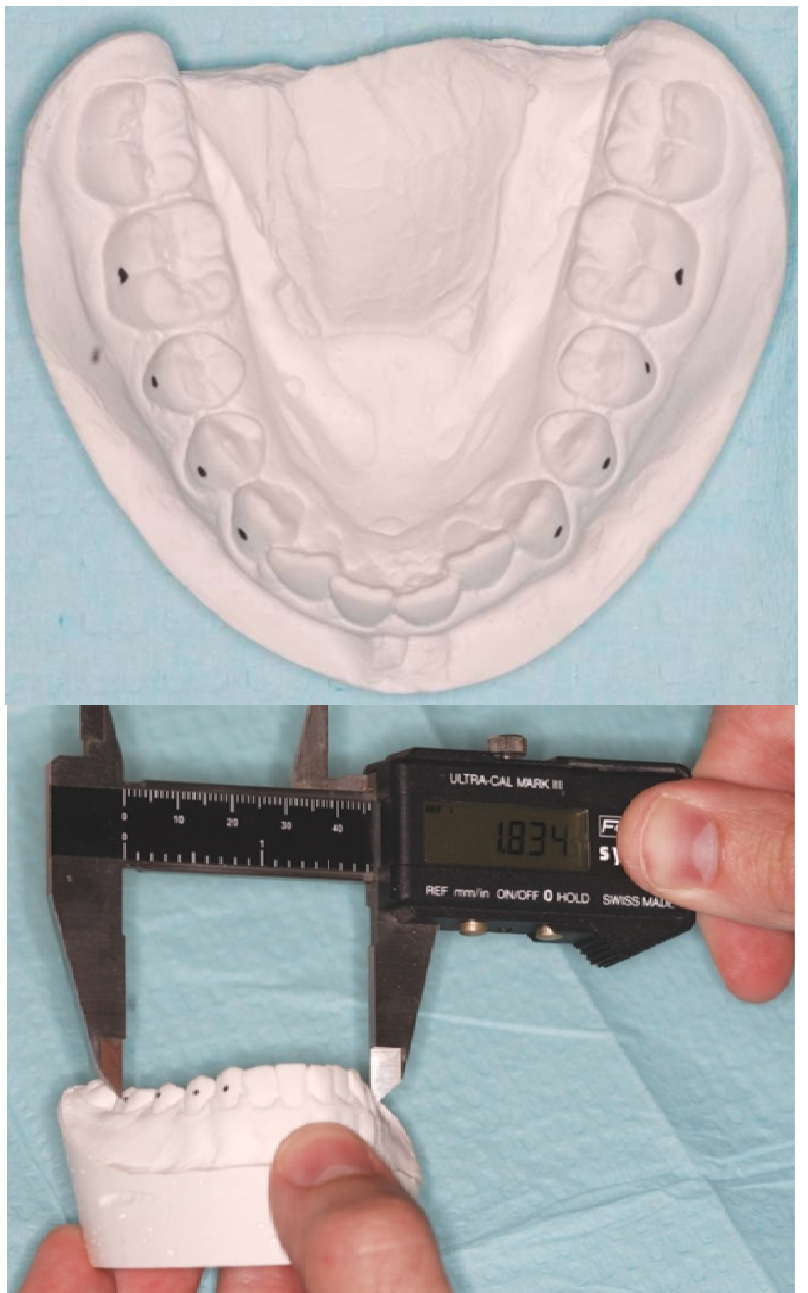

Figure 16. Marking of FA Points and Measuring Transverse Dimension 


\section{Measurements of Changes to the WALA Ridge}

All the control and experimental groups pre, and post treatment mandibular casts were taken and the WALA Ridge was outlined from second molar to second molar. The facial axis of the clinical crown (FACC) of the above mentioned teeth was marked and extended gingivally until it intersected with the already highlighted WALA Ridge. The transverse distance at the intersection of the WALA Ridge and the FACC was then measured to the one thousandth of a millimeter (Figure 17).

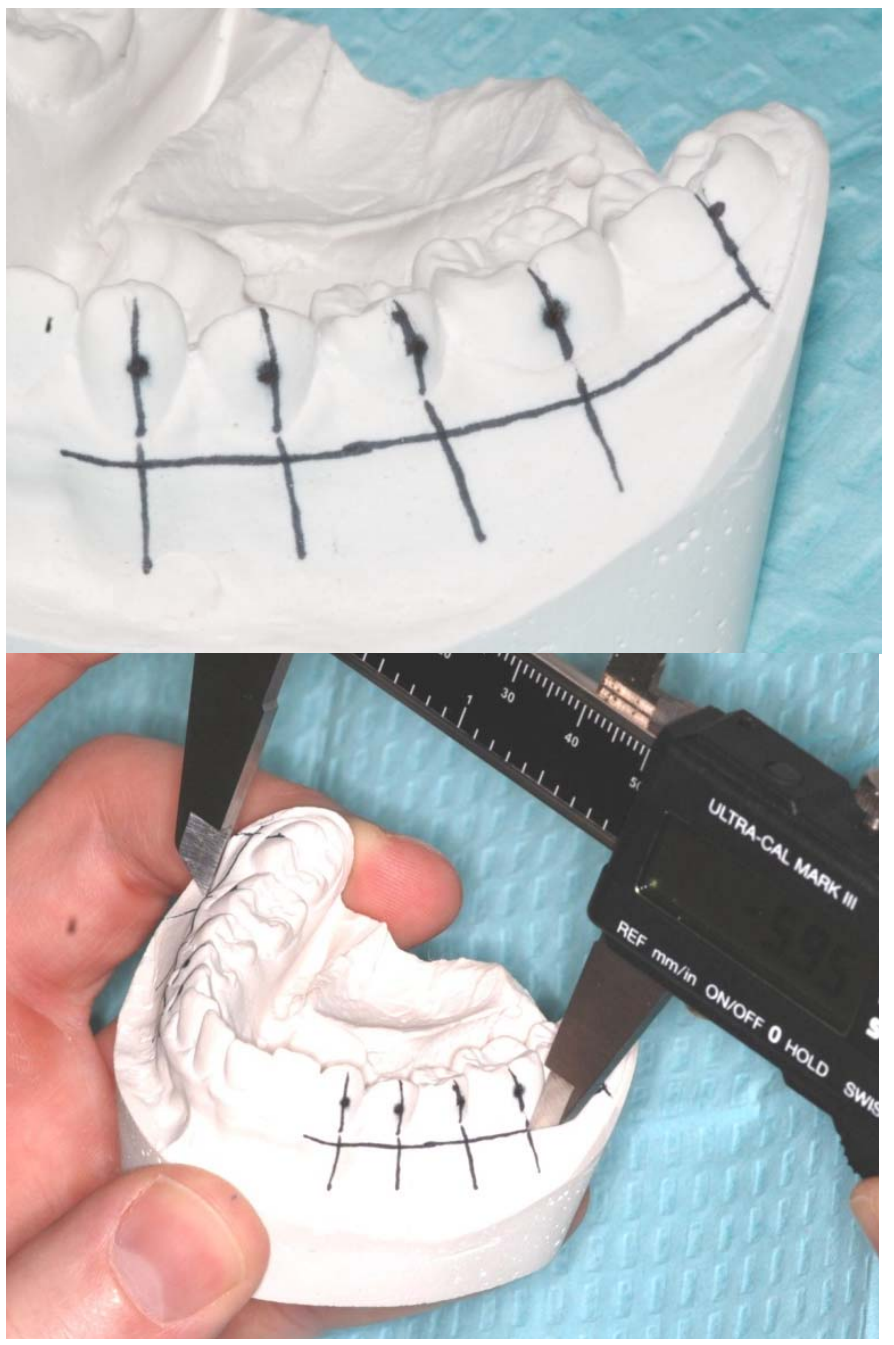

Figure 17. Identification of WALA Ridge and FACC and Measuring the Intersection 


\section{Correction of Rotated Teeth}

If the pretreatment casts had any significant rotation mesially or distally, a corrected FA point and FACC mark was placed in what would be the corrected position following treatment. This was done in order to attempt measurements of the WALA Ridge at the same anteroposterior position. This is important due to the tapering nature of the arch as you move from a posterior to more anterior position. Without this correction, the difference in measurements could simply just be the result of measuring in a wider or narrower part of the arch, thus not actually reflecting any real change that may have taken place.

\section{Survey}

Along with the data collected from cast analysis a written survey was electronically mailed to all active orthodontists in the United States listed in the 20092010 American Association of Orthodontists directory (Figure 18). The data collected from the survey was intended to supplement the information gained from the study, and provide insight into the trends of clinical practice regarding archform selection in the United States. 
What state do you practice in?

Where did you complete your orthodontic residency?

What year did you complete you Residency?

What is your primary Orthodontic Treatment Philosophy?

$\begin{array}{lll}\text { R_Roth } & \text { Andrews' Six Elements _ Tweed } \\ \text { Damon } & \text { B Bioprogressive } & \\ \text { MBT } & \text { _Alexander }\end{array}$

Stainless steel arch forms used in your practice (Please Circle)

Preformed Customized

If you use preformed stainless steel wires, what arch form do you use?

If you customize your archwire how do you determine your arch form?

_ Wax Bite

_ WALA Ridge

Other
Existing Dental Form

Suresmile

(Specify)

Figure 18. Arch Form Survey 


\section{Error Measurements}

o Intra-rater reliability was tested by randomly selecting 10 patients and remeasuring the models at least 2 weeks from original measurements.

o Comparisons were made between original and second measurements to establish a coefficient of reliability.

\section{Statistics}

The analysis of variance (ANOVA) was used to compare each of the three groups with respect to mean changes from T1 to T2. The Tukey-Kramer multiple comparison procedure was used to compare the mean difference for all pairs of groups. The ANOVA was again repeated to determine the significance of the differences in change from $\mathrm{T} 1$ to T2 of the two experimental groups and the control. Finally, an ANOVA was used to compare the net treatment changes of the two experimental groups . 


\section{Chapter IV: Results}

\section{Survey Sample Size}

The previously mentioned survey was electronically distributed to all active orthodontists in the United States listed in the 2009-2010 American Association of Orthodontists membership directory. The number of responses collected from this survey totaled 1333. Data was analyzed to gather trends related to their archform selection and are reported in the following sections.

\section{Survey Responses}

Of the total number of active orthodontists listed in the 2009-2010 American Association of Orthodontists Directory, a total of 1,333 responses were returned.

Geographic distrubution as a percentage of total responses is listed in table 6 .

\begin{tabular}{|c|c|c|}
\hline State & Percentage of Total & Number of Responses \\
\hline Alabama & $0.9 \%$ & (12) \\
\hline Alaska & $0.5 \%$ & (6) \\
\hline Arizona & U1.7\% & $(22)$ \\
\hline Arkansas & $0.7 \%$ & (9) \\
\hline California & $5.7 \%$ & $(76)$ \\
\hline Colorado & $2.3 \%$ & (31) \\
\hline Connecticut & $1.6 \%$ & $(21)$ \\
\hline Delaware & $0.2 \%$ & (3) \\
\hline Florida & $4.4 \%$ & $(58)$ \\
\hline Georgia & I $3.2 \%$ & (42) \\
\hline Hawaii & $0.2 \%$ & $(2)$ \\
\hline Idaho & $0.5 \%$ & (6) \\
\hline Illinois & $4.7 \%$ & (63) \\
\hline Indiana & $2.1 \%$ & (28) \\
\hline Iowa & $0.9 \%$ & $(12)$ \\
\hline Kansas & $1.0 \%$ & (13) \\
\hline Kentucky & U $1.9 \%$ & $(25)$ \\
\hline
\end{tabular}




\begin{tabular}{|c|c|c|}
\hline Louisiana & II 1.8\% & (24) \\
\hline Maine & $0.7 \%$ & (9) \\
\hline Maryland & III $2.0 \%$ & (27) \\
\hline Massachusetts & II $1.9 \%$ & $(25)$ \\
\hline Michigan & II $2.4 \%$ & (32) \\
\hline Minnesota & III $2.0 \%$ & (27) \\
\hline Mississippi & |I $0.3 \%$ & (4) \\
\hline Missouri & III $2.3 \%$ & (31) \\
\hline Montana & $0.3 \%$ & (4) \\
\hline Nebraska & 0.7\% & (9) \\
\hline Nevada & $1.0 \%$ & (13) \\
\hline New Hampshire & $0.5 \%$ & (7) \\
\hline New Jersey & 1.8\% & (50) \\
\hline New Mexico & $0.3 \%$ & (4) \\
\hline New York & $4.7 \%$ & (63) \\
\hline North Carolina & $4.1 \%$ & (54) \\
\hline North Dakota & II) $0.1 \%$ & (1) \\
\hline Ohio & $4.8 \%$ & (64) \\
\hline Oklahoma & III 1.3\% & (17) \\
\hline Oregon & W $2.0 \%$ & (26) \\
\hline Pennsylvania & $4.7 \%$ & (63) \\
\hline Rhode Island & | $0.4 \%$ & (5) \\
\hline South Carolina & III $1.7 \%$ & (23) \\
\hline South Dakota & II $0.8 \%$ & (10) \\
\hline Tennessee & III $2.9 \%$ & (38) \\
\hline Texas & 9.3\% & (124) \\
\hline Utah & III $1.6 \%$ & (21) \\
\hline Vermont & & $(0)$ \\
\hline Virginia & II 2.9\% & (38) \\
\hline Washington & I $3.8 \%$ & (51) \\
\hline Washington D.C. & $0.5 \%$ & (6) \\
\hline West Virginia & $1.0 \%$ & (13) \\
\hline Wisconsin & III $1.5 \%$ & (20) \\
\hline Wyoming & 川 $0.1 \%$ & (1) \\
\hline TOTAL & 1 & 1333 \\
\hline
\end{tabular}

Table 1. Geographic Distribution of Responses to Survey 


\section{Years of Practice}

Responses to the survey related to years of practice, asked by year of graduation from an orthodontic residency, ranged from 1955 to 2009. A breakdown of the number of responses per graduating year is listed in Table 2.

\begin{tabular}{rr} 
Year & Responses \\
1955 & 1 \\
1958 & 1 \\
1960 & 3 \\
1961 & 2 \\
1962 & 2 \\
1963 & 1 \\
1964 & 4 \\
1965 & 5 \\
1966 & 4 \\
1967 & 5 \\
1968 & 12 \\
1969 & 8 \\
1970 & 13 \\
1971 & 14 \\
1972 & 18 \\
1973 & 28 \\
1974 & 32 \\
1975 & 32 \\
1976 & 23 \\
1977 & 27 \\
1978 & 27 \\
1979 & 33 \\
1980 & 30 \\
1981 & 26 \\
1982 & 30 \\
1983 & 38 \\
1984 & 39 \\
1985 & 34 \\
1987 & 39 \\
1988 & 25 \\
1989 & 39 \\
1990 & 33 \\
1991 & 39 \\
1992 & 35 \\
1993 & 36 \\
& \\
\hline & 3 \\
19
\end{tabular}


Table 2. Number of Responses by Residency Graduation

\section{Treatment Philosophy}

Responses to the survey related to predominant treatment philosophy are shown in Figure 19. Most orthodontists report that they are followers of the Roth philosophy of orthodontic treatment at $30 \%$. The MBT treatment philosophy is second largest at $23 \%$. Or the respondents, $12 \%$ identify themselves with the Damon philosophy of treatment and 9\% say that Andrews' Six Elements of Orofacial Harmony is their predominant treatment philosophy. The Alexander Discipline was 6\%, Bioprogressive was 3\%, Tweed was $2 \%$, and $15 \%$ identify themselves as a mix or other treatment philosophy. 


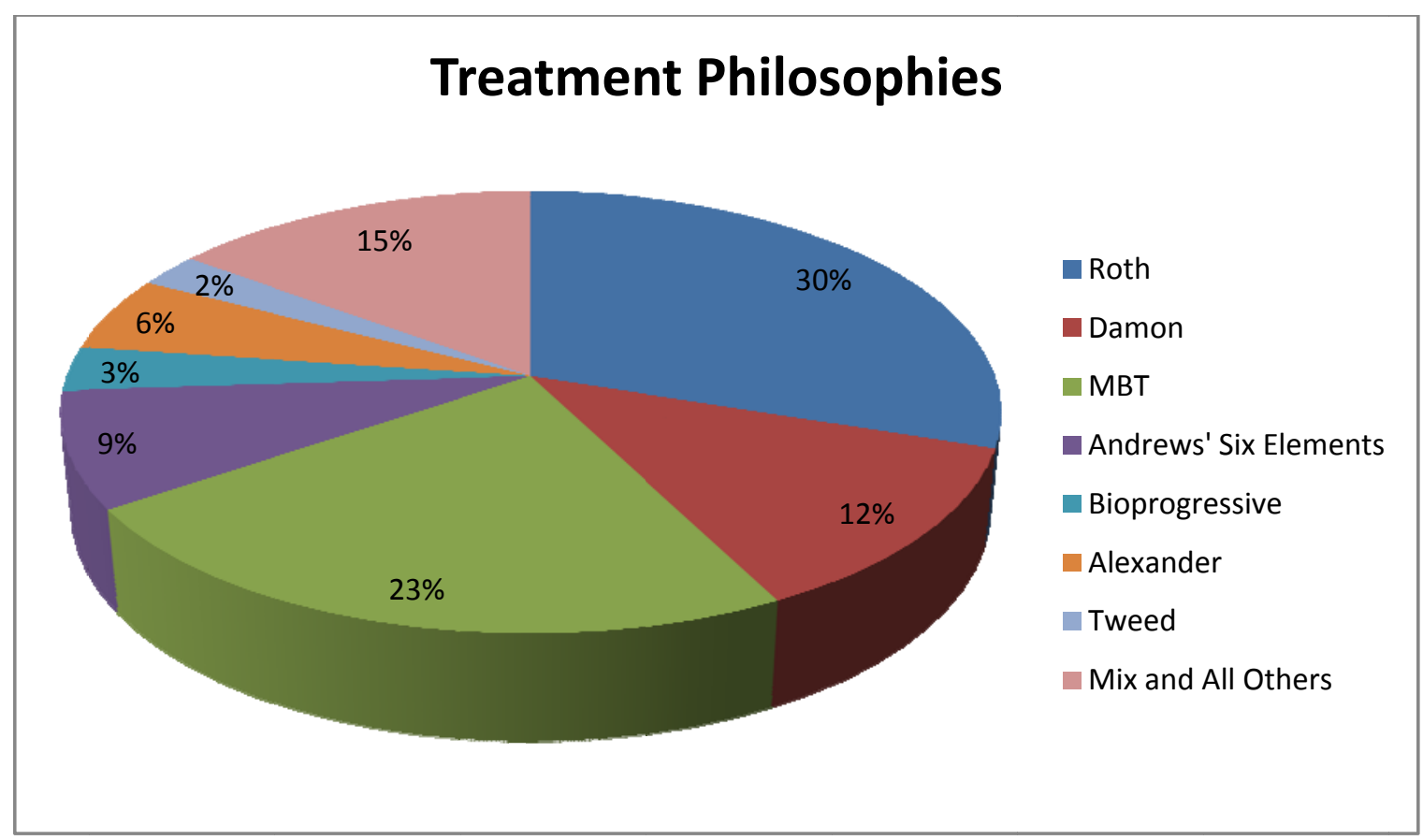

Figure 19. Distribution of Treatment Philosophies

\section{Use of Preformed vs. Customized Archwires}

Responses to the survey related to selection of preformed finishing archwires or customized archwires are illustrated in Figure 20. Two thirds of respondents use only preformed archwires in daily clinical practice. 


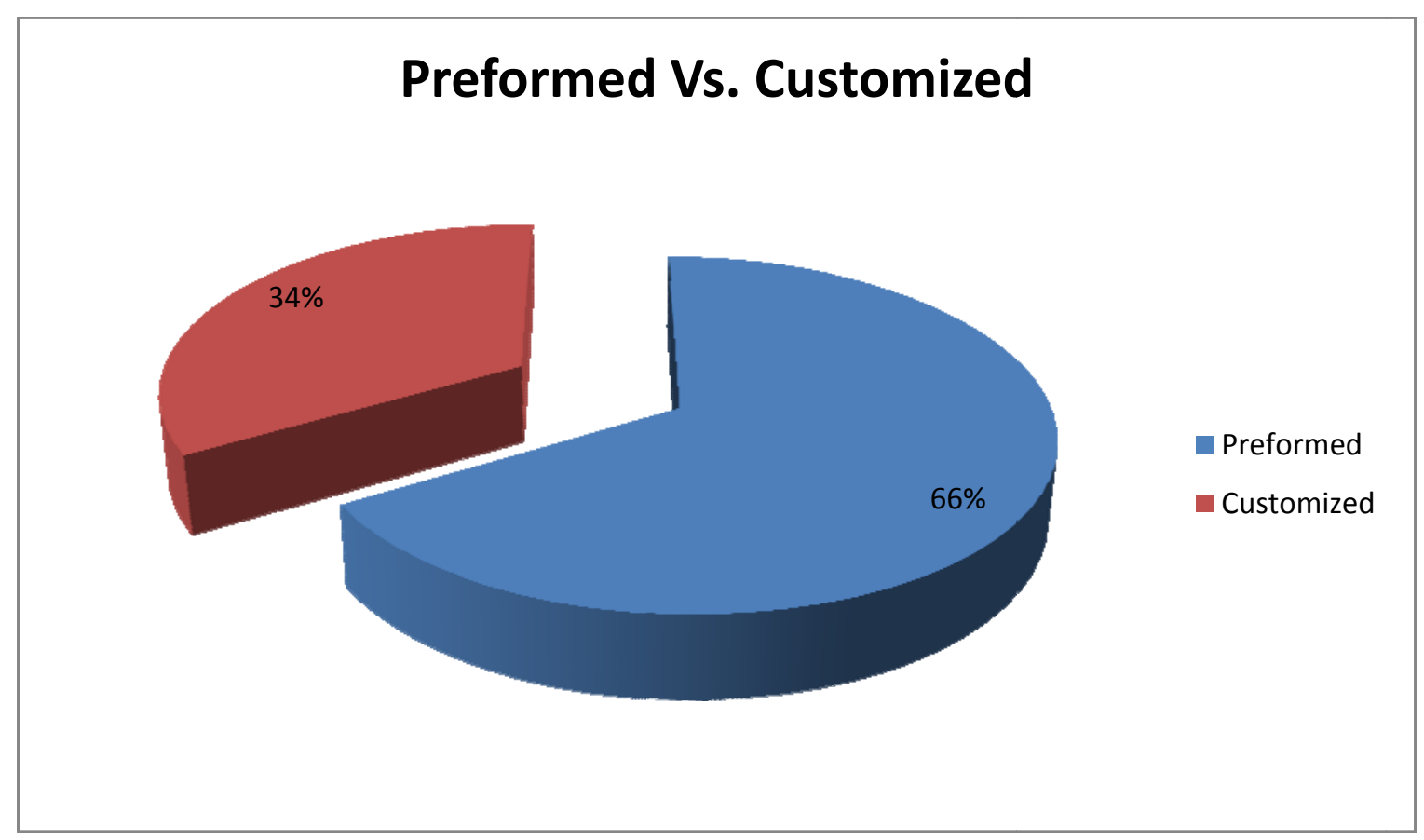

Figure 20. Percentage Preformed and Cusotmized Archwire Use

\section{Methods of Determining Custom Archform}

Of the respondents that say they customize their finishing archwires, 335 (61\%) customize their archwires to the existing dental archform, 82 (14.9\%) shape their archwires to a wax bite taken of the teeth prior to placement of stainless steel archwires, 39 (7.1\%) shape their archwires to the WALA Ridge, 24 (4.4\%) employ the use of Suresmile to shape archwires, and 69 (12.6\%) list other as a means of determining the shape of their archform. 


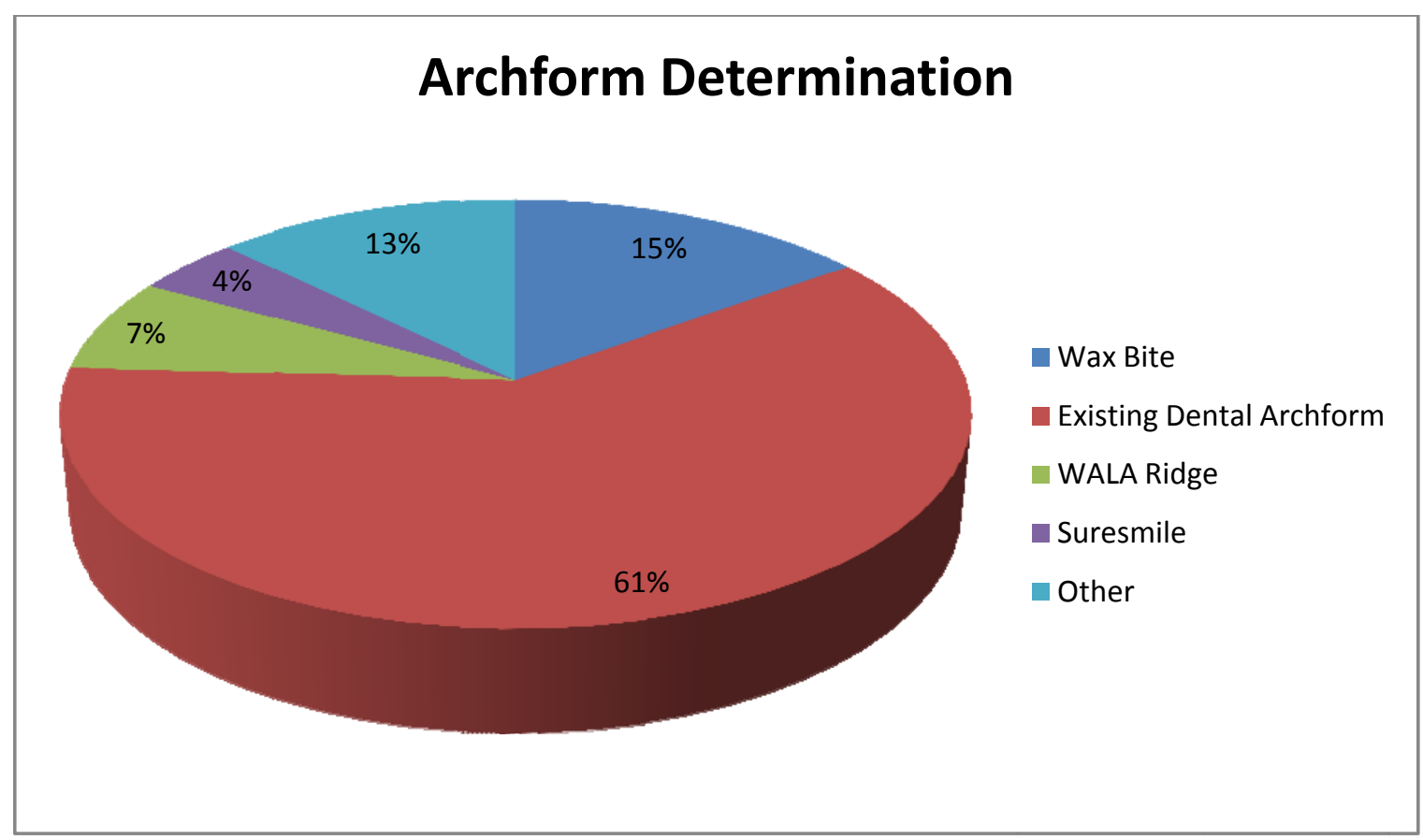

Figure 21. Distribution of Landmark Selection for Customizing Archforms

\section{Archform Sample Size}

In addition to the survey, a total of fifty subjects with mandibular pre and post treatment models were marked and measured in this study. The subjects were categorized using the previously mentioned methodology into the untreated control group, subjects treated using preformed archwires, and subjects treated using customized WALA Ridge archwires. Category numbers were as follows: 10 Control subjects; 20 preformed archwire subjects; and 20 customized archwire subjects.

\section{Distribution of Variable Measurements}

The measurements for each of the variables was described previously in the materials and methods. The dental arch width measurements included FA to FA point of the second molar to second molar (7-7D), FA to FA point of the first molar to first molar 
(6-6D), FA to FA point of the second bicuspid to second bicuspid (5-5D), FA to FA point of the first bicuspid to first bicuspid (4-4D), FA to FA point of the cuspid to cuspid (33D). The dentoalveolar arch width measurements included WALA Ridge to WALA Ridge at the second molar (7-7W), WALA Ridge to WALA Ridge at the first molar (66W), WALA Ridge to WALA Ridge at the second bicuspid (5-5W), WALA Ridge to WALA Ridge at the first bicuspid (4-4W), and WALA Ridge to WALA Ridge at the cuspid (3-3W). These measurements were analyzed using a repeated measures analysis. The results of the variable measurements are recorded in the following sections.

\section{Reliability of Variable Measurements}

Due to the fact that one examiner made all measurements in this study a reliability test of measurements was completed. This test was performed to determine the repeatability of the transverse measurements made for the variables, FA to FA point of the second molar to second molar (7-7D), FA to FA point of the first molar to first molar (6-6D), FA to FA point of the second bicuspid to second bicuspid (5-5D), FA to FA point of the first bicuspid to first bicuspid (4-4D), FA to FA point of the cuspid to cuspid (33D), WALA Ridge to WALA Ridge at the second molar (7-7W), WALA Ridge to WALA Ridge at the first molar (6-6W), WALA Ridge to WALA Ridge at the second bicuspid (5-5W), WALA Ridge to WALA Rridge at the first bicuspid (4-4W), and WALA Ridge to WALA Ridge at the cuspid (3-3W). A random sample of ten subjects had the data collection process repeated, and all markings and measurements were completed a second time. It is important to note that this reliability test was done no sooner than two weeks after the first measurements were completed. The results showed that a reliability coefficient of was found to be 0.93 FA to FA point of the second molar 
to second molar (7-7D), 0.94 FA to FA point of the first molar to first molar (6-6D), 0.91 FA to FA point of the second bicuspid to second bicuspid(5-5D), 0.91 FA to FA point of the first bicuspid to first bicuspid (4-4D), 0.76 FA to FA point of the cuspid to cuspid (33D), 0.95 WALA Ridge to WALA Ridge at the second molars (7-7W), 0.99 WALA Ridge to WALA Ridge at the first molars (6-6W), 0.97 WALA Ridge to WALA Ridge at the second bicuspids (5-5W), 0.89 WALA Ridge to WALA Ridge at the first bicuspids (4-4W), and 0.95 WALA Ridge to WALA Ridge at the cuspids (3-3W).

\begin{tabular}{|c|c|c|c|c|c|c|c|c|c|}
\hline $7-7 D$ & $6-6 D$ & $5-5 D$ & $4-4 D$ & $3-3 D$ & $7-7 W$ & $6-6 W$ & $5-5 W$ & $4-4 W$ & $3-3 W$ \\
\hline 0.93 & 0.94 & 0.91 & 0.91 & 0.76 & 0.95 & 0.99 & 0.97 & 0.89 & 0.95 \\
\hline
\end{tabular}

Table 3. Summary of Reliability of Variable Measurements

\section{Comparison of Dental and Dentoalveolar Arch Width Changes From T1 to T2 at the Second Molars for the Control Subjects}

The mean dental arch width measurements for the control from T1 to T2 at the second molars (7-7D) were compared to one another, along with the mean dentoalveolar arch width measurements (7-7W), using an ANOVA analysis. This test was used to determine if there was a statistically significant change that took place in the position of the second molars (7-7D), and whether a corresponding significant change took place to the WALA Ridge (7-7W). The results showed that no significant change took place in dental arch width $(0.14 \mathrm{~mm})$ or dentoalvoelar arch width $(-0.01 \mathrm{~mm})$, with a P-value equal to 0.74 and 0.98 respectively. 


\section{Comparison of Dental and Dentoalveolar Arch Width Changes From T1 to T2 at the Second Molars for the Preformed Archwire Subjects}

The mean dental arch width measurements for the preformed archwire group from $\mathrm{T} 1$ to $\mathrm{T} 2$ at the second molars (7-7D) were compared to one another, along with the dentoalveolar arch width measurements (7-7W), using an ANOVA analysis. This test was used to determine if there was a statistically significant change that took place in the position of the second molars (7-7D), and whether a corresponding significant change took place to the WALA Ridge (7-7W). The results showed a significant change took place in dental arch width $(2.03 \mathrm{~mm})$, as well as dentoalveolar arch width $(0.89 \mathrm{~mm})$ in subjects treated with preformed archwires. The P-values were equal to 3.8 e-8 and 0.0001 respectively.

\section{Comparison of Dental and Dentoalveolar Arch Width Changes From T1 to T2 at the Second Molars for the Customized Archwire Subjects}

The mean dental arch width measurements for the customized archwire group from $\mathrm{T} 1$ and $\mathrm{T} 2$ at the second molars (7-7D) were compared to one another, along with the dentoalveolar arch width measurements (7-7W), using an ANOVA analysis. This test was used to determine if there was a statistically significant change that took place in the position of the second molars (7-7D), and whether a corresponding significant change took place to the WALA Ridge (7-7W). The results showed a significant change took place in dental arch width $(1.38 \mathrm{~mm})$ as well as dentoalveolar arch width $(0.44 \mathrm{~mm})$ in subjects treated with customized WALA Ridge archwires with P-values of 4.8e-5 and 0.0367 respectively. 


\begin{tabular}{|c|c|c|c|c|}
\hline \multicolumn{5}{|c|}{ Change in Arch Width (T2-T1) } \\
\hline Groups & Mean(mm) & SD(mm) & p Value & Sig \\
\hline Control (7-7D) & 0.14 & 0.76 & 0.74 & NS \\
\hline Preformed Archwire (7-7D) & 2.03 & 1.67 & $3.8 \mathrm{e}-8$ & S \\
\hline Customized Archwire (7-7D) & 1.38 & 1.29 & $4.8 \mathrm{e}-5$ & S \\
\hline
\end{tabular}

Table 4. Summary of Changes in Dental Arch Width at the Second Molars From T1 to T2

\begin{tabular}{|l|c|c|c|c|}
\hline \multicolumn{5}{|c|}{ Change in Dentoalveolar Width (T2-T1) } \\
\hline Group & Mean (mm) & SD(mm) & p Value & Sig \\
\hline Control (7-7W) & -0.01 & 0.48 & 0.98 & NS \\
\hline Preformed Archwire (7-7W) & 0.89 & 1.25 & 0.0001 & S \\
\hline Customized Archwire (7-7W) & 0.44 & 0.66 & 0.0367 & S \\
\hline
\end{tabular}

Table 5. Summary of Changes in Dentoalveolar Arch Width at the Second Molars from T1 to T2 


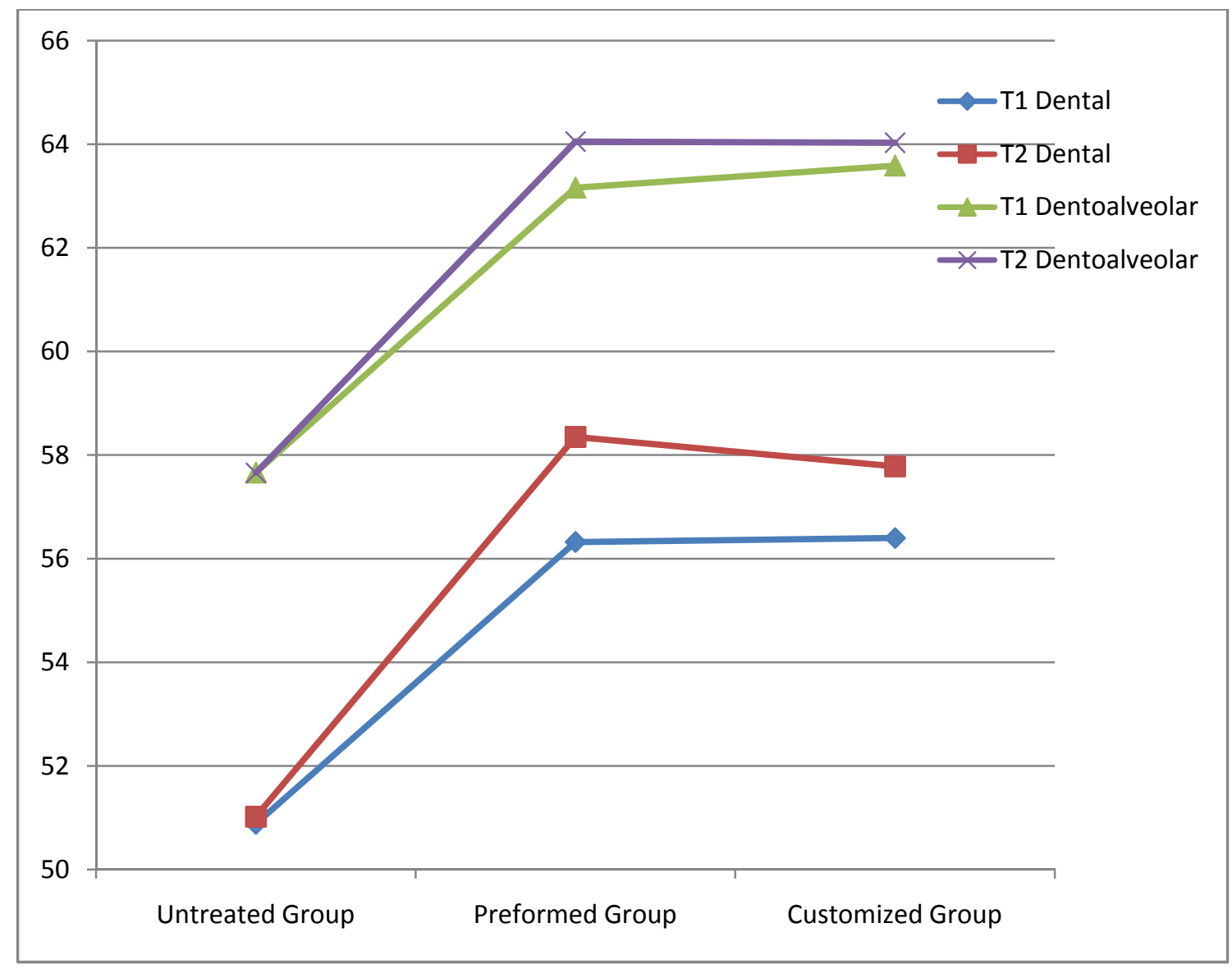

Figure 22. Means Values Plot (7-7D) and (7-7W)

\section{Comparison of Dental and Dentoalveolar Arch Width Changes From T1 to T2 at the First Molars for the Control Subjects}

The mean dental arch width measurements for the control from T1 and T2 at the first molars (6-6D) were compared to one another, along with T1 and T2 dentoalveolar measurements (6-6W) to one another, using an ANOVA analysis. This test was used to determine if there was a statistically significant change that took place in the position of the first molars (6-6D), and whether a corresponding significant change took place to the WALA Ridge (6-6W). The results showed that no statistically significant change took 
place in dental arch $(0.32 \mathrm{~mm})$ width or dentoalveolar arch width $(0.06 \mathrm{~mm})$ in the control group with a P-value equal to 0.48 and 0.84 respectively.

\section{Comparison of Dental and Dentoalveolar Arch Width Changes From T1 to T2 at the First Molars for the Preformed Archwire Subjects}

The mean dental arch width measurements for the preformed archwire group at the first molars (6-6D) were compared to one another, along with dentoalveolar arch width measurements (6-6W), using an ANOVA analysis. This test was used to determine if there was a statistically significant change that took place in the position of the first molars (6-6D), and whether a corresponding significant change took place to the WALA Ridge (6-6W). The results showed a significant change took place in dental arch width $(1.76 \mathrm{~mm})$, as well as dentoalveolar arch width $(1.23 \mathrm{~mm})$, in subjects treated with preformed archwires. The P-values were equal to 1.9 e-6 and 7.5 e-7 respectively.

\section{Comparison of Dental and Dentoalveolar Arch Width Changes From T1 to T2 at the First Molars for the Customized Archwire Subjects}

The mean dental arch width measurements for the customized archwire group from T1 to T2 at the first molars (6-6D) were compared to one another, along with dentoalveolar arch width measurements (6-6W), using an ANOVA analysis. This test was used to determine if there was a statistically significant change that took place in the position of the first molars (6-6D), and whether a corresponding significant change took place to the WALA Ridge (6-6W). The results showed that a significant change took place in dental arch width $(1.23 \mathrm{~mm})$ from $\mathrm{T} 1$ to $\mathrm{T} 2$, however, a non-significant change 
took place in dentoalveolar arch width $(0.07 \mathrm{~mm})$ in subjects treated with customized WALA Ridge archwires. The P-values were equal to 0.0004 and 0.73 respectively.

\begin{tabular}{|l|c|c|c|c|}
\hline \multicolumn{5}{|c|}{ Change In Arch Width (T2-T1) } \\
\hline Groups & Mean (mm) & SD (mm) & p Value & Sig \\
\hline Control (6-6D) & 0.32 & 0.46 & 0.48 & NS \\
\hline Preformed Archwire (6-6D) & 1.76 & 1.6 & $1.9 \mathrm{e}-6$ & S \\
\hline Customized Archwire (6-6D) & 1.23 & 1.58 & 0.0004 & S \\
\hline
\end{tabular}

Table 6. Summary of Change in Dental Arch Width at the First Molars From T1 to T2

\section{Change in Dentoalveolar Width (T2-T1)}

\begin{tabular}{|l|c|c|c|c|}
\hline \multicolumn{1}{|c|}{ Groups } & Mean(mm) & SD (mm) & p Value & Sig \\
\hline Control (6-6W) & 0.06 & 0.62 & 0.84 & NS \\
\hline Preformed Archwire (6-6W) & 1.23 & 0.07 & $7.5 e-7$ & S \\
\hline Customized Archwire (6-6W) & 0.07 & 1.14 & 0.73 & NS \\
\hline
\end{tabular}

Table 7. Summary of Changes in Dentoalveolar Arch Width at the First Molars from T1 to T2 


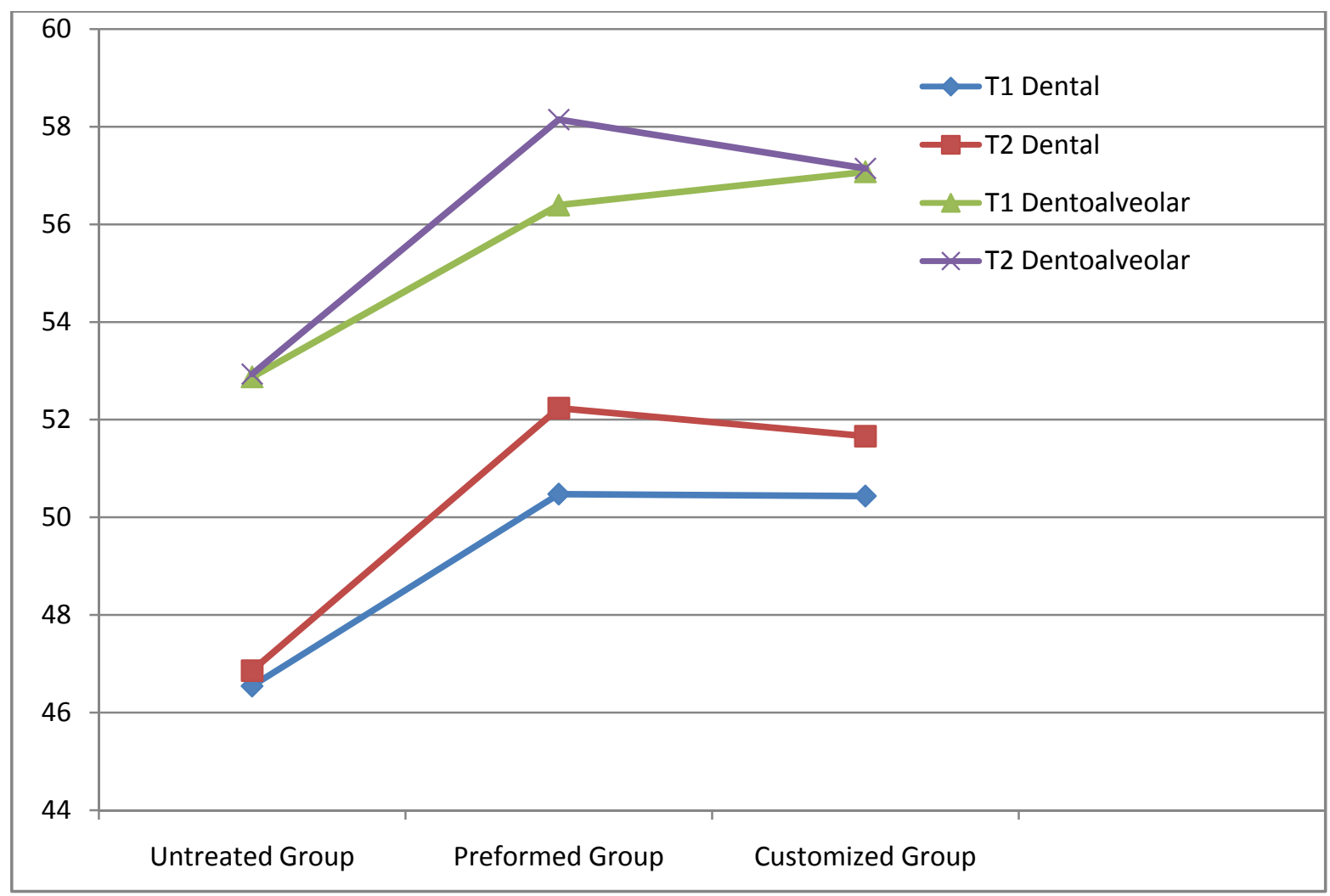

Figure 23. Mean Values Plot (6-6D) and (6-6W)

\section{Comparison of Dental and Dentoalveolar Arch Width Changes From T1 to T2 at the Second Bicuspids for the Control Subjects}

The T1 and T2 mean dental arch width measurements for the control at the second bicuspids (5-5D) were compared to one another, along with T1 and T2 mean dentoalveolar arch width measurements (5-5W), using an ANOVA analysis. This test was used to determine if there was a statistically significant change that took place in the position of the second bicuspids (5-5D), and whether a corresponding significant change took place to the WALA Ridge (5-5W). The results showed that no significant change took place in dental arch width $(0.41 \mathrm{~mm})$ or dentoalvoelar arch width $(-0.14 \mathrm{~mm})$ at the second bicuspids with P-values equal to 0.30 and 0.59 respectively. 


\section{Comparison of Dental and Dentoalveolar Arch Width Changes From T1 to T2 at the Second Bicuspids for the Preformed Archwire Subjects}

The T1 and T2 mean dental arch width measurements for the preformed archwire group at the second bicuspids (5-5D) were compared to one another, along with T1 and T2 dentoalveolar arch width measurements (5-5W), using an ANOVA analysis. This test was used to determine if there was a statistically significant change that took place in the position of the second bicuspids (5-5D), and whether a corresponding significant change took place to the WALA Ridge (5-5W). The results showed a significant change took place dental arch width $(1.78 \mathrm{~mm})$, as well as dentoalveolar arch width $(1.79 \mathrm{~mm})$, in subjects treated with preformed archwires. The P-values were equal to $9.5 \mathrm{e}-8$ and $7 \mathrm{e}-13$ respectively.

\section{Comparison of Dental and Dentoalveolar Arch Width from T1 to T2 at the Second Bicuspids for the Customized Archwire Subjects}

The T1 and T2 mean dental arch width measurements for the customized archwire group at the second bicuspids (5-5D) were compared to one another, along with T1 and T2 mean dentoalveolar measurements (5-5W) to one another, using an ANOVA analysis. This test was used to determine if there was a statistically significant change that took place in the position of the second bicuspids (5-5D), and whether a corresponding significant change took place to the WALA Ridge (5-5W) in subjects treated with WALA ridge customized archwires. The results showed a significant change took place dental arch width $(1.16 \mathrm{~mm})$ second bicuspid to second bicuspid from T1 to T2, however, a non-significant change took place in the dentoalveolar arch width $(0 \mathrm{~mm})$ when using 
customized WALA Ridge archwires. The P-values were equal to 0.0001 and 0.98 respectively.

\begin{tabular}{|l|c|c|c|c|}
\hline \multicolumn{5}{|c|}{ Change in Arch Width(T2-T1) } \\
\hline \multicolumn{1}{|c|}{ Groups } & T2-T1(mm) & SD(mm) & p Value & Sig \\
\hline Control (5-5D) & 0.41 & 0.72 & 0.30 & NS \\
\hline Preformed Archwire (5-5D) & 1.78 & 1.36 & $9.5 e-8$ & S \\
\hline Customized Archwire (5-5D) & 1.16 & 1.36 & 0.0001 & S \\
\hline
\end{tabular}

Table 8. Summary of Change in Dental Arch Width at the Second Bicuspids From T1 to T2

\begin{tabular}{|l|c|c|c|c|}
\hline \multicolumn{5}{|c|}{ Change in Dentoalveolar Width (T2-T1) } \\
\hline \multicolumn{1}{|c|}{ Groups } & T2-T1(mm) & SD(mm) & p Value & Sig \\
\hline Control (5-5W) & $-0.14 \mathrm{~mm}$ & 0.75 & 0.59 & NS \\
\hline Preformed Archwire (5-5W) & $1.79 \mathrm{~mm}$ & 1.11 & $7 \mathrm{e}-13$ & S \\
\hline Customized Archwire (5-5W) & $0 \mathrm{~mm}$ & 0.37 & 0.98 & NS \\
\hline
\end{tabular}




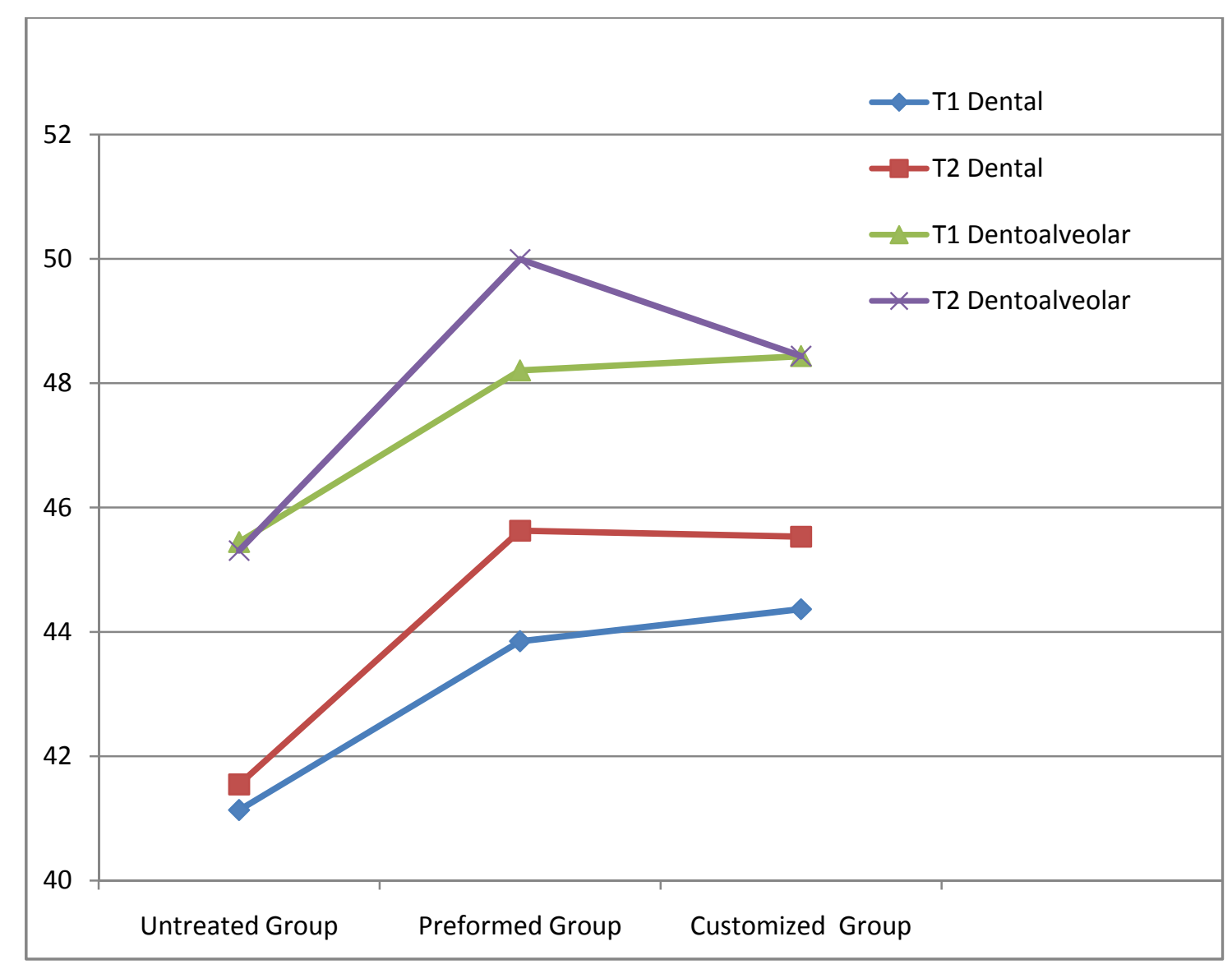

Figure 24. Mean Values Plot (5-5D) and (5-5W)

\section{Comparison of Dental and Dentoalveolar Arch Width Changes From T1 to T2 at the First Bicuspids for the Control Subjects}

The mean dental arch width measurements for the control from T1 and T2 at the first bicuspids (4-4D) were compared to one another, along with T1 and T2 mean dentoalveolar arch width measurements (4-4W), using an ANOVA analysis. This test was used to determine if there was a statistically significant change that took place in the position of the first bicuspids (4-4D), and whether a corresponding significant change took place to the WALA Ridge (4-4W). The results showed that no significant change 
took place in dental arch width $(0.21 \mathrm{~mm})$ or dentoalveolar arch width $(-0.05)$ in the control group, with P-values equal to 0.60 and 0.92 respectively.

\section{Comparison of Dental and Dentoalveolar Arch Width Changes From T1 to T2 at the First Bicuspids for the Preformed Archwire Subjects}

The T1 and T2 mean dental arch width measurements for the preformed archwire group at the first bicuspids (4-4D) were compared to one another, along with T1 and T2 mean dentoalveolar arch width (4-4W), using an ANOVA analysis. This test was used to determine if there was a statistically significant change that took place in the position of the first bicuspids (4-4D), and whether a corresponding significant change took place to the WALA Ridge (4-4W). The results showed a significant change took place in dental arch width $(1.76 \mathrm{~mm})$, as well as dentoalveolar arch width $(1.80 \mathrm{~mm})$, in subjects treated with preformed archwires. The P-values were equal to 2.7 e-7 and 2.1 e-5 respectively.

\section{Comparison of Dental and Dentoalveolar Arch Width Changes From T1 to T2 at the First Bicuspids for the Customized Archwire Subjects}

The T1 and T2 mean dental arch width measurements for the customized archwire group at the first bicuspids (4-4D) were compared to one another, along with T1 and T2 mean dentoalveolar arch width measurements (4-4W), using an ANOVA analysis. This test was used to determine if there was a statistically significant change that took place in the position of the first bicuspids (4-4D), and whether a corresponding significant change took place to the WALA Ridge (4-4W). The results showed that a significant change took place in dental arch width $(0.90 \mathrm{~mm})$ in first bicuspid position from $\mathrm{T} 1$ to $\mathrm{T} 2$, 
however, a non-significant change took place in the dentoalveolar arch width $(0.49 \mathrm{~mm})$ in patients treated with WALA Ridge customized archwires. The p-values were equal to 0.0035 and 0.20 respectively.

\begin{tabular}{|l|c|c|c|c|}
\hline \multicolumn{5}{|c|}{ Change in Arch Width (T2-T1) } \\
\hline \multicolumn{1}{|c|}{ Groups } & Mean (mm) & SD (mm) & p Value & Sig \\
\hline Control (4-4D) & $0.21 \mathrm{~mm}$ & 0.5 & 0.60 & NS \\
\hline Preformed Archwire (4-4D) & $1.76 \mathrm{~mm}$ & 1.53 & $2.7 \mathrm{e}-7$ & S \\
\hline Customized Archwire (4-4D) & $0.90 \mathrm{~mm}$ & 1.34 & 0.0035 & S \\
\hline
\end{tabular}

Table 10. Summary of Changes in Dental Arch Width at the First Bicuspids From T1 to T2

\begin{tabular}{|l|c|c|c|c|}
\hline \multicolumn{5}{|c|}{ Change in Dentoalveolar Width (T2-T1) } \\
\hline Groups & Mean (mm) & SD (mm) & p Value & Sig \\
\hline Control (4-4W) & $-0.05 m m$ & 0.46 & 0.92 & NS \\
\hline Preformed Archwire (4-4W) & $1.80 \mathrm{~mm}$ & 1.38 & $2.1 \mathrm{e}-5$ & S \\
\hline Customized Archwire (4-4W) & $0.49 \mathrm{~mm}$ & 2.27 & 0.20 & NS \\
\hline
\end{tabular}

Table 11. Summary of Change in Dentoalveolar Arch Width at the First Bicuspids from T1 to T2 


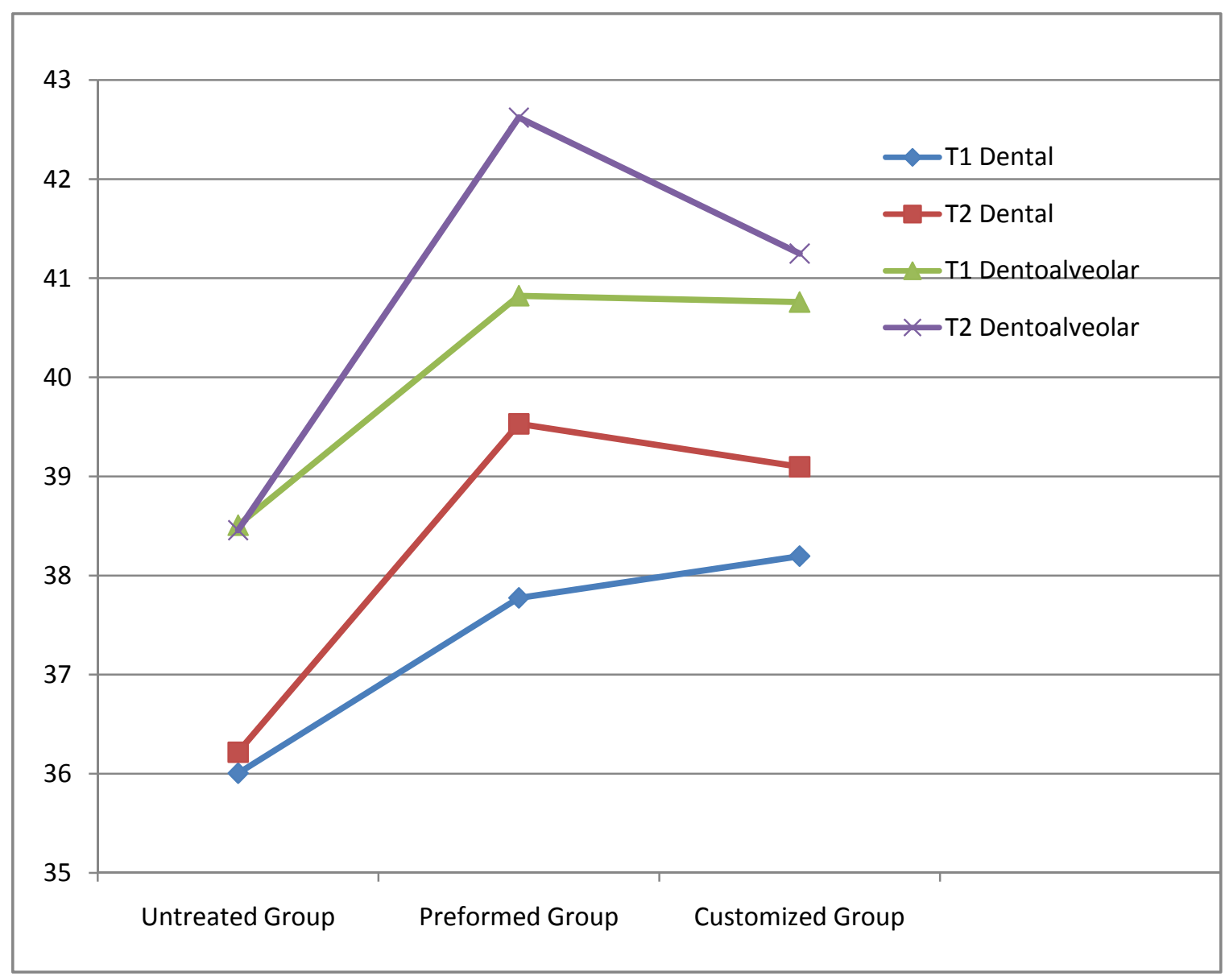

Figure 25. Means Values Plot (4-4D) and (4-4W)

\section{Comparison of Dental and Dentoalveolar Arch Width Changes From T1 to T2 at the Cuspids for the Control Subjects}

The T1 and T2 mean dental arch width measurements for the control at the cuspids (3-3D) were compared to one another, along with T1 and T2 mean dentoalveolar arch width measurements (3-3W), using an ANOVA analysis. This test was used to determine if there was a statistically significant change that took place in the position of the cuspids (3-3D), and whether a corresponding significant change took place to the WALA Ridge (3-3W). The results showed that no significant change in dental arch 
width $(0.27 \mathrm{~mm})$ or dentoalveolar arch width $(-0.09 \mathrm{~mm})$ took place in the control group, with P-values equal to 0.57 and 0.78 .

\section{Comparison of Dental and Dentoalveolar Arch Width Changes From T1 to T2 at the Cuspids for the Preformed Archwire Subjects}

The mean T1 and T2 dental arch width measurements for the preformed archwire group at the cuspids (3-3D) were compared to one another, along with T1 and T2 mean dentoalveolar arch width measurements (3-3W) using an ANOVA analysis. This test was used to determine if there was a statistically significant change that took place in the position of the cuspids (3-3D), and whether a corresponding significant change took place to the WALA Ridge (3-3W). The results showed a significant change took place in dental arch width $(1.14 \mathrm{~mm})$, as well as dentoalveolar arch width $(0.85 \mathrm{~mm})$, in subjects treated with preformed archwires. The P-values were equal to 0.0016 and 0.0007 respectively.

\section{Comparison of Dental and Dentoalveolar Arch Width Changes From T1 to T2 at the Cuspids for the Customized Archwire Subjects}

The mean T1 and T2 dental arch width measurements for the customized archwire group at the cuspids (3-3D) were compared to one another, along with T1 and T2 mean dentoalveoalar arch width measurements (3-3W) using an ANOVA analysis. This test was used to determine if there was a statistically significant change that took place in the position of the cuspids (3-3D), and whether a corresponding significant change took place to the WALA Ridge (3-3W). The results showed that a non-significant change took place in dental arch width at the cuspids $(0.47 \mathrm{~mm})$ from $\mathrm{T} 1$ to $\mathrm{T} 2$, and a non-significant 
change took place in dentoalveolar arch width $(-0.26 \mathrm{~mm})$ in subjects treated with WALA Ridge customized archwires. The P-values were equal to 0.17 and 0.26 respectively.

\begin{tabular}{|l|c|c|c|c|}
\hline \multicolumn{5}{|c|}{ Change in Arch Width (T2-T1) } \\
\hline Groups & Mean (mm) & SD(mm) & p Value & Sig \\
\hline Control (3-3D) & $0.27 \mathrm{~mm}$ & 0.29 & 0.57 & NS \\
\hline Preformed Archwire (3-3D) & $1.14 \mathrm{~mm}$ & 1.77 & 0.0016 & S \\
\hline Customized Archwire (3-3D) & $0.47 \mathrm{~mm}$ & 1.61 & 0.17 & NS \\
\hline
\end{tabular}

Table 12. S Summary of Change in Dental Arch Width at the Cuspids From T1 to T2

\begin{tabular}{|l|c|c|c|c|}
\hline \multicolumn{7}{|c|}{ Change in Dentoalveolar Width (T2-T1) } \\
\hline Groups & Mean (mm) & SD(mm) & P Value & Sig \\
\hline Control (3-3W) & $-0.09 \mathrm{~mm}$ & 0.61 & 0.78 & NS \\
\hline Preformed Archwire (3-3W) & $0.85 \mathrm{~mm}$ & 1.48 & 0.0007 & S \\
\hline Customized Archwire (3-3W) & $-0.26 \mathrm{~mm}$ & 0.56 & 0.26 & NS \\
\hline
\end{tabular}

Table 13. Summary of Change in Dentoalveolar Arch Width at the Cuspids from T1 to T2 


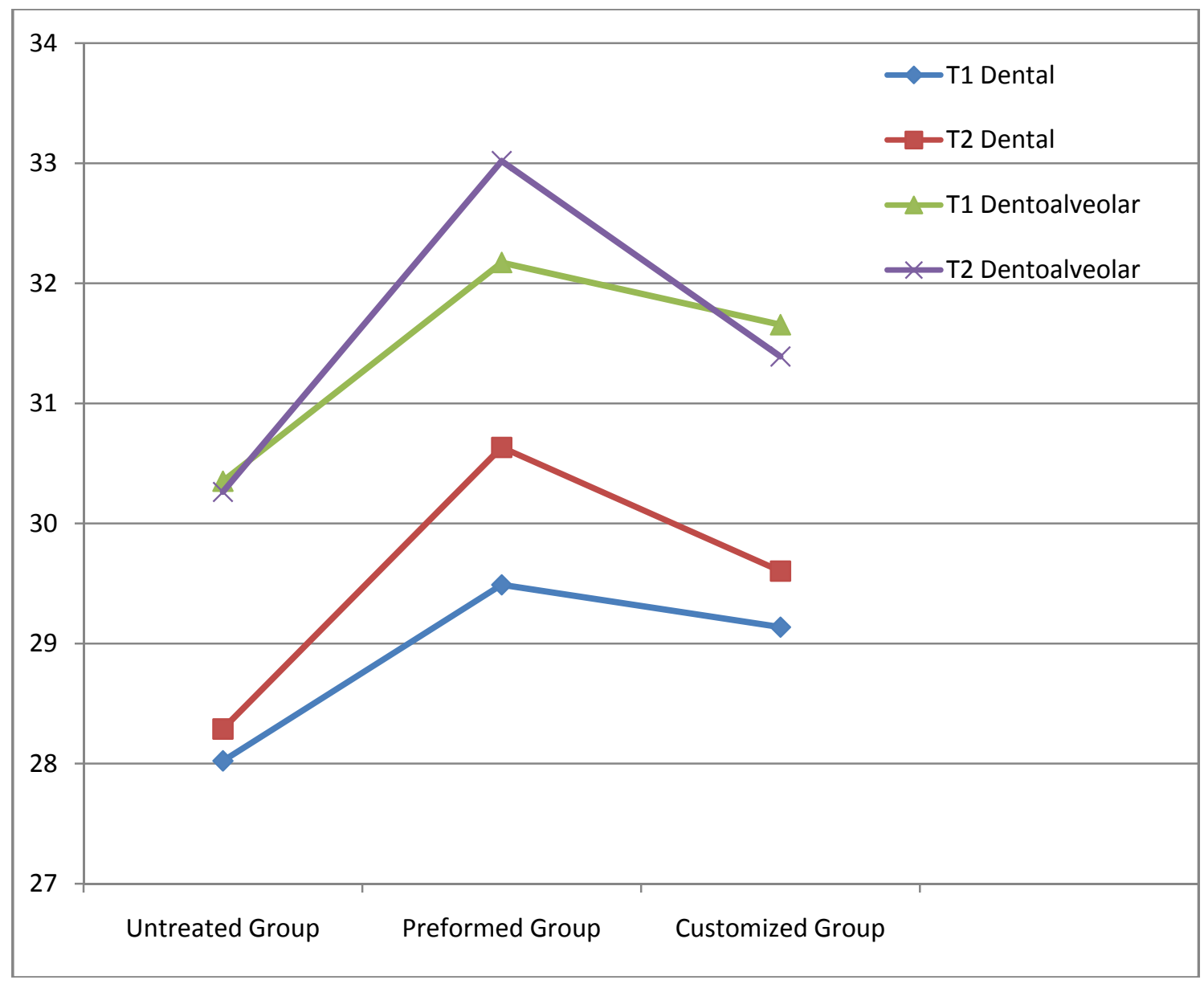

Figure 26. Least Square Means Plot (3-3D) and (3-3W)

\section{Comparison of Dental and Dentoalveolar Arch Width Changes of the Preformed and Customized Archwire Groups Against the Control at the Second Molars}

Comparison of the changes in dental arch width at the second molars in the treated groups against the control group shows a statistically significant difference of $1.89 \mathrm{~mm}$ for the preformed group, and statistically non-significant difference of $1.24 \mathrm{~mm}$ for the customized group. Corresponding dentoalveolar arch width changes at the second molars measured at the WALA Ridge in the preformed archwire group showed a 
statistically significant difference of $0.90 \mathrm{~mm}$. The customized archwire group showed a statistically non-significant difference of $0.45 \mathrm{~mm}$.

\section{Comparison of Dental and Dentoalveolar Arch Width Changes of the Preformed and Customized Archwire Groups Against the Control at the First Molars}

Comparison of changes in dental arch width at the first molars in the treated groups against the control group shows a statistically significant difference of $1.44 \mathrm{~mm}$ for the preformed archwire group, and a statistically non-significant difference of 0.91 $\mathrm{mm}$ for the customized archwire group. Corresponding dentoalveolar arch width changes at the first molars when measured at the WALA Ridge in the preformed archwire group had a significant difference of $1.14 \mathrm{~mm}$. The customized archwire group had a statistically non-significant difference of $0.01 \mathrm{~mm}$.

\section{Comparison of Dental and Dentoalveolar Arch Width Changes of the Preformed and Customized Archwire Groups Against the Control at the Second Bicuspids}

Comparison of the mean changes in dental arch width at the second bicuspids in the experimental groups against the control shows that the preformed group showed a mean difference of $1.37 \mathrm{~mm}$, which is statistically significant. The customized archwire group showed a non-significant difference of $0.75 \mathrm{~mm}$. Evaluation of dentoalveolar arch width changes measured at the WALA Ridge showed a statistically significant change $1.93 \mathrm{~mm}$ in the preformed group, however, the $0.14 \mathrm{~mm}$ difference with the customized archwire group was non-significant. 


\section{Comparison of Dental and Dentoalveolar Arch Width Changes of the Preformed and Customized Archwire Groups Against the Control at the First Bicuspids}

Comparison of the mean changes in dental arch width at the first bicuspids in the experimental groups against the control shows that the preformed group showed a mean difference of $1.55 \mathrm{~mm}$, which is statistically significant. The customized archwire group showed a non-significant difference of $0.69 \mathrm{~mm}$. Evaluation of dentoalveolar arch width changes measured at the WALA Ridge showed a significant change $1.85 \mathrm{~mm}$ in the preformed group, however, the $0.54 \mathrm{~mm}$ difference with the customized archwire group was non-significant.

\section{Comparison of Dental and Dentoalveolar Arch Width Changes of the Preformed and Customized Archwire Groups Against the Control at the Cuspids}

Comparison of the mean changes in dental arch width at the cuspids in the experimental groups against the control, shows that the preformed group showed a mean difference of $0.87 \mathrm{~mm}$, which is statistically non-significant. The customized archwire group showed a non-significant difference of $0.20 \mathrm{~mm}$. Evaluation of dentoalveolar arch width changes measured at the WALA Ridge showed a non-significant difference $0.94 \mathrm{~mm}$ in the preformed group, and a non-significant difference of $-0.17 \mathrm{~mm}$ with the customized archwire group. 

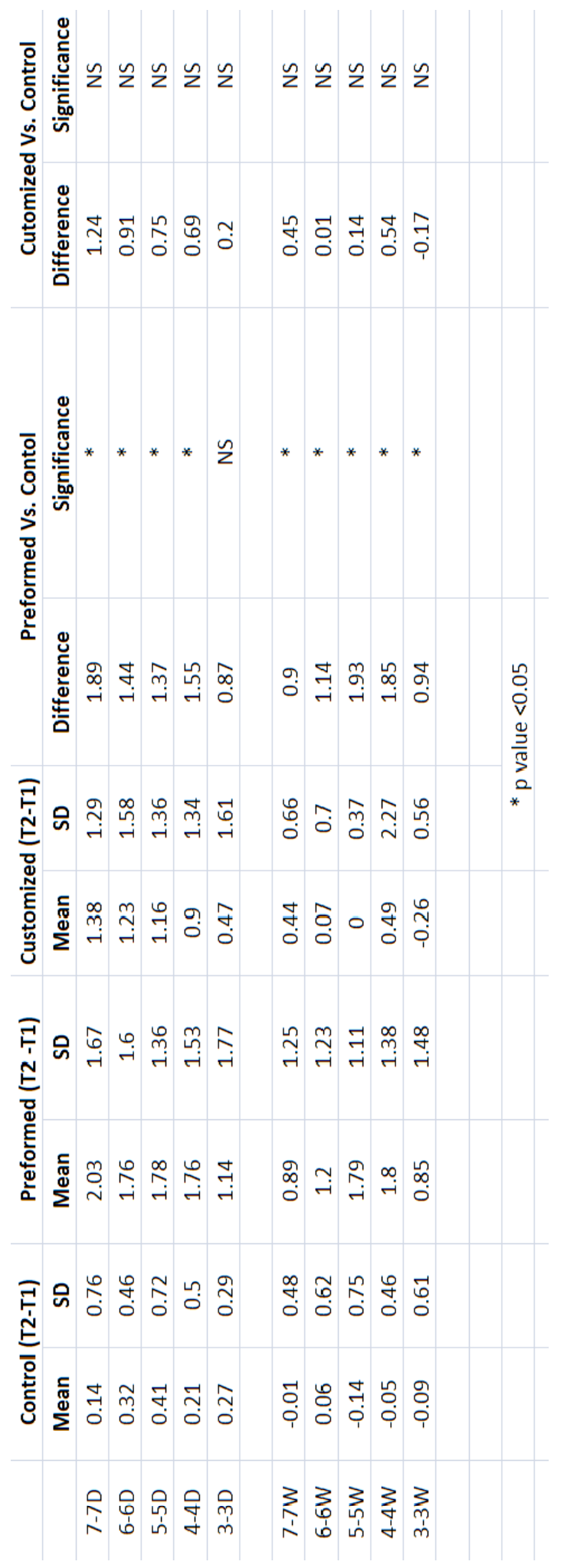

Table 14. Summary Of Dental and Dentoalveolar Changes and Comparisons 


\section{Comparison of Net Treatment Changes to Dental and Dentoalveolar Arch Width Between the Preformed and Customized Archwire Groups at the Second Molars}

Comparison of the net treatment changes (Treatment - Control) between the experimental groups showed that a difference of $0.65 \mathrm{~mm}$ in dental arch width occurred in the preformed group at the second molars. This difference between the two groups is statistically non-significant (p-value 0.18 ). The net treatment change in the dentoalveolar arch width at the second molars was $0.45 \mathrm{~mm}$ in the preformed group, which is statistically non-significant (p-value 0.16).

\section{Comparison of Net Treatment Changes to Dental and Dentoalveolar Arch Width Between the Preformed and Customized Archwire Groups at the First Molars}

Comparison of the net treatment changes ( Treatment - Control) between the experimental groups at the first molars showed that a difference of $0.53 \mathrm{~mm}$ in dental arch width occurred in the preformed group. This difference between the two groups is statistically insignificant (p-value 0.30). The net treatment change in the dentoalveolar arch width by measurement of the WALA Ridge at the first molars was $1.13 \mathrm{~mm}$ in the preformed group, which is statistically significant (p-value 0.001).

\section{Comparison of Net Treatment Changes to Dental and Dentoalveolar Arch Width Between the Preformed and Customized Archwire Groups at the Second Bicuspids}

Comparison of the net treatment changes (Treatment - Control) between the experimental groups showed that a difference of $0.62 \mathrm{~mm}$ in dental arch width occurred in the preformed group at the second bicuspids. This difference between the two groups is 
statistically insignificant (p-value 0.16). The net treatment change in the dentoalveolar arch width when measured at the second bicuspids was $1.79 \mathrm{~mm}$ in the preformed group, which is statistically significant( $p$-value $<0.0001$ ).

\section{Comparison of Net Treatment Changes to Dental and Dentoalveolar Arch Width Between the Preformed and Customized Archwire Groups at the First Bicuspids}

Comparison of the net treatment changes (Treatment - Control) between the experimental groups at the first bicuspids showed that a difference of $0.86 \mathrm{~mm}$ in dental arch width occurred in the preformed group. This difference between the two groups is statistically insignificant (p-value 0.07). The net treatment change in the dentoalveolar arch width by measurement of the WALA Ridge at the first bicuspids was $1.31 \mathrm{~mm}$ in the preformed group, which is statistically significant (p-value 0.03 ).

\section{Comparison of Net Treatment Changes to Dental and Dentoalveolar Arch Width Between the Preformed and Customized Archwire Groups at the Cuspids}

\section{Comparison of the net treatment changes between the experimental groups} showed that a difference of $0.67 \mathrm{~mm}$ in dental arch width occurred in the preformed group at the cuspids. This difference between the two groups is statistically insignificant (p-value 0.21). The net treatment change in the dentoalveolar arch width when measured at the cuspids was $1.11 \mathrm{~mm}$ in the preformed group, which is statistically significant (p-value 0.003). 


\begin{tabular}{|c|c|c|c|}
\hline & \multicolumn{3}{|c|}{ Net Tx Change Preformed Vs. Customized } \\
\hline & Difference & P Value & Significance \\
\hline 7-7D & 0.65 & 0.18 & NS \\
\hline $6-6 \mathrm{D}$ & 0.53 & 0.3 & NS \\
\hline $5-5 D$ & 0.62 & 0.16 & NS \\
\hline 4-4D & 0.86 & 0.07 & NS \\
\hline $3-3 D$ & 0.67 & 0.21 & NS \\
\hline $7-7 \mathrm{~W}$ & 0.45 & 0.04 & * \\
\hline $6-6 W$ & 1.13 & 0 & $* * *$ \\
\hline $5-5 W$ & 1.79 & 0 & $* * *$ \\
\hline $4-4 W$ & 1.31 & 0.03 & $*$ \\
\hline \multirow[t]{4}{*}{$3-3 W$} & 1.11 & 0 & $* *$ \\
\hline & \multicolumn{3}{|c|}{${ }^{*} p$ value $<0.05$} \\
\hline & \multicolumn{3}{|c|}{$* *$ pvalue $<0.01$} \\
\hline & \multicolumn{3}{|c|}{$* * *$ p value $<0.001$} \\
\hline
\end{tabular}

Table 15. Summary of Net Treatment Changes

\section{Correlation Between the Net Treatment Change in Dental and Dentoalveolar Arch Width in the Preformed Archwire Group}

Evaluation of net treatment dental arch width changes and net treatment

dentoalveolar arch width changes in the preformed group was done to determine if there was a correlation between the amount of change that took place between the two at the corresponding dental and dentoalveolar landmarks. The correlation coefficient between net dental treatment change at the second molar (7-7D) and the corresponding net treatment change in the dentoalveolar width at the second molars (7-7W) was 0.55 and a 
p-value of 0.01 . The correlation coefficient between net dental treatment changes at the first molar (6-6D) and the corresponding net treatment changes in dentoalveolar width at the first molars (6-6W) was 0.65 and a p-value of 0.002 . The correlation coefficient between the net dental treatment change at the second bicuspid (5-5D) and the corresponding net treatment change in the dentoalveolar width at the second bicuspids (5-5W) was 0.61 and a p-value of 0.004 . The correlation coefficient between the net dental treatment change at the first bicuspid (4-4D) and the corresponding net treatment change in the dentoalveolar width at the first bicuspids (4-4W) was 0.75 and a p-value 0.0001. Finally, the correlation coefficient between the net dental treatment change at the cuspids (3-3D) and the corresponding net treatment change in the dentoalveolar width at the cuspids (3-3W) was 0.73 and a p-value of 0.0003 .

\section{Correlation Between Net Treatment Change in Dental and Dentoalveolar Arch Width in the Customized Archwire Group}

Evaluation of net treatment dental arch width changes and net treatment dentoalveolar arch width changes in the preformed group was done to determine if there was a correlation between the amount of change that took place between the two at the corresponding dental and dentoalveolar landmarks. The correlation coefficient between net dental treatment change at the second molar (7-7D) and the corresponding net treatment change in the dentoalveolar width at the second molars (7-7W) was 0.62 and a $\mathrm{p}$-value of 0.003 . The correlation coefficient between net dental treatment changes at the first molar (6-6D) and the corresponding net treatment changes in dentoalveolar width at the first molars (6-6W) was 0.69 and a p-value of 0.0008 . The correlation coefficient between the net dental treatment change at the second bicuspid (5-5D) and the 
corresponding net treatment change in the dentoalveolar width at the second bicuspids (5-5W) was 0.51 and a p-value of 0.02 . The correlation coefficient between the net dental treatment change at the first bicuspid (4-4D) and the corresponding net treatment change in the dentoalveolar width at the first bicuspids (4-4W) was 0.13 and a p-value of 0.59. Finally, the correlation coefficient between the net dental treatment change at the cuspids (3-3D) and the corresponding net treatment change in the dentoalveolar width at the cuspids (3-3W) was -0.24 and a p-value of 0.31 .

\begin{tabular}{|l|c|c|c|c|c|c|}
\hline \multicolumn{5}{|c|}{ Correlation of Net Tx Change In Dental and Dentoalveolar Arch Width } \\
\hline
\end{tabular}

Table 16. Correlation Of Net Treatment Change in Dental Arch Width and Dentoalveolar Arch Width in the Preformed and Customized Archwire Groups 


\section{Chapter V: Discussion}

\section{Introduction}

The purpose of this study was to gain insight into the trends of archwire shape selection in private practice orthodontics within the United States. This was also assessed by the use of an electronically submitted survey. Data collected from the 1333 responses is reported in the results section. Furthermore, this study determined the stability of the WALA Ridge when subjected to orthodontic treatment. This study further compared orthodontic treatment employing the use of preformed archwires and the use of customized archwires shaped to the individual patient’s WALA ridge. A total of fifty subjects were analyzed in this study and divided into categories of an untreated control group, a group treated using preformed archwires, and a group treated using archwires shaped to the WALA ridge. Pre and post treatment mandibular casts were used as a means of determining transverse dental and transverse dentoalveolar changes that took place during treatment. The statistics for the variables measured were reported in the results section, but looking at the means of these variables and the changes that took place within the groups, the results were different.

\section{Materials and Methods}

The selection criteria for the treated subjects was limited. The main criteria included a permanent dentition with fully erupted second molars, class I pretreatment occlusion, non-extraction treatment plan, and no previous orthodontic treatment. The untreated subjects consisted of 10 subjects with a minimum of two years between the T1 and T2 time points. This group was collected from the Wade study group, which was 
gathered and stored at The Ohio State University. The preformed subject group consisted of 20 subjects that had preformed archwires throughout the course of treatment. This group was collected from the private practice of Dr. Terry Dischinger, Lake Oswego, Oregon. The customized archwire subject consisted of 20 subjects that had stainless steel archwires shaped to the WALA Ridge. This group was collected from the private practice of Dr. Timothy Tremont, White Oak, Pennsylvania.

Analysis of the casts was done by first marking the FA points of the teeth from second molar to cuspid bilaterally. If significant dental rotation existed, FA points would be repositioned to a corrected position in order to more closely relate the points of measurement on the WALA Ridge in an A-P dimension to that of post treatment casts. Transverse measurements from corresponding contralateral teeth were then taken. The WALA Ridge was then marked, and a line was drawn down the long axis of each tooth second molar to cuspid bilaterally. The intersection of the WALA Ridge with the line drawn along the long axis of the tooth was then transversely measured to the corresponding contralateral side. These steps were repeated for all subjects in the study.

\section{Practice Trends Related to Archform within the United States}

Based on the responses to the distributed survey, $66 \%$ of orthodontists employ the use of preformed archwires in the United States. Meaning that no modification to the archwire is done by the orthodontist, and the shape is determined during the manufacturing process and not changed prior to placement in the patient's mouth. A multitude of preformed archforms are available on the market, and a few were discussed briefly in the literature review section or this paper. Data was obtained from the survey as to the types of preformed archwires employed in practice, however, responses to this 
question on the survey were highly variable, or not reported by the responder due to an inability to identify the archform used in their practice. Therefore, reporting of this data is not included within this paper.

Based on the information received from the survey, 34\% of orthodontists customize their archforms, however, it is obvious from the responses that there is no consensus within the profession as to what should serve as the landmark for shaping the archform. The breakdown of landmarks and the percentages associated with them are reported on in the results section and graphically illustrated in Figure 21.

The reason for the diversity in the profession is unknown, and not within the scope of this survey. Speculation leads to the possible explanation that inadequate knowledge is available for a consensus in determining an individual's ideal archform. There isn’t a scientifically established guideline within the literature for accurately determining what a patient's ideal archform is, and what most accurately reflects basal bone anatomy. The recent publication by Ronay et al ${ }^{127}$ attempted to address this . Another possible expalanation for the use of preformed archwires over customized archwires in daily practice is the simplicity allowed by the use of preformed archwires. It is much easier, and definitely quicker, to simply pull an archwire from a box and place it in the patient's mouth. In a profession where efficiency and volume equate with profitability there is a strong motivating factor for the use of preformed archwires. 


\section{Comparison of Transverse Dental Changes (7-7D) and Transverse Dentoalveolar Changes (7-7W) at the Second Molar}

Comparison of transverse dental changes in the untreated group with the treated groups at the second molars yielded differing results. Referring to Table 14, the untreated group had a statistically significant transverse dental mean change $0.14 \mathrm{~mm}$. The preformed group has a statistically significant transverse dental mean change of 2.03 $\mathrm{mm}$. The customized archwire group had a statistically significant transverse mean change of $1.38 \mathrm{~mm}$. This information concludes that there is a significant difference in the untreated and both treatment groups, and that statistically significant dental expansion took place at the second molars in both treatment groups, with a greater mean expansion taking place in the preformed archwire group when the groups are compared against themselves. This is likely due to the greater transverse width in the preformed archwires that was likely present in most cases in the area of the second molars than was likely present in the customized WALA Ridge archwires, and as is demonstrated in Figure 14. Comparison of the transverse dental changes of the two experimental groups against the control at the second molars resulted in a statistically significant $1.89 \mathrm{~mm}$ difference with the preformed group, and a statistically insignificant difference of $1.24 \mathrm{~mm}$ in the customized archwire group. This shows that less transverse archform change took place in the customized archwire group compared to the control. Looking at Table 14, and evaluating corresponding dentoalveolar changes being represented by the WALA Ridge and comparing the groups against themselves, shows that the untreated group had a statistically insignificant change of $-0.01 \mathrm{~mm}$. The preformed archwire group had a statistically significant mean change of $0.89 \mathrm{~mm}$. The customized archwire group had a statistically nonsignificant mean change of $0.44 \mathrm{~mm}$. This information concludes that 
there is a significant difference with both treatment groups with respect to changes to the WALA Ridge when compared to the untreated group. Again a greater change was observed at the WALA Ridge in the preformed archwire group when compared to the customized archwire group. When the two experimental groups were compared against the control, this showed a significant difference of $0.9 \mathrm{~mm}$ in the preformed group, and a statistically non-significant change of $0.45 \mathrm{~mm}$ in the WALA Ridge customized archwire group. This shows that dental change resulting with the use of customized WALA Ridge archwires results in less change to the dentoalveolar anatomy when measured at the WALA Ridge. Although some of these changes are statistically significant, the question of clinical significance related to issues of stability, periodontium, and other factors is unknown, and needs to be determined. The difference in the value of these changes is likely due to the greater width present at the second molars in the preformed archwires and a poorer resemblance to pretreatment archform, resulting in a greater dentoalveolar change as a result of significant change in dental arch width.

\section{Comparison of Transverse Dental Changes (6-6D) and Transverse Dentoalveolar Changes (6-6W) at the First Molar}

Comparison of transverse dental changes in the untreated group with the treated groups at the first molars also yielded differing results. Referring to Table 6, the untreated group had a statistically insignificant transverse mean change $0.32 \mathrm{~mm}$ (P-value 0.48). The preformed archwire group had a statistically significant transverse mean change of $1.76 \mathrm{~mm}$ (P-value $1.9 \mathrm{e}-6)$. The customized archwire group had a statistically significant transverse mean change of $1.23 \mathrm{~mm}$ (P-value 0.0004 ). This

information concludes that there is a statistically significant difference between the 
untreated and both treatment groups, and that statistically significant dental expansion took place at the first molars in both treatment groups. Greater dental expansion took place in the preformed group than the customized group. Again, this is likely due to the broader form of the preformed archwires used in the preformed archwire experimental group. Referring to Table 7, and evaluating corresponding changes to the transverse dentoalveolar measurements, the untreated group shows a statistically insignificant mean change of $0.06 \mathrm{~mm}$ (P-value 0.83 ). The preformed group had a statistically significant mean change of $1.20 \mathrm{~mm}$ (P-value $7.5 \mathrm{e}-7)$. The customized archwire group had a statistically insignificant mean change of $0.08 \mathrm{~mm}$ (P-value 0.73 ). This information concludes that there is a statistically significant difference between the two treatment groups, and between the preformed treatment group and the untreated group with respect to changes taking place in basal bone anatomy when measured at the WALA Ridge. The possible cause in the change to the WALA Ridge is that greater expansion took place in the preformed group at the first molars, expanding the teeth beyond what the customized WALA Ridge archwires did, resulting in bony changes. However, comparing the transverse dental changes (Table 14) of the two experimental groups against the control at the first molars resulted in a statistically significant difference of $1.44 \mathrm{~mm}$ between the control and the preformed archwire group, but the difference of $0.91 \mathrm{~mm}$ with the customized archwire group was nonsignificant. Looking at Table 14, and evaluating corresponding dentoalveolar changes being represented by the WALA Ridge and comparing the groups against the control, shows that the preformed group had a statistically significant difference of $1.14 \mathrm{~mm}$, and the customized group had an insignificant difference of $0.01 \mathrm{~mm}$. The net treatment changes between the two 
experimental groups showed a statistically insignificant difference in changes to dental arch width $0.53 \mathrm{~mm}$, and a significant dentoalveolar arch width difference of $1.13 \mathrm{~mm}$. This shows that dental change with the use of customized WALA Ridge archwires results in less change to the dentoalveolar anatomy when measured at the WALA Ridge. Again, despite the statistical significance, the clinical significance is unknown. Although some of these changes are statistically significant, the question of clinical significance related to issues of stability, periodontium, and other factors is unknown, and needs to be determined.

\section{Comparison of Transverse Dental Changes (5-5D) and Transverse Dentoalveolar Changes (5-5W) at the Second Bicuspid}

Comparison of transverse dental arch width changes in the untreated group with the treated groups at the second bicuspids yielded similar results to the first molars. Referring to Table 8, the untreated group had a statistically insignificant transverse mean change $0.42 \mathrm{~mm}$. The preformed group has a statistically significant transverse mean change of $1.78 \mathrm{~mm}$. The customized archwire group had a statistically significant transverse mean change of $1.16 \mathrm{~mm}$. This information concludes that there is a significant difference in the untreated and both treatment groups, and that statistically significant increases in dental arch width took place at the second bicuspids in both treatment groups. Greater dental expansion took place in the preformed group than the customized archwire group. Referring to Table 9, evaluation of corresponding changes to the dentoalveolar arch width being measured at the WALA Ridge, showed that in the untreated group a non-significant mean change of $-0.14 \mathrm{~mm}$ occurred. The preformed group had a statistically significant mean change of $1.78 \mathrm{~mm}$. The customized group had 
a statistically insignificant mean change of $0.00 \mathrm{~mm}$. This information concludes that there is a significant difference between the two treatment groups, and between the preformed treatment group and the untreated group with respect to changes taking place at the WALA Ridge. Again, the possible cause in the change to the WALA Ridge is that greater dental expansion took place in the preformed group than the customized archwire group at the second bicuspids altering the archform enough to result in changes to the dentoalveolar anatomy when measured at the WALA Ridge. Comparing the mean transverse dental changes (Table 14) of the two experimental groups against the control at the second bicuspids resulted in a statistically significant difference $1.37 \mathrm{~mm}$ between the control and the preformed archwire group, but the difference of $0.75 \mathrm{~mm}$ with the customized archwire group was statistically insignificant. Looking at Table 14 and evaluating corresponding dentoalveolar changes being represented by measurement taken at the WALA Ridge and comparing the groups against the control, shows that the preformed group had a statistically significant difference of $1.93 \mathrm{~mm}$, and the customized group had a insignificant difference of $0.14 \mathrm{~mm}$. The net treatment changes between the two experimental groups showed a statistically insignificant difference in changes to dental arch width of $0.62 \mathrm{~mm}$ (p-value 0.3 ) and a dentoalveolar difference of $1.79 \mathrm{~mm}$ (p value 0.00 ). This shows that dental change with the use of customized WALA Ridge archwires results in less change to the dentoalveolar anatomy when measured at the WALA Ridge. Again, despite the statistical significance, the clinical significance is unknown, and should be further investigated. 


\section{Comparison of Transverse Dental Changes (4-4D) and Transverse Dentoalveolar Changes (4-4W) at the First Bicuspid}

Comparison of transverse dental arch width changes in the untreated group with the treated groups at the first bicuspids had different results. Referring to Table 10, the untreated group had a statistically insignificant transverse dental arch width mean change of $0.02 \mathrm{~mm}$. The preformed archwire group had a statistically significant dental arch width transverse mean change of $1.76 \mathrm{~mm}$. The customized archwire group had a statistically significant dental arch width mean change of $0.90 \mathrm{~mm}$. This information concludes that there is a significant difference in the untreated and both treatment groups, and that statistically significant dental expansion took place at the first bicuspids in both treatment groups. Again, greater dental expansion took place in the preformed group than the customized group, due to likely similar reasons stated above. Evaluating corresponding dentoalveolar changes, and referring to Table 11, changes in the untreated group showed a statistically insignificant mean change of $-0.05 \mathrm{~mm}$. The preformed archwire group had significant mean change of $1.80 \mathrm{~mm}$. The customized archwire group had a statistically insignificant mean change of $0.49 \mathrm{~mm}$. This information concludes that there is a significant difference between the two treatment groups, and between the preformed archwire treatment group and the untreated group with respect to changes taking place to the dentoalveoalr anatomy when measured at the WALA Ridge. Comparing the transverse dental changes (Table 14) of the two experimental groups against the control at the first bicuspids resulted in a statistically significant difference of $1.55 \mathrm{~mm}$ between the control and the preformed archwire group, but the difference of 0.69mm with the customized archwire group was statistically insignificant. Looking at Table 14, and evaluating corresponding dentoalveolar changes being represented by the 
WALA Ridge and comparing the groups against the control, shows that the preformed group had a statistically significant difference of $1.85 \mathrm{~mm}$, and the customized group had a statistically insignificant difference of $0.54 \mathrm{~mm}$. The net treatment changes between the two experimental groups showed a statistically insignificant change in transverse dental arch width difference of $0.86 \mathrm{~mm}$, and a statistically significant difference in dentoalveolar archwidth changes measured at WALA Ridge of $1.31 \mathrm{~mm}$. This shows that dental change with the use of customized WALA Ridge archwires results in less change to the dentoalveolar anatomy when measured at the WALA Ridge. The possible cause in the change to the WALA Ridge is that greater expansion took place in the preformed archwire group at the first bicuspids, possibly expanding the teeth beyond the pretreatment dentoalveolar archform than what the customized archwires did, resulting in a skeletal change when measured at the WALA Ridge. Although some of these changes are statistically significant, the question of clinical significance related to issues of stability periodontium, and other factors is unknown, and needs to be determined.

\section{Comparison of Transverse Dental Changes (3-3D) and Transverse Dentoalveolar Changes (3-3W) at the Cuspid}

Comparison of transverse dental changes in the untreated group with the treated groups at the cuspids also yielded differing results. Referring to Table 12, the untreated group had a statistically insignificant dental arch width mean change $0.27 \mathrm{~mm}$. The

preformed archwire group had a statistically significant dental arch width mean change of $1.14 \mathrm{~mm}$. The customized archwire group had a statistically insignificant dental arch width mean change of $0.46 \mathrm{~mm}$. This information concludes that there is a significant difference in the preformed and both the untreated and customized archwire groups, and 
that statistically significant dental expansion took place at the cuspids in the preformed group. Greater dental expansion took place again in the preformed archwire group than the customized archwire group at the cuspids. Referring to Table 13, evaluating corresponding transverse dentoalveolar changes measured at the WALA Ridge in the untreated group shows a statistically insignificant mean change of $-0.09 \mathrm{~mm}$. The preformed group had significant mean change of $0.85 \mathrm{~mm}$. The customized archwire group had a statistically insignificant mean change of $-0.26 \mathrm{~mm}$. This information concludes that there is a significant difference between the two treatment groups, and between the preformed and untreated group with respect to changes taking place at the WALA Ridge. Comparing the dental arch width changes (Table 14) of the two experimental groups against the control at the cuspids resulted in a statistically insignificant difference $0.87 \mathrm{~mm}$ between the control and the preformed archwire group, and insignificant difference of $0.2 \mathrm{~mm}$ with the customized archwire group. Looking at Table 14 and evaluating corresponding dentoalveolar changes being represented by measurements taken at the WALA Ridge and comparing the groups against the control, shows that the preformed group had a statistically significant difference of $0.94 \mathrm{~mm}$, and the customized group had an insignificant difference of $-0.17 \mathrm{~mm}$. The net treatment changes between the two experimental groups showed a statistically insignificant dental arch width difference of $0.67 \mathrm{~mm}$, and a statistically significant difference in change to dentoalveolar anatomy of $1.11 \mathrm{~mm}$. This shows that dental change with the use of customized WALA Ridge archwires results in less change to the dentoalveolar anatomy when measured at the WALA Ridge. As at the other locations, the likely difference in the change to the WALA Ridge is that greater expansion due to the shape of the archform 
took place in the preformed archwire group than in the customized archform group. This potentially expanded the teeth beyond what a customized WALA Ridge archwires would, resulting in a change in dentoalveolar anatomy. It is interesting to note that mean transverse measurements at the cuspids actually decreased by $-0.26 \mathrm{~mm}$ at the canines in the customized archwire group, which would favor well with research findings suggesting that expansion at the canines is unstable. ${ }^{16,17,24,27,33,39,128}$

\section{The Correlation Between Dental and Dentoalveolar Arch Width Changes in the Preformed and Customized Archwire Groups}

In the present study, significant correlations were found between the amount of dental and skeletal arch width changes for the preformed archwire group. For the customized archwire group, significant correlation in dental and skeletal arch width changes were only found for the second bicuspid to the second molars. These findings suggest that smaller increases in dental arch width can occur without changes in dentoalveolar anatomy when measured at the WALA Ridge. The question is to what point does change start to take place. Larry Andrews ${ }^{71}$ hypothesized that the WALA Ridge was the limit, and through the use of customized archwires shaped to WALA Ridge, orthodontists would simply cause an uprighting of teeth to their proper inclination centered within basal bone. Concerns about the physiologic compatibility of over expanding is highly debated, especially with the re-emergence of the bone growing theory ${ }^{125}$, and the employment of "light", "biologically" compatible forces.

Furthermore, it appears that by evaluating the correlation coefficients in the preformed archwire group, where statistically significant changes in dental and dentoalveolar arch width took place at the variable locations, a greater correlation 
between the change in dental arch width and skeletal arch width existed in the more anterior locations, specifically at the first bisuspids and cuspids. This implies that there is less amount of transverse change that can take place before dentoalveolar change takes place. This would relate well with Andrews' findings ${ }^{71}$ as well as Ronay et $\mathrm{al}^{129}$, in the closer relationship of the FA point to the WALA Ridge as you move anteriorly in the arch. This is also supported by the findings in this study within the customized archwire group as evidenced by the nonsignificant changes that resulted in these locations. 


\section{Chapter VI: Summary and Conclusions}

\section{Summary}

The purpose of this study was to determine whether or not the WALA Ridge was a stable landmark when subjected to orthodontic treatment. To do so, a total of fifty subjects were analyzed in this study and divided into categories of an untreated group, a group treated using preformed archwires, and a group treated using customized archwires shaped to the WALA Ridge. The T1 and T2 timepoint mandibular casts of each subject in each group was marked on the FA points of the teeth from second molar to cuspid bilaterally. Transverse dental measurements were then taken between corresponding contralateral teeth. The WALA Ridge was marked on the casts along with the long axis of each of the marked teeth which was extended to intersect with the WALA Rridge. Once all the teeth second molar to cuspid are marked, the transverse measurements at the points of intersection between the long axis and WALA Ridge on the corresponding contralateral side was then taken. The T1 and T2 measurements were then statistically analyzed to determine whether or not a statistically significant change took place in transverse dental width, and whether a corresponding statistically significant change occurred at the WALA Ridge. In addition, a survey was distributed to active members listed in the 2009-2010 American Association of Orthodontists Directory in order to determine current practice trends related to archform and the use of preformed or customized archwires.

From the information gathered in this study, the following hypotheses were able to be accepted of rejected: 
1. There is no significant difference between the change in dental and dentoalveolar arch width in untreated subjects, or when treated with preformed or WALA Ridge customized arch wires.

2. There is no significant difference in dental and dentoalveolar arch width changes between the experimental groups and the control .

3. There is no significant difference in the net treatment changes of the two experimental groups.

4. There is no significant correlation in dental and dentoalveolar arch width changes.

From the results and discussion above, it can be concluded that all the null hypotheses are rejected due to significance found between the groups.

\section{Conclusions}

Results from this study lead to the following conclusions:

1. The WALA Ridge is a stable landmark when subjected to orthodontic treatment when the archwires used in treatment are customized for each patient to the WALA Ridge.

2. Significant dental change in the transverse dimension can take place during treatment without significant changes to the WALA Ridge. However, there appears to be a limit at which a threshold is reached and dentoalveolar changes measured at the WALA Ridge result.

3. The WALA Ridge is a defendable landmark for the shaping of customized archwires in order to create changes in dental arch width with insignificant change in dentoalveolar anatomy at the WALA Ridge. 
4. Dental arch width expansion beyond that of what a customized WALA Ridge archwire would produce, results in a change of shape to the dentoalveolar anatomy.

5. The majority of orthodontists use preformed archwires in their daily clinical practice.

6. There is no consensus amongst orthodontists that customize archwires as to what should serve as the landmark for shaping their archwires. 


\section{Chapter VII: Recommendations for Future Research}

Upon completion of this study, the following were recommended:

1. Repeat the study employing the use of CBCT to evaluate actual bony changes taking place at the level of the WALA Ridge and the position of the teeth within the basal bone.

2. Repeat the study correlating the degree of uprighting of the teeth and any changes to the WALA Ridge.

3. Compare long term periodontal effects of orthodontic treatment in patients treated with preformed archwires and customized WALA ridge archwires.

4. Evaluate with CBCT whether or not bone grows along with teeth being expanded beyond the basal bone when employing the use of light continuous forces.

5. Perform a longitudinal study evaluating the change to the WALA ridge with growth and determine a point at which it the WALA ridge becomes stable.

6. Compare post treatment stability between patients treated with preformed archwires and those treated with customized WALA Ridge archwires. 


\section{Reference List}

1. McLaughlin, R., Bennett, J. \& Trevisi, H. Systemized Orthodontic Treatment Mechanics. Elsevier, St. Louis (2005).

2. Bonwil, W. Geometrical and mechanical laws of articulation. Trans Ocont Soc Pa 119, 33 (2009).

3. Brader, A. Dental arch form related to intraoral forces: PR = C. Am. J Orthod. 61, 541-552 (1972).

4. Engel, G. Preformed arch wires: reliability of fit. Am. J Orthod. 76, 497-504 (1979).

5. Hawley, C. Determination of the normal arch and its application to orthodontia. Dent Cosmos 47, 541-542 (1905).

6. McKelvain, G. An arch form designed for use with a specific straight wire orthodontic appliance. 1982. Dallas, Baylor.

Ref Type: Thesis/Dissertation

7. Ricketts, R. Research in factors of appliance design and arch form. Foundation for Orthodontic Research, Pacific Palisades (2009).

8. Roth, R. Straight wire mechanics syllabus. Foundation for Advanced Continuing Education, Burlingame (1978).

9. BeGole, E. A. A computer program for the analysis of dental arch form using the cubic spline function. Comput. Programs Biomed. 10, 136-142 (1979).

10. Currier, J. H. Human dental arch form. Am. J Orthod. 56, 164-179 (1969).

11. Diggs, D. The quantification of arch form. 1982. Seattle, University of Washington.

Ref Type: Thesis/Dissertation

12. Lu, K. Analysis of dental arch symmetry. J Dent Res 43, 780. 1964. Ref Type: Abstract

13. Sampson, P. Dental arch shape: a statistical analysis using conic sections. Am. $J$ Orthod. 79, 535-548 (1981).

14. Sanin, C., Savara, B., Thomas, D. \& Clarkson, O. Arc length of the dental arch estimated by multiple regression. J Dent Res 49, 885 (1970). 
15. Wheller, R. A textbook of dental anatomy and physiology. WB Saunder Co, Philadelphia (1950).

16. Amott, R. D. A serial study of dental arch measurements on orthodontic subjects. 1962. Northwestern Universtiy. Ref Type: Thesis/Dissertation

17. Arnold, M. L. A study of the changes of the mandibular intercanine and intermolar widths during orthodontic treatment and following a postretention period of five or more years. 1963. University of Washington.

Ref Type: Thesis/Dissertation

18. Barrow, G. V. \& White, J. R. Developmental changes of the maxillary and mandibular dental arches. Angle Orthod. 22, 41-46 (1952).

19. Brodie, A. G. Cephalometric appraisal of orthodontic results. Angle Orthod. 8, 261-351 (1938).

20. Burke, S. P. et al. A meta-analysis of mandibular intercanine width in treatment and postretention. Angle Orthod. 68, 53-60 (1998).

21. Cole, H. J. Certain results of extraction inthe treatment of malocclusion. Angle Orthod. 18, 102-113 (1948).

22. de la, C. A., Sampson, P., Little, R. M., Artun, J. \& Shapiro, P. A. Long-term changes in arch form after orthodontic treatment and retention. Am. J Orthod. Dentofacial Orthop. 107, 518-530 (1995).

23. DeKock, W. H. Dental arch depth and width studied longitudinally from twelve years of age to adulthood. Am. J Orthod. 62, 56-66 (2009).

24. Dona, A. A. An analysis of dental casts of patients mad before and after orthodontic treatment. 1952. University of Washington.

Ref Type: Thesis/Dissertation

25. Felton, M. J., Sinclair P.M., Jones, D. L. \& Alexander, R. G. A computerized analysis of the shape and stability of mandibular arch form. Am. J Orthod. 92, 478-483 (1987).

26. Howes, A. Expansion as a treatment procedure-Where does it stand today? Am. $J$ Orthod. 46, 515-534 (1960).

27. Kelly, R. R. Growth and orthodontic relapse. 1959. University of Washington. Ref Type: Thesis/Dissertation

28. Ladner, P. T. \& Muhl, Z. F. Changes concurrent with orthodontic treatment when macillary expansion is a primary goal. Am. J Orthod. 66, 58-70 (1995). 
29. Litowitz, R. A study of movements of certain teeth during and following orthodontic treatment. Angle Orthod. 18, 113-131 (1948).

30. McCauley, D. R. The cuspid and its function in retention. Am. J Orthod. 30, 196205 (1944).

31. McReynolds, D. C. \& Little, R. M. Mandibular second premolar extraction-postretention evaluation of stability and relapse. Angle Orthod. 61, 133-144 (1991).

32. Moorrees, C. F. A. The dentition of the growing child. Harvard University Press, Cambridge, Mass (1959).

33. Peak, J. D. Cuspid Stability. Am. J Orthod. 42, 608-614 (1956).

34. Rogers, A. P. Making facial muscles our allies in treatment and retention. Dent. Cosmos 64, 711-730 (1922).

35. Shapiro, P. A. Mandibular arch form and dimension. Am. J Orthod. 66, 58-70 (1974).

36. Strang, R. H. The fallacy of denture expansion as a treatment procedure. Angle Orthod. 19, 12-17 (1949).

37. Strang, R. H. Factor associated with successful orthodontic treatment. Am. J. Orthod. Oral Surg. 790-800 (1952).

38. Weinstein, S. Minimal forces in tooth movement. Am. J Orthod. 881-903 (1967).

39. Welch, K. N. A study of treatment and postretention dimensional changes in mandibular dental arches. 1956. University of Washington.

Ref Type: Thesis/Dissertation

40. Frush, J. O. \& Fisher, R. D. The dynesthetic intepretation of the dentogenic concept. J Prosthetic Dent 8, 558-581 (1958).

41. Hulsey, D. M. An esthetic evaluation of lip-teeth relationships present in the smile. Am. J Orthod. Dentofacial Orthop. 57, 134-144 (1970).

42. Martin, A. J., Buschang, P. H., Boley, J. C., Taylor, R. W. \& McKinney, T. W. The impact of buccal corridors on smile attractiveness. Eur. J Orthod 29, 530-537 (2007).

43. Moore, T., Southard, K. A., Casko, J. S., Qian, F. \& Southard, T. E. Buccal corridors and smile esthetics. Am. J Orthod. Dentofacial Orthop. 127, 208-213 (2005). 
44. Roden-Johnson, D., Gallerano, R. \& English, J. The effects of buccal corridor spaces and arch form on smile esthetics. Am. J Orthod. Dentofacial Orthop. 127, 343-350 (2005).

45. Sarver, D. M. The importance of incisor positioning in the estetic smile: the smile arc. Am. J Orthod. Dentofacial Orthop. 120, 98-111 (2001).

46. Sarver, D. M. \& Ackerman, M. B. Dynamic smile visualization and quantification: Part 2: Smile analysis and tratment strategies. Am. J Orthod. Dentofacial Orthop. 124, 116-127 (2003).

47. Andrews, L. F. Straight Wire: The Concept and the Appliance. L.A. Wells Co., San Diego (2009).

48. Kirschen, R. H., O'Higgins, E. A. \& Lee, R. T. The Royal London Space Planning: an integration of space analysis and treatment planning: Part I: Assessing the space required to meet treatment objectives. Am. J Orthod. Dentofacial Orthop. 118, 448-455 (2000).

49. Braun, S., Hnat, W. P. \& Baxter, J. E. The curve of Spee revisited. Am. J Orthod. Dentofacial Orthop. 110, 206-210 (1996).

50. Germane, N., Lindauer, S. J., Rubenstein, L. K., Revere, J. H., Jr. \& Isaacson, R. J. Increase in arch perimeter due to orthodontic expansion. Am. J Orthod Dentofacial Orthop. 100, 421-427 (1991).

51. Germane, N., Staggers, J. A., Rubenstein, L. \& Revere, J. T. Arch length considerations due to the curve of Spee: a mathematical model. Am. J Orthod. Dentofacial Orthop. 102, 251-255 (1992).

52. Andlin-Sobocki, A. \& Bodin, L. Dimensional alterations of the gingiva related to changes of facial/lingual tooth position in permanent anterior teeth of children. A 2-year longitudinal study. J Clin. Periodontol. 20, 219-224 (1993).

53. Batenhorst, K., Bowers, G. \& Williams, J. Tissue changes resulting from facial tipping and extrusion of incisors in monkeys. J Clin. Periodontol. 45, 660 (1974).

54. Coatoam, G., Behrents, R. \& Bissada, N. The width of keratinized gingiva during orthodontic treatment: its significance and impact on periodontal status. J Clin. Periodontol. 52, 307 (1981).

55. Karring $\mathrm{T}$ Bone regeneration in orthodontically produced alveolar bone dehiscences. J Periodontal Res 17, 309 (1982).

56. Nyman, S., Karring T \& Bergenholtz, G. Bone regeneration in alveolar bone dehiscences produced by jiggling forces. J Periodontal Res 17, 316 (1982). 
57. Steiner, G., Pearson, J. \& Ainamo, J. Changes of the marginal periodontium as a result of labial tooth movement in monkeys. J Clin. Periodontol. 52, 314 (1981).

58. Thilander, B. Bone regeneration in alveolar bone dehiscences related to orthodontic tooth movements. Eur. J. Orthod. 5, 105 (1983).

59. Wennstrom, J. L., Lindhe, J., Sinclair, F. \& Thilander, B. Some periodontal tissue reactions to orthodontic tooth movement in monkeys. J Clin. Periodontol. 14, 121-129 (1987).

60. Ronay, V., Miner, R. M., Will, L. A. \& Arai, K. Mandibular arch form: the relationship between dental and basal anatomy. Am. J. Orthod. Dentofacial Orthop. 134, 430-438 (2008).

61. Andrews, L. F. \& Andrews, W. A. The six elements of orofacial harmony. Andrews $J$ 1, 13-22 (2000).

62. Brash, J. The aetiology of irregularity and malocclusion of the teeth. Dental Board of the United KIngdom, London (1956).

63. Weinstein, S., Haack DC, Morris LY, Snyder BB \& Attaway, H. On an equilibrium theory of tooth position. Angle Orthod. 33, 1-25 (1963).

64. Angle, E. Bone-growing. Dent Cosmos 52, 261-267 (1910).

65. Lundstrom, A. Malocclusion of the teeth regarded as a problem in connectionwith the apical base. Int J Orthod Oral Surg Radiogr 9, 591-602 (1925).

66. Betts, N. J., Vanarsdall, R. L., Barber, H. D., Higgins-Barber, K. \& Fonseca, R. J. Diagnosis and treatment of transverse maxillary deficiency. Int. J Adult. Orthodon. Orthognath. Surg 10, 75-96 (1995).

67. Tweed, C. Clinical orthodontics. Mosby, St. Louis (1966).

68. Begg PR Begg orthodontic theory and technique. Saunders, Philadelphia (1965).

69. Damon, D. Orthodontics: current principles and techniques. Graber, T., Vanarsdall, R. \& Vig, K. (eds.), pp. 753-832 (Elsevier-Mosby, St. Louis,2005).

70. Little, R. M., Wallen, T. R. \& Riedel, R. A. Stability and relapse of mandibular anterior alignment-first premolar extraction cases treated by traditional edgewise orthodontics. Am. J Orthod. 80, 349-365 (1981).

71. Andrews, L. F. \& Andrews, W. The six elements of orofacial harmony. Andrews Journal 1, 13-22 (2000). 
72. Ronay, V., Miner, R. M., Will, L. A. \& Arai, K. Mandibular arch form: the relationship between dental and basal anatomy. Am. J. Orthod. Dentofacial Orthop. 134, 430-438 (2008).

73. Ackerman, J. L. \& Profitt, W. R. Current orthodontic concepts and techniques. (W.B. Saunders Co., Philadelphia,1975).

74. Andrews, L. F. The diagnostic system: occlusal analysis. Dent Clin. North Am. 20, 671-690 (1976).

75. Angle, E. Treatment of malocclusion of the teeth. The S.S. White Dental Mfg. Co., (1907).

76. Mayne, W. R. Graber, T. M. \& Swain, B. F. (eds.) (W.B. Saunders Co., Philadelphia,1975).

77. Andrews, L. F. The six keys to normal occlusion. Am. J Orthod. 62, 296-309 (1972).

78. Kirschen, R. H., O'Higgins, E. A. \& Lee, R. T. The Royal London Space Planning: an integration of space analysis and treatment planning: Part I: Assessing the space required to meet treatment objectives. Am. J Orthod. Dentofacial Orthop. 118, 448-455 (2000).

79. Adkins, M. D., Nanda, R. S. \& Currier, G. F. Arch perimeter changes on rapid palatal expansion. Am. J Orthod Dentofacial Orthop. 97, 194-199 (1990).

80. Akkaya, S., Lorenzon, S. \& Ucem, T. T. Comparison of dental arch and arch perimeter changes between bonded rapid and slow maxillary expansion procedures. Eur. J Orthod 20, 255-261 (1998).

81. Kirschen, R. H., O'Higgins, E. A. \& Lee, R. T. The Royal London Space Planning: an integration of space analysis and treatment planning: Part I: Assessing the space required to meet treatment objectives. Am. J Orthod. Dentofacial Orthop. 118, 448-455 (2000).

82. Profitt, W. R. \& Fields, H. W. Contemporary Orthodontics. Mosby, New York (2000).

83. Baldridge, D. W. Leveling the curve of Spee: its effect on mandibular arch lengths. J Pract Orthod 3, 26-41 (1969).

84. Garcia, R. Leveling the curve of Spee: anew prediction formula. $J$ Tweed Found 13, 65-72 (1985).

85. Germane, N., Staggers, J. A., Rubenstein, L. \& Revere, J. T. Arch length considerations due to the curve of Spee: a mathematical model. Am. J Orthod. Dentofacial Orthop. 102, 251-255 (1992). 
86. Kirschen, R. H., O'Higgins, E. A. \& Lee, R. T. The Royal London Space Planning: an integration of space analysis and treatment planning: Part I: Assessing the space required to meet treatment objectives. Am. J Orthod. Dentofacial Orthop. 118, 448-455 (2000).

87. Miller, A. G. Role of physical attractiveness in impression formation. Psychological Science 19, 241-243 (1970).

88. Goldstein, R. E. Study of need for esthetics in dentistry. J Prosthetic Dent 21, 589-598 (1969).

89. Kokich, V. G. Esthetics: the orthodontic-periodontic restorative connection. Seminars in Orthodontics 2, 21-30 (1996).

90. Peck, S. \& Peck, L. Selected aspects of the art and science of facial esthetics. Seminars in Orthodontics 1, 105-126 (1995).

91. Tjan, A. H. \& Miller, G. D. Some esthetic factors in a smile. J Prosthetic Dent 51, 24-28 (1984).

92. Alkhatib, M. N., Holt, R. \& Bedi, R. Prevalence of self-assessed tooth discolouration in the United Kingdom. Journal of Dentistry 32, 561-566 (2004).

93. Shulman, J. D., Maupome, G., Clark, D. C. \& Levy, S. M. Perceptions of desirable tooth color among parents, dentists and children. Journal of the American Dental Association 135, 595-604 (2004).

94. Levin, E. I. Dental esthetics and the golden proportion. J Prosthetic Dent 40, 244252 (1978).

95. Ricketts, R. M. The biologic significance of the divine proportionand Fibonacci series. Am. J Orthod. Dentofacial Orthop. 81, 351-370 (1982).

96. Dunn, W. J., Murchinson, D. F. \& Broome, J. C. Esthetics: patients' perception s of dental attractiveness. J Prosthetic Dent 51, 24-28 (1996).

97. Martin, A. J., Buschang, P. H., Boley, J. C., Taylor, R. W. \& McKinney, T. W. The impact of buccal corridors on smile attractiveness. Eur. J Orthod 29, 530-537 (2007).

98. Angle, E. Malocclusion of the teeth. White Dental Manufacturing Company, Phladelphia (1907).

99. de la Cruz, A., Sampson, P., Little, R. M., Artun, J. \& Shapiro, P. A. Long-term changes in arch form after orthodontic treatment and retention. Am. J Orthod. Dentofacial Orthop. 107, 518-530 (1995). 
100. Burke, S. P. et al. A meta-analysis of mandibular intercanine width in treatment and postretention. Angle Orthod. 68, 53-60 (1998).

101. Shapiro, P. A. Mandibular dental arch form and dimension. Treatment and postretention changes. Am. J. Orthod. 66, 58-70 (1974).

102. Shapiro, P. A. Mandibular dental arch form and dimension. Treatment and postretention changes. Am. J. Orthod. 66, 58-70 (1974).

103. Little, R. M., Wallen, T. R. \& Riedel, R. A. Stability and relapse of mandibular anterior alignment-first premolar extraction cases treated by traditional edgewise orthodontics. Am. J Orthod. 80, 349-365 (1981).

104. Graber, T. M., Vanarsdall, R. L. \& Vig, K. Orthodontics: Current Principles and Techniques. Elsevier Mosby, St. Louis (2005).

105. Andlin-Sobocki, A. \& Bodin, L. Dimensional alterations of the gingiva related to changes of facial/lingual tooth position in permanent anterior teeth of children. A 2-year longitudinal study. J Clin. Periodontol. 20, 219-224 (1993).

106. Engelking, G. \& Zachrisson, B. U. Effects of incisor repositioning on monkey periodontium after expansion through the cortical plate. Am. J Orthod 82, 23-32 (1982).

107. Wennstrom, J. L., Lindhe, J., Sinclair, F. \& Thilander, B. Some periodontal tissue reactions to orthodontic tooth movement in monkeys. J Clin. Periodontol. 14, 121-129 (1987).

108. Anzilotti, C., Vanarsdall, R. \& Balakrishnan, M. Expansion and evaluation of post-retention gingival recession. 2002. University of Pennsylvania. Ref Type: Thesis/Dissertation

109. Bonwill, W., Hawley \& C Individual Arch Form. Mosby, St. Louis (1966).

110. Pepe, S. H. Polynomial and catenary curve fiits to human dental arches. $J$ Rest Dent 54, 1124-1132 (1975).

111. Germane, N., Lindauer, S. J., Rubenstein, L. K., Revere, J. H., Jr. \& Isaacson, R. J. Increase in arch perimeter due to orthodontic expansion. Am. J Orthod Dentofacial Orthop. 100, 421-427 (1991).

112. Riolo, M. L. \& Avery, J. K. Essentials for Orthodontic Practice. EFOP Press, Grand Haven (2003).

113. Neilans, L. C. A computerized analysis of human dental arch form as compared to the catenary curve. 1968. Philadelphia, Temple University. Ref Type: Thesis/Dissertation 
114. White, L. W. Accurate arch discrepancy measurements. Am. J Orthod Dentofacial Orthop. 72, 303-308 (1977).

115. BeGole, E. A. A computer program for the analysis of dental arch form using the cubic spline function. Comput. Programs Biomed. 10, 136-142 (1979).

116. Diggs, D. B. The quantification of arch form. 1962. Seattle, University of Washington.

Ref Type: Thesis/Dissertation

117. Lu, K. H. Analysis of dental arch symmetry (abstract). J Dent Res 43, 780 (1964).

118. Sanin, C., Savara, B. S., Thomas, D. R. \& Clarkson, O. D. Arch length of the dental arch estimated by mutiple regression. J Dent Res 49, 885 (1970).

119. Braun, S., Hnat, W. P., Fender, D. E. \& Legan, H. L. The form of the human dental arch. Angle Orthod 68, 29-36 (1998).

120. Engel, G. A. Preformed arch wires: reliability of fit. Am. J Orthod Dentofacial Orthop. 76, 497-504 (1979).

121. Ricketts, R. M. Research in factors of appliance design and arch form. Foundation for Orthodontic Research, Pacific Palisades (1979).

122. Roth, R. H. Straight wire mechanics syllabus. Foundation for Advanced Continuing Education, Burlingame (1978).

123. Ronay, V., Miner, R. M., Will, L. A. \& Arai, K. Mandibular arch form: the relationship between dental and basal anatomy. Am. J. Orthod. Dentofacial Orthop. 134, 430-438 (2008).

124. McLaughlin, R., Bennett, J. \& Trevisi, H. Systemized Orthodontic Treatment Mechanics. Elsevier, St. Louis (2005).

125. Damon, D. Damon System. Sybron Dental Specialites Ormco, Orange (2004).

126. Mah, J. \& Sachdeva, R. Computer-assisted orthodontic treatment: the SureSmile process. Am J Orthod Dentofacial Orthop. 120, 85-87 (2001).

127. Ronay, V., Miner, R. M., Will, L. A. \& Arai, K. Mandibular arch form: the relationship between dental and basal anatomy. Am. J. Orthod. Dentofacial Orthop. 134, 430-438 (2008).

128. Shapiro, P. A. Mandibular dental arch form and dimension. Treatment and postretention changes. Am. J. Orthod. 66, 58-70 (1974). 
129. Ronay, V., Miner, R. M., Will, L. A. \& Arai, K. Mandibular arch form: the relationship between dental and basal anatomy. Am. J. Orthod. Dentofacial Orthop. 134, 430-438 (2008). 
APPENDIX A

IRB APPROVAL 


\begin{aligned} & IRB PROTOCOL - Details \\ \hline Pracking \# & $\mathrm{H}-22072 \\$ Title & The Stability of the WALA Ridge as a Landmark for Determining Dental Archform \\ Version & 2 \\ Status & Exempt \\ Status Date & $12 / 3 / 20099: 15: 42$ AM \\ Board & Board Gold \\ Meeting Date & \\ Approval Date & $12 / 03 / 2009 \\$ Expiration Date & \end{aligned}




\section{APPENDIX B}

\section{CONTROL DATA}




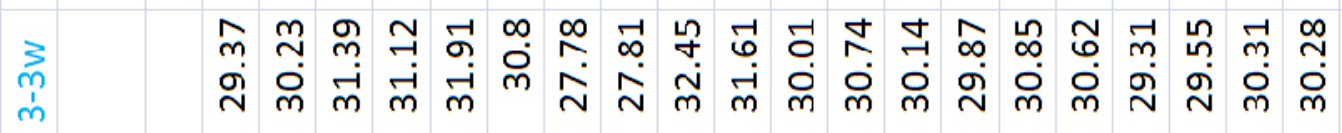

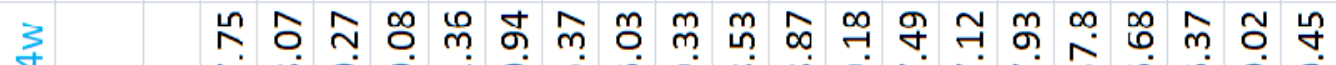

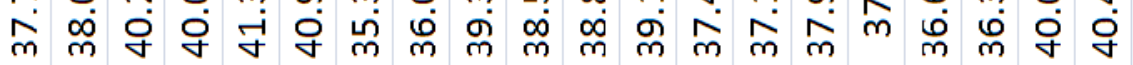

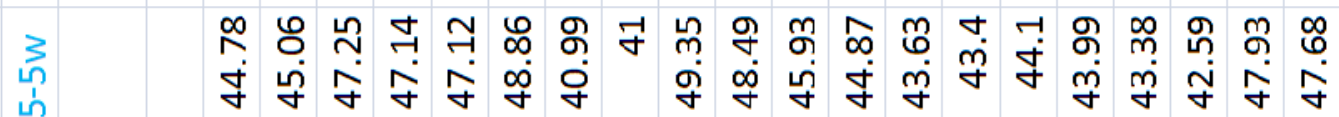

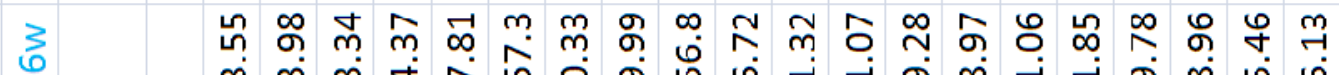
bै ñ

$3 \quad$ \ุ

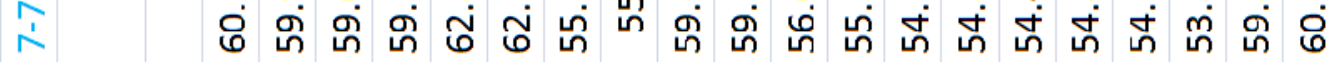

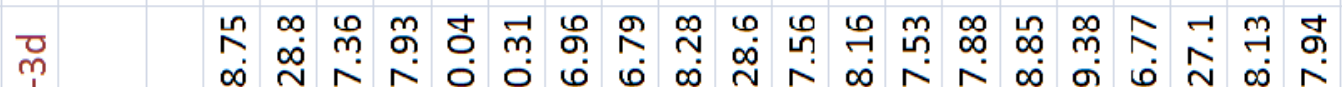

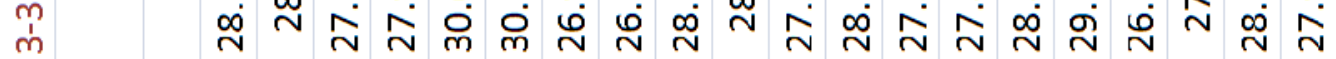

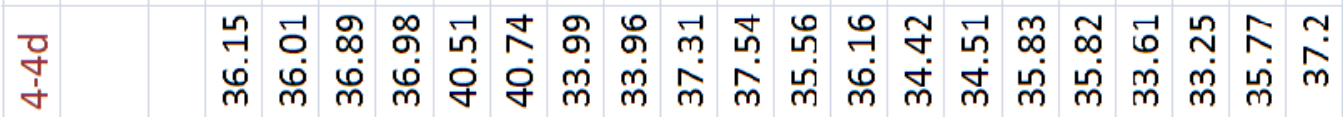

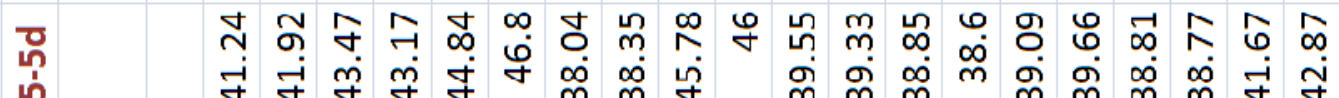

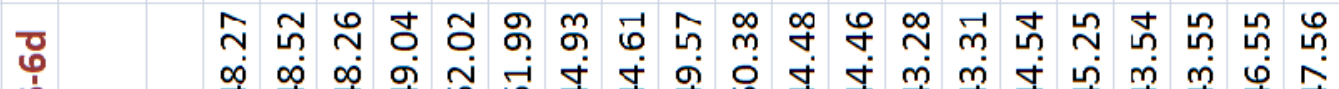
ம் $\quad$ o

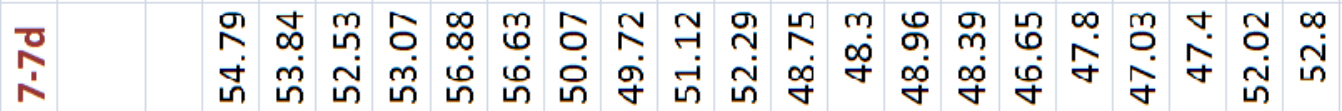

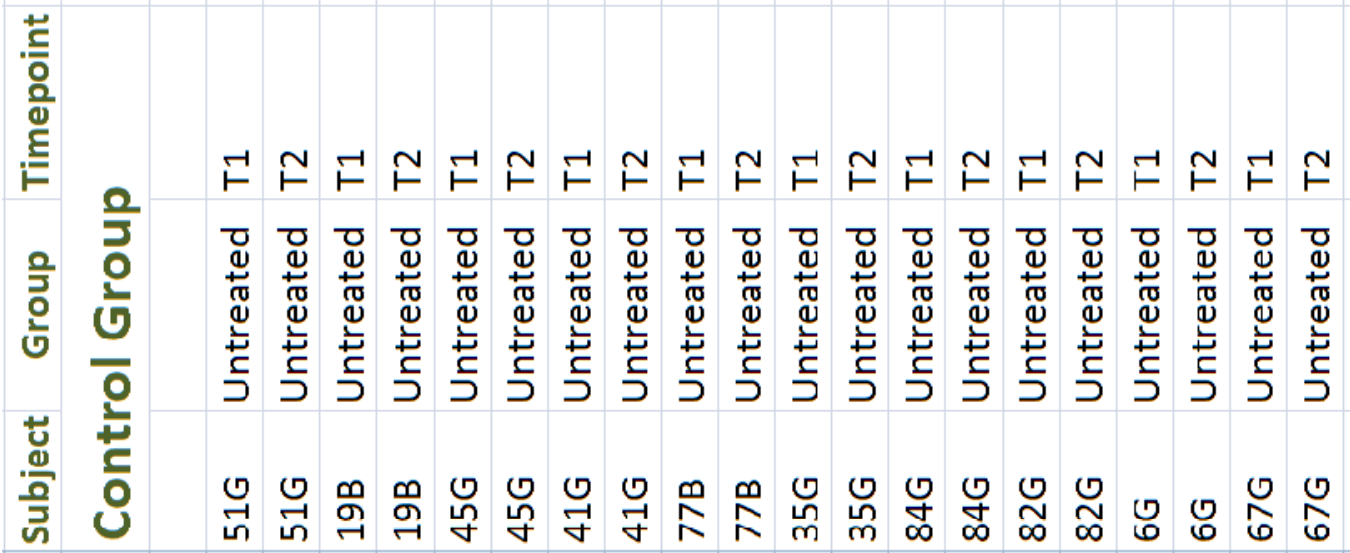




\section{APPENDIX C}

\section{PREFORMED ARCHWIRE DATA}




\begin{tabular}{|c|c|c|c|c|c|c|c|c|c|c|c|c|c|c|c|c|c|c|c|c|c|}
\hline $\begin{array}{l}3 \\
m \\
m \\
m\end{array}$ & & $\begin{array}{l}\text { ஸे } \\
\text { จे }\end{array}$ & $\begin{array}{l}\text { ने } \\
\text { ले }\end{array}$ & $\begin{array}{l}\stackrel{\mathscr{n}}{N} \\
\stackrel{-}{m}\end{array}$ & $\begin{array}{l}\stackrel{\bullet}{\stackrel{n}{m}} \\
\stackrel{m}{m}\end{array}$ & $\begin{array}{l}\underset{m}{N} \\
\underset{m}{n}\end{array}$ & $\begin{array}{l}\hat{o} \\
\dot{m} \\
m\end{array}$ & $\begin{array}{l}N \\
\infty \\
\dot{m}\end{array}$ & $\begin{array}{l}\text { ने } \\
\text { m}\end{array}$ & $\stackrel{\vec{N}}{\stackrel{\infty}{N}}$ & $\begin{array}{l}\mathscr{0} \\
0 \\
0\end{array}$ & $\begin{array}{l}\text { ஸे } \\
\text { ஸ் }\end{array}$ & $\begin{array}{l}\stackrel{m}{N} \\
\stackrel{\sim}{m}\end{array}$ & $\begin{array}{l}\text { ஸ் } \\
\text { ஜீ }\end{array}$ & $\begin{array}{l}\text { กิ } \\
\text { ก̇ }\end{array}$ & $\begin{array}{l}\text { ने } \\
\text { m் }\end{array}$ & $\underset{⿱ 亠 䒑}{\mathfrak{m}}$ & $\begin{array}{l}m \\
o \\
\dot{j}\end{array}$ & $\begin{array}{l}\tilde{D} \\
\dot{j} \\
\tilde{m}\end{array}$ & $\begin{array}{l}\dddot{\oplus} \\
\ddot{m} \\
m\end{array}$ & $\begin{array}{l}\stackrel{\omega}{m} \\
\stackrel{m}{m}\end{array}$ \\
\hline$\frac{d}{2}$ & & ? & $\begin{array}{l}\stackrel{m}{+} \\
\stackrel{+}{+}\end{array}$ & $\begin{array}{c}\stackrel{\infty}{m} \\
\underset{\sim}{+}\end{array}$ & $\begin{array}{l}\text { ஸ̃ } \\
\text { ஸ் }\end{array}$ & $\begin{array}{l}\text { ஜு } \\
\text { ஸ் }\end{array}$ & $\begin{array}{r}\stackrel{\mathscr{m}}{\sigma} \\
\stackrel{m}{+}\end{array}$ & 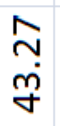 & $\begin{array}{l}\stackrel{N}{N} \\
\stackrel{m}{q}\end{array}$ & $\begin{array}{l}\text { ñ } \\
\text { ọ }\end{array}$ & $\begin{array}{l}\text { กี } \\
\text { ̇ }\end{array}$ & 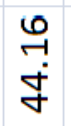 & 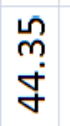 & $\begin{array}{l}\text { g् } \\
\text { 뭄 }\end{array}$ & テ & $\begin{array}{l}\text { ๙ิ } \\
\text { ๙่ }\end{array}$ & $\begin{array}{l}\vec{m} \\
\dot{g}\end{array}$ & 今ં & 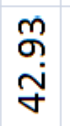 & 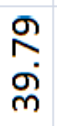 & $\begin{array}{l}\text { ने } \\
\text { 워 }\end{array}$ \\
\hline 莡 & & 몸 & $\underset{m}{m}$ & \begin{tabular}{l}
\multirow{\infty}{\infty}{} \\
$\infty$ \\
$\dot{\sigma}$
\end{tabular} & 寉 & $\begin{array}{l}\mathscr{\infty} \\
\infty \\
\infty \\
+\end{array}$ & $\begin{array}{l}\infty \\
0 \\
0\end{array}$ & $\begin{array}{l}\widehat{\emptyset} \\
\stackrel{\infty}{\sigma}\end{array}$ & $\begin{array}{l}\text { ○̄ } \\
\text { 유 }\end{array}$ & $\begin{array}{l}\text { g } \\
\text { ஸ் } \\
\text { g }\end{array}$ & $\begin{array}{l}\infty \\
\infty \\
\infty \\
\infty\end{array}$ & $\begin{array}{l}\text { லீ } \\
\text { ஒ் }\end{array}$ & $\begin{array}{l}\text { ஸ̃ } \\
\text { ஸ் }\end{array}$ & $\begin{array}{l}\hat{\sigma} \\
\dot{q}\end{array}$ & $\begin{array}{l}\stackrel{\sim}{7} \\
\text { g் }\end{array}$ & ஸ̃ & 뭄 & $\begin{array}{l}\text { ণิ } \\
\text { क் }\end{array}$ & $\begin{array}{l}\hat{0} \\
0 \\
\text { ம் }\end{array}$ & $\begin{array}{l}m \\
0 \\
\dot{\varphi}\end{array}$ & ஸे \\
\hline $\begin{array}{l}3 \\
6 \\
1 \\
6\end{array}$ & & $\begin{array}{l}\text { ने } \\
\text { กี่ }\end{array}$ & $\begin{array}{l}\infty \\
\text { ఠ } \\
\text { ஸ் }\end{array}$ & $\begin{array}{l}\stackrel{N}{N} \\
\text { กn }\end{array}$ & $\begin{array}{l}\text { શ } \\
\text { ต் }\end{array}$ & $\begin{array}{l}\text { ñ } \\
\text { ஸ் }\end{array}$ & 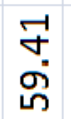 & $\begin{array}{l}\mathscr{0} \\
\stackrel{\infty}{ஸ}\end{array}$ & $\begin{array}{l}\stackrel{N}{N} \\
\infty \\
\stackrel{0}{n}\end{array}$ & m̊ & $\begin{array}{l}\text { ஸे } \\
\text { ம் }\end{array}$ & ஸ̂ & $\begin{array}{l}1 \\
0 \\
0\end{array}$ & 䒞 & ஸ் & $\begin{array}{l}\text { ஸ் } \\
\text { ஸ் }\end{array}$ & $\begin{array}{l}\text { ণ } \\
\text { ஸ் }\end{array}$ & Ư & $\begin{array}{l}\text { D } \\
\text { ஸे }\end{array}$ & $\begin{array}{c}\text { 芩 } \\
\text { ஸ் }\end{array}$ & $\begin{array}{l}\overrightarrow{6} \\
\text { ம் }\end{array}$ \\
\hline$\frac{3}{\frac{3}{n}}$ & & & $\begin{array}{l}\varphi \\
m \\
\infty \\
\infty \\
\end{array}$ & $\begin{array}{l}\text { ণூ } \\
\text { ஸ் }\end{array}$ & $\begin{array}{l}\text { 우 } \\
\dot{\emptyset}\end{array}$ & $\begin{array}{l}n \\
\stackrel{n}{0}\end{array}$ & $\begin{array}{l}\mathscr{0} \\
\infty \\
\end{array}$ & $\begin{array}{l}\text { ऽ } \\
\dot{0} \\
\dot{\sigma}\end{array}$ & 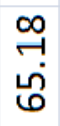 & $\begin{array}{l}\mathscr{0} \\
\ddot{\emptyset} \\
\ddot{0}\end{array}$ & 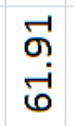 & $\begin{array}{l}\hat{N} \\
\tilde{\sigma}\end{array}$ & $\begin{array}{l}\dot{y} \\
\ddot{\varphi} \\
\ddot{\sigma}\end{array}$ & $\begin{array}{l}\overrightarrow{0} \\
\dot{0} \\
0\end{array}$ & $\begin{array}{l}\stackrel{m}{\sigma} \\
\ddot{v}\end{array}$ & $\begin{array}{l}\text { ঢ } \\
\text { ப் }\end{array}$ & 穴 & $\begin{array}{l}\tilde{0} \\
0 \\
0\end{array}$ & ஸึ & $\begin{array}{c}\stackrel{m}{r} \\
\underset{\sigma}{\sigma}\end{array}$ & $\begin{array}{l}0 \\
0 \\
\text { ஸే }\end{array}$ \\
\hline $\begin{array}{l}\text { m} \\
\dot{m}\end{array}$ & & ? & $\begin{array}{l}\text { 寸 } \\
\text { ণ্் }\end{array}$ & $\begin{array}{l}\text { ọ } \\
\text { வ் }\end{array}$ & $\begin{array}{l}\stackrel{-}{7} \\
\stackrel{-}{\mathrm{r}}\end{array}$ & $\begin{array}{l}\text { ○े } \\
\text { ஸे }\end{array}$ & $\stackrel{+}{m}$ & 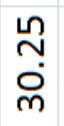 & $\begin{array}{l}\text { ㅇ } \\
\infty \\
\text { வ }\end{array}$ & $\begin{array}{l}\hat{m} \\
\stackrel{\infty}{N}\end{array}$ & 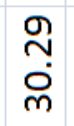 & $\begin{array}{l}m \\
\stackrel{m}{+} \\
\stackrel{m}{m}\end{array}$ & $\begin{array}{l}\stackrel{\sim}{N} \\
\underset{m}{m}\end{array}$ & $\begin{array}{l}\text { ホ } \\
\text { வ் }\end{array}$ & $\begin{array}{l}\dot{m} \\
\text { ஸ் }\end{array}$ & $\begin{array}{l}m \\
\text { ஸ̊ } \\
\text { on }\end{array}$ & $\begin{array}{l}\infty \\
\infty \\
0 \\
0\end{array}$ & व़் & $\begin{array}{l}\stackrel{\sim}{f} \\
\dot{\sim}\end{array}$ & $\begin{array}{l}\infty \\
0 \\
\text { స் }\end{array}$ & 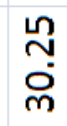 \\
\hline $\begin{array}{l}\text { Ơ } \\
\text { ’ } \\
\text { 寸่ }\end{array}$ & & i & 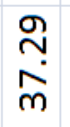 & $\begin{array}{l}\widetilde{D} \\
\infty \\
m \\
m\end{array}$ & $\begin{array}{l}\text { ஸீ } \\
\text { ஸे } \\
\text { m }\end{array}$ & $\begin{array}{l}\dot{0} \\
\dot{\varphi} \\
m\end{array}$ & $\begin{array}{l}\text { ণे } \\
\text { ळे }\end{array}$ & $\begin{array}{l}\stackrel{\varphi}{m} \\
\stackrel{m}{m}\end{array}$ & $\begin{array}{l}\text { g日 } \\
\infty \\
m \\
m\end{array}$ & $\begin{array}{l}\stackrel{\omega}{+} \\
\infty \\
\stackrel{\infty}{m}\end{array}$ & $\begin{array}{l}\text { ळ } \\
\text { ஸ் }\end{array}$ & $\begin{array}{l}\infty \\
+ \\
\stackrel{+}{+}\end{array}$ & $\begin{array}{l}\dot{J} \\
\dot{\sim} \\
\dot{v}\end{array}$ & $\stackrel{\substack{m \\
m}}{m}$ & $\begin{array}{l}\text { ஸे } \\
\infty \\
\text { ஸे }\end{array}$ & $\begin{array}{l}\text { ஸे } \\
\text { ஸे }\end{array}$ & $\begin{array}{l}0 \\
0 \\
0 \\
\text { o }\end{array}$ & बे & $\begin{array}{l}\dot{m} \\
\text { m. } \\
\text { m}\end{array}$ & 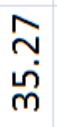 & $\begin{array}{l}\text { 广 } \\
\infty \\
m\end{array}$ \\
\hline 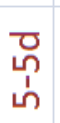 & & $\begin{array}{l}\text { ஸ் } \\
\text { ஸ் }\end{array}$ & 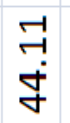 & $\begin{array}{l}\text { ○े } \\
\text { ஸ் }\end{array}$ & $\begin{array}{l}\text { ல } \\
\dot{\sigma}\end{array}$ & $\begin{array}{l}\text { ஸ̃ } \\
\text { 巳 }\end{array}$ & $\begin{array}{l}\stackrel{\sigma}{+} \\
\text { ஸ் }\end{array}$ & & $\begin{array}{l}\text { Ð } \\
\text { ஸ் }\end{array}$ & $\begin{array}{l}\mathscr{} \\
\text { ற் } \\
\dot{\square}\end{array}$ & ஸே & $\begin{array}{l}\text { ஸ̊ } \\
\text { ஸ் } \\
\text { ஸे }\end{array}$ & $\stackrel{\Upsilon}{\mathscr{\gamma}}$ & $\begin{array}{l}m \\
\stackrel{m}{ } \\
\stackrel{f}{y}\end{array}$ & $\begin{array}{l}\stackrel{0}{r} \\
\dot{g}\end{array}$ & $\stackrel{\infty}{\stackrel{\infty}{\sim}}$ & $\begin{array}{l}\vec{\infty} \\
\text { ஸ் } \\
\text { மे }\end{array}$ & 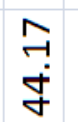 & $\begin{array}{l}\stackrel{\sim}{f} \\
\dot{\&}\end{array}$ & $\begin{array}{l}\stackrel{\bullet}{\sim} \\
\underset{\sim}{\sim}\end{array}$ & $\begin{array}{l}\text { ஸூ } \\
\text { ஸ் }\end{array}$ \\
\hline $\begin{array}{l}\text { రृ } \\
\dot{1} \\
6\end{array}$ & & 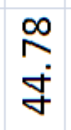 & $\begin{array}{l}\text { ஸீ } \\
\text { ஒ் }\end{array}$ & $\begin{array}{l}\stackrel{\sim}{+} \\
\stackrel{+}{+}\end{array}$ & $\begin{array}{l}\dot{\forall} \\
\stackrel{+}{ }\end{array}$ & $\begin{array}{l}\text { ○े } \\
\text { ஸ் }\end{array}$ & $\stackrel{\vec{T}}{\tilde{n}}$ & $\begin{array}{l}\stackrel{\mathscr{m}}{n} \\
\dot{H}\end{array}$ & $\begin{array}{l}\stackrel{\bullet}{\sim} \\
\text { 붕 }\end{array}$ & $\begin{array}{l}\varphi \\
\stackrel{\sim}{\sim} \\
\stackrel{\infty}{+}\end{array}$ & 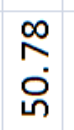 & $\begin{array}{l}\hat{\sigma} \\
\dot{H} \\
\text { ம் }\end{array}$ & $\begin{array}{l}\text { ஸि } \\
\text { ஸें }\end{array}$ & $\begin{array}{l}\vec{n} \\
\text { 우 }\end{array}$ & $\begin{array}{l}\text { नै } \\
\text { กี่ }\end{array}$ & $\begin{array}{l}\infty \\
\text { ñ } \\
\text { ஸ் }\end{array}$ & $\stackrel{N}{N}$ & $\begin{array}{l}\text { f } \\
\text { 윰 }\end{array}$ & ஸ் & $\begin{array}{l}\text { テे } \\
\infty \\
\text { ণ }\end{array}$ & 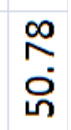 \\
\hline$\frac{0}{i}$ & $\pi$ & $\begin{array}{l}\text { Øீ } \\
\text { ல் }\end{array}$ & in & $\begin{array}{l}\text { Ō } \\
\text { ஸึ่ }\end{array}$ & $\begin{array}{l}0 \\
0 \\
0\end{array}$ & $\begin{array}{l}\stackrel{\mathscr{N}}{N} \\
\stackrel{\infty}{n}\end{array}$ & $\begin{array}{l}0 \\
\infty \\
\infty \\
\end{array}$ & ஸे & $\begin{array}{l}\text { ஸे } \\
\text { ర் }\end{array}$ & $\begin{array}{l}\mathscr{\varphi} \\
\text { ஸ் } \\
\text { กิ }\end{array}$ & 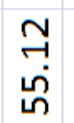 & ஸn & $\begin{array}{l}\infty \\
0 \\
0 \\
0\end{array}$ & $\begin{array}{l}\infty \\
0 \\
\dot{+} \\
\omega\end{array}$ & $\begin{array}{l}\text { ָे } \\
\infty \\
\text { ஸ் }\end{array}$ & $\begin{array}{l}\text { व } \\
\infty \\
\text { ஸ் }\end{array}$ & $\begin{array}{l}\text { ○े } \\
\text { ஸ் }\end{array}$ & 守 & $\begin{array}{l}\hat{\infty} \\
\text { in }\end{array}$ & $\begin{array}{l}\text { ஸி } \\
\text { ம் }\end{array}$ & 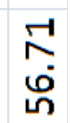 \\
\hline 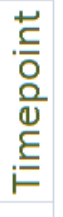 & 를 & $\rightleftarrows$ & $\stackrel{N}{F}$ & $\vec{F}$ & $\stackrel{\sim}{F}$ & $\vec{F}$ & $\stackrel{\sim}{\vdash}$ & $\stackrel{\vdash}{\vdash}$ & $\stackrel{\sim}{F}$ & $\stackrel{ }{\vdash}$ & $\stackrel{N}{\vdash}$ & $\stackrel{ }{\vdash}$ & $\stackrel{\sim}{\vdash}$ & $\stackrel{\rightleftarrows}{\vdash}$ & $\stackrel{\sim}{\vdash}$ & $\stackrel{\vdash}{\vdash}$ & $\stackrel{\sim}{\vdash}$ & $\stackrel{ }{\vdash}$ & $\stackrel{\sim}{\vdash}$ & $\stackrel{\overrightarrow{ }}{\vdash}$ & $\stackrel{F}{F}$ \\
\hline $\begin{array}{l}\frac{2}{7} \\
\text { 인 }\end{array}$ & 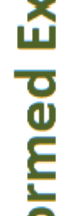 & $\begin{array}{l}\overline{0} \\
\stackrel{d}{ } \\
\frac{1}{2} \\
\frac{0}{0} \\
\frac{1}{\alpha}\end{array}$ & 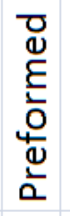 & 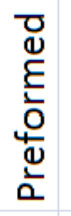 & 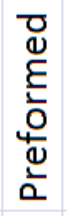 & 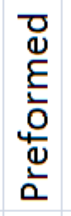 & 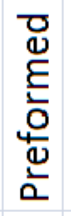 & 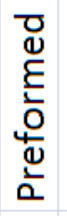 & 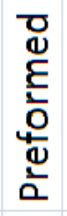 & 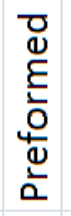 & 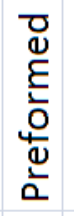 & 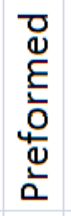 & 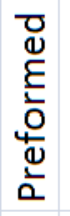 & 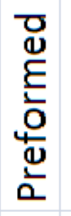 & 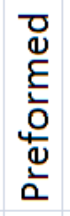 & 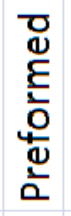 & 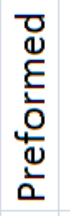 & 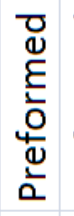 & 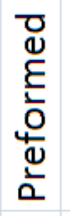 & 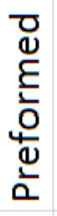 & 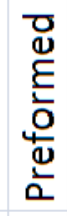 \\
\hline 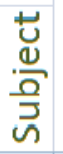 & $\frac{0}{\mathbf{0}}$ & $\vec{a}$ & $a$ & $\widetilde{N}$ & $\widetilde{\Sigma}$ & $\tilde{a}$ & $\stackrel{m}{a}$ & $\stackrel{\checkmark}{\square}$ & さ & 只 & $\stackrel{n}{a}$ & $\ddot{a}$ & $\begin{array}{l}6 \\
a\end{array}$ & $\hat{a}$ & $\hat{a}$ & $\stackrel{\infty}{\alpha}$ & $\stackrel{\infty}{a}$ & ஜ & ஜ & 음 & 움 \\
\hline
\end{tabular}




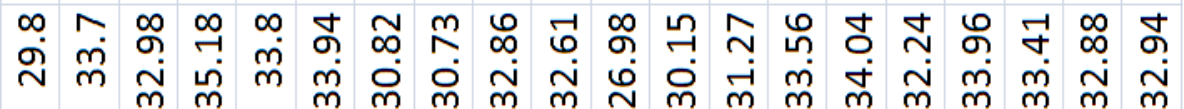

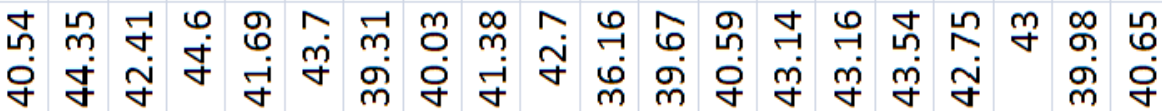

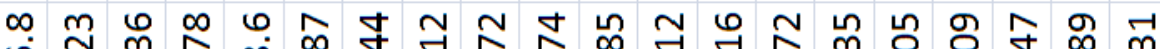

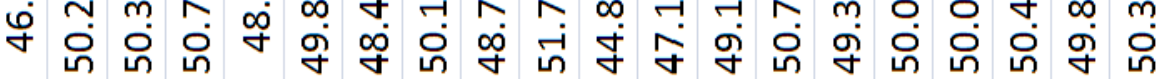

œ ஸ் ஸ⿱

ต ஜ

ஸั กิ ๆ 휴 $\dot{m}$ m

ஸூ 宛 宛 守

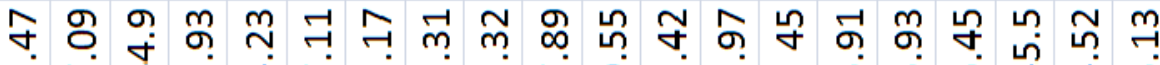

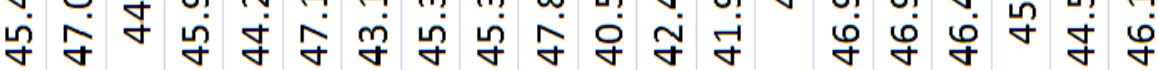
๓ 눙 ที่ ป่ं

m ஸ் ஸ்

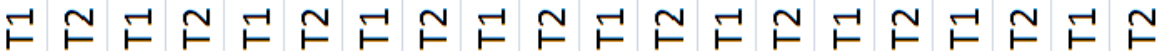

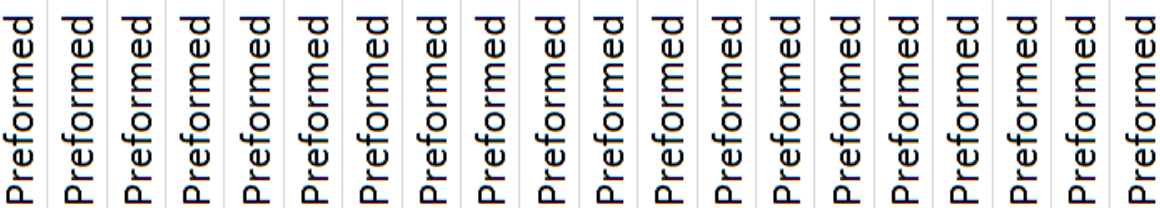

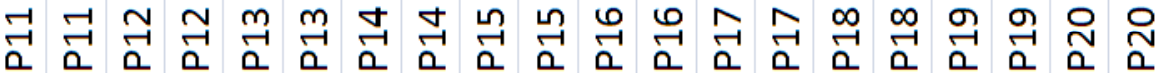




\section{APPENDIX D}

\section{CUSTOMIZED ARCWIRE DATA}




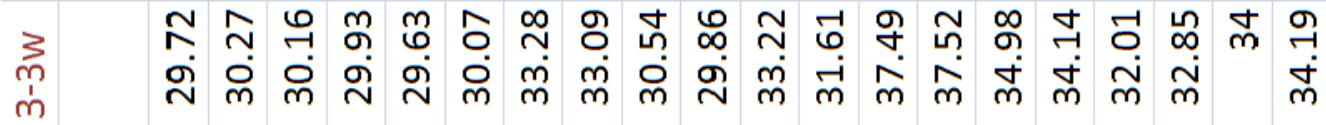

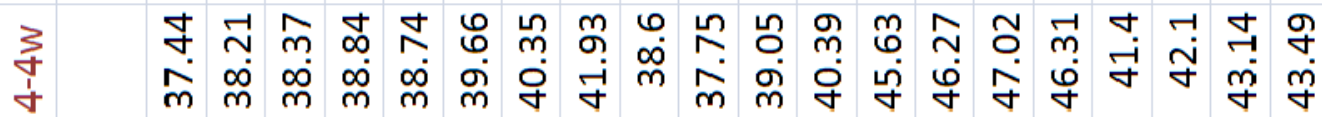

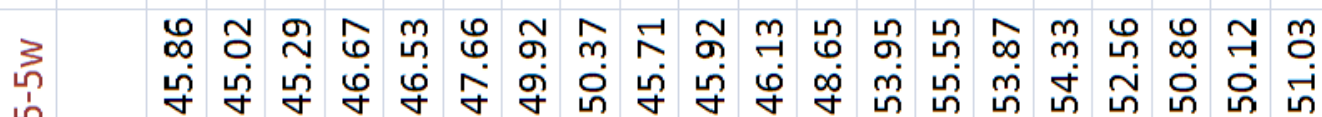

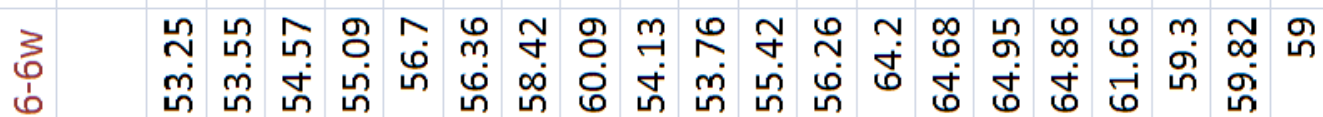

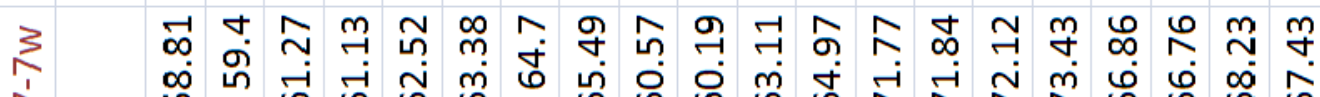

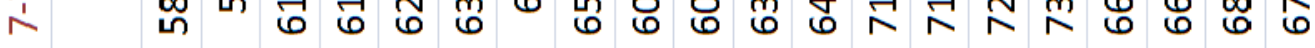

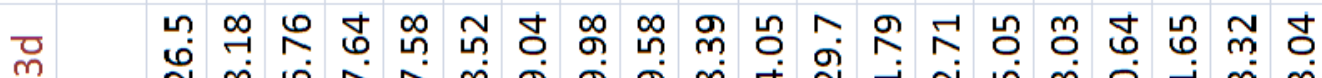

m. $\quad \stackrel{\infty}{\sim} \grave{N} \stackrel{\sim}{\sim}$ D

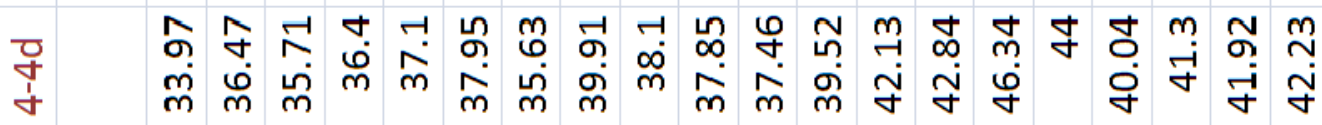

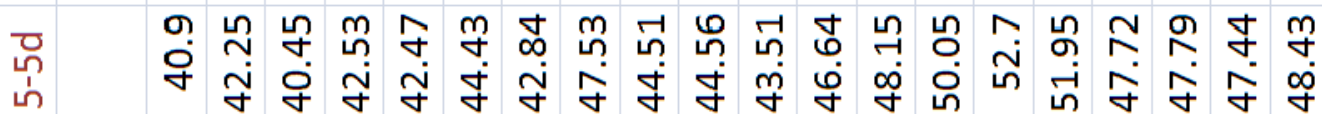

ர

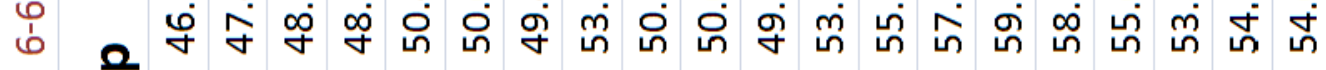

ர ํํำ

ヘ

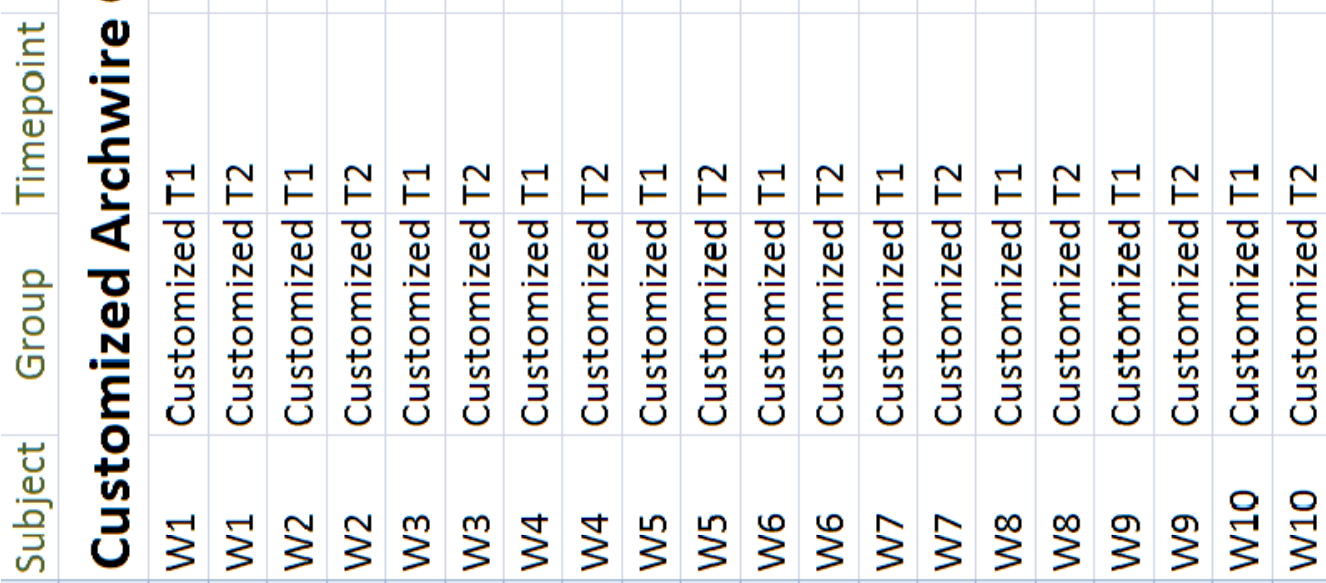




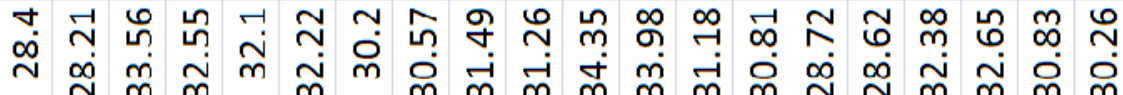

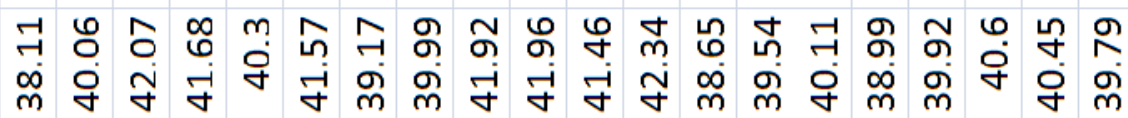

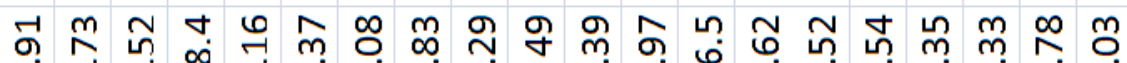

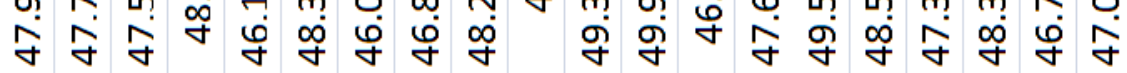

ஸ்

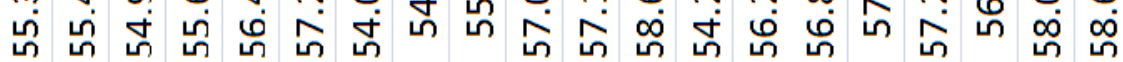

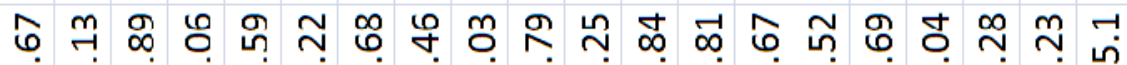

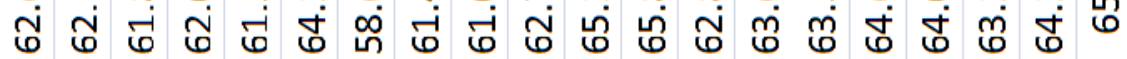

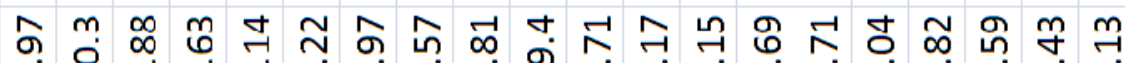
సิ

ஸै ป

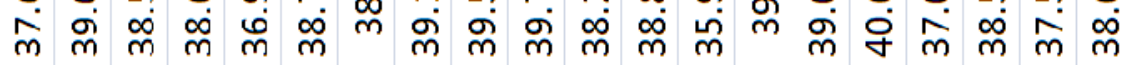

ヘ 导 守 竎 국 กี่ ที

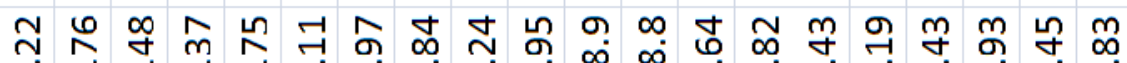

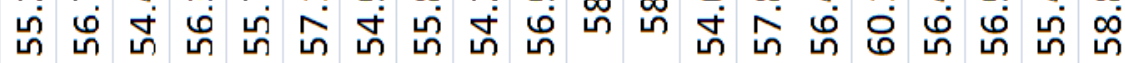

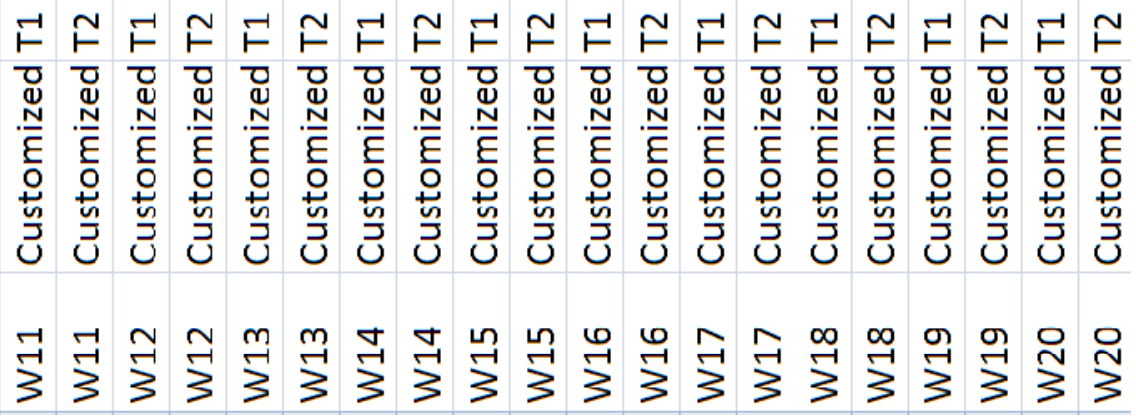




\section{CURRICULUM VITAE}

Name:

Date of Birth:

Place of Birth:

\section{Education:}

August 1998 - May 2002

August 2003 - May 2007

July 2007 - Present
Kolin E. Weaver, D.D.S.

April 5, 1979

Windsor, ON

Canada

Arkansas State University

Jonesboro, Arkansas

Bachelor of Science (Biology),

Pre-professional Studies

West Virginia University

School of Dentistry

Morgantown, West Virginia

Doctorate of Dental Surgery

West Virginia University

School of Dentistry

Department of Orthodontics

Morgantown, West Virginia

Master of Science (anticipated May 2010)

\section{Professional Memberships:}

June 2003 - May 2007

American Student Dental Association

May 2007 - Present

American Dental Association

July 2007 - Present

American Association of Orthodontists 